\title{
A BATHYMETRIC CHART OF CARMEL BAY, CALIFORNIA
}

\section{RALPH ANTHONY ZARDESKAS}







\section{United States \\ Naval Postgraduate School
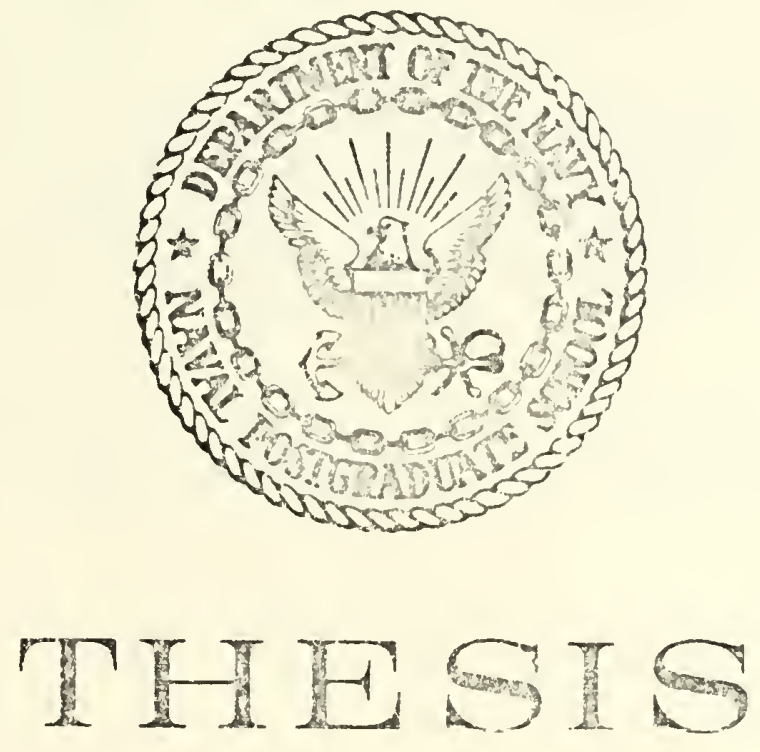

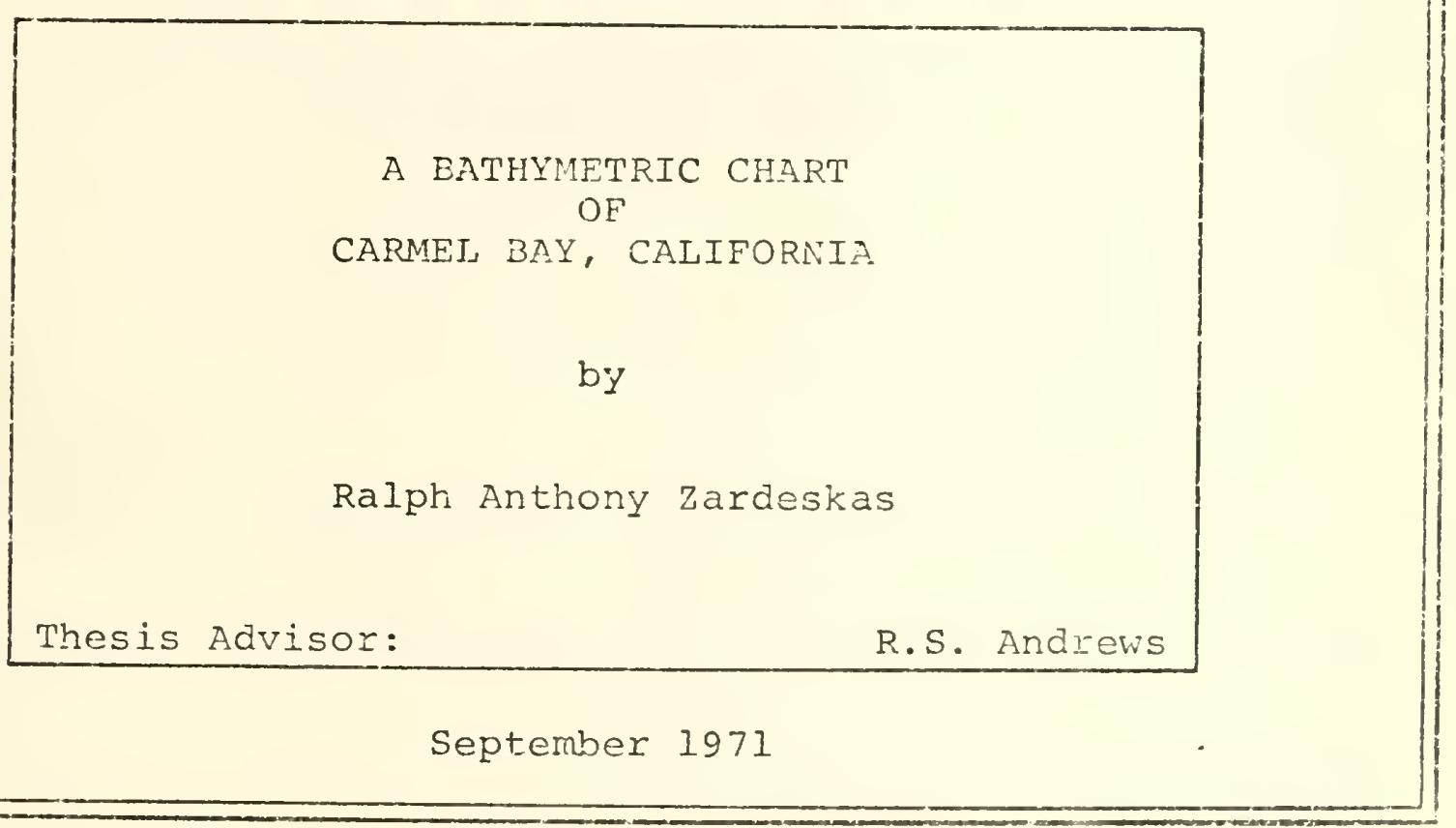

Approved for puolic release; distribution unlimited. 

A Bathymetric Chart

of

Carmel Bay, California

by

Ralph Anthony, Zardeskas Lieutenant, United States Navy A.E., Wentworth Institute, 1964

B.S., Naval Postgraduate School, 1970

Submitted in partial fulfillment of the requirements for the degree of

MASTER OF SCIENCE IN OCEANOGRAPHY

from the

NAVAL POSTGRADUATE SCHOOL

September 1971 



\section{ABSTRACT}

This study has as its final product a bathymetric chart of Carmel Bay, California, which is improved over any other previously existing chart. The unique problems of applying the echo-sounding corrections necessary to create accurate bathymetric charts of areas with steep bottom slopes are discussed. 



\section{TABLE CF CONTENTS}

I. INTRODUCTION --

A. OBJECTIVE -

B. DESCRIPTION OF AREA --_-_-_-_-_---_--- 11

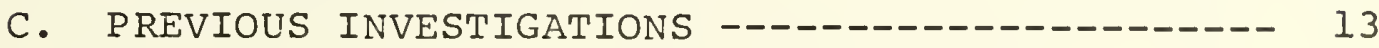

II. PROCUREMENT OF DATA -

A. SOUNDING LINES --_-

1. Echo-sounding Equipment ----------------- 15

a. Fathometer --_-n--n 15

b. $3 \cdot 5-\mathrm{kHz}$ High Resclution

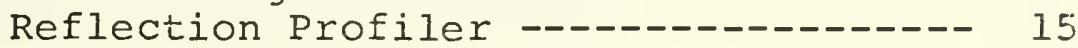

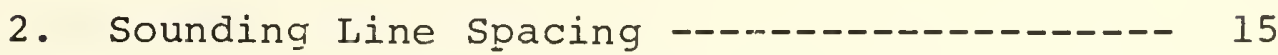

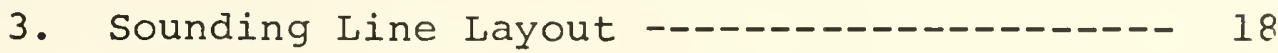

4. Sounding Lines Accomplished --_-_-_----- 19

B. NAVIGATION -...-... 19

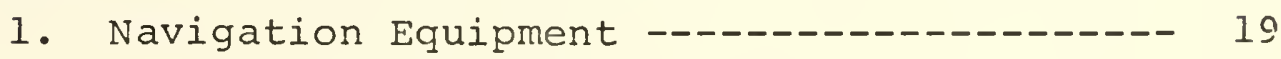

2. Transponder Positioning Requirements ----- 21

3. Transponder Positioning -_-_-_-_-_----- 21

4. Fixes --

C. TRACK MAINTENANCE -.-.-_-

D. AREA OF SURVEY COVERAGE -.-_-

1. Shallows ------------------------- 25

2. Kelp Beds --_- 25

3. Equipment Limitations -_-_-_-_-_-_-_--- 27

E. DATA COLLECTION --_-_- 

III. CORRECTIONS APPLIED

A. TRANSDUCER DEPTH -_- 29

B. TIDE CORRECTION -...-_-_ 29

C. INSTRUMENT ERROR -

D. SOUND VELOCITY CORRECTIONS - 30

1. Computation of Mean Vertical

Sounding Speed --_-_-_-_-_-_ 32

2. Computation of Sound Speed Error -.----- 32

E. SLOPE CORRECTIONS - 32

1. Statement of the Problem -..-- 32

2. Corrections for Slope Angles

Less Than $15^{\circ}$

3. Corrections for Slope Angles

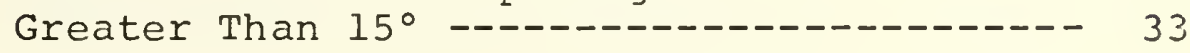

F. CROSS SLOPE CORRECTION - 36

1. Statement of the Problem -............ 36

2. Correction for Cross Slope - 37

IV. RESOLUTION OF BATHYMETRIC DATA _............ 39

A. DATA REDUCTION - 39

1. Calculation of the Mean Lower

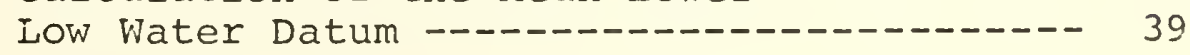

2. Preliminary Annotation of

Bathymetric Records -......... 40

3. Application of Slope Corrections -.-.-.- 40

a. Calculation of Apparent Echo

Slope Angle --

b. Calculation of Apparent Bottom

Slope Angle -.-

(1) Echo Slope Angles Less

Than $15^{\circ}$

(2) Echo Slope Angles

Greater Thar. $15^{\circ}$ 

c. Calculation of True Bottom Slope ---- 41

d. Final Annotation of Bathymetric

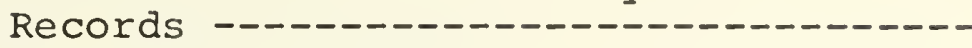

e. Ambiguity of ' $V$ ' Shaped

Depressions -----------------------

V. CARTCGRAPHY 44

A. CONSTRUCTION OF THE SMOOTH SHEET -

B. CONSTRUCTION OF THE FINISHED CHART -------- 44

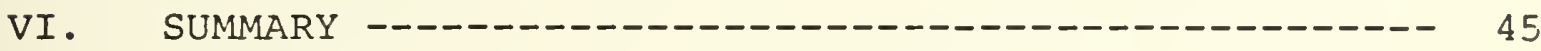

VII. FUTURE WORK -

APPENDIX A: PRECISION DEPTH RECORDER SLOPE CONVERTED TO APPARENT BOTTOM

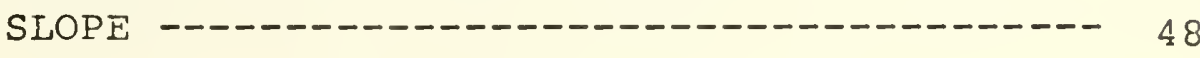

APPENDIX B: CORRECTIONS FOR TRUE EOTTOM SLOPES

LESS THAN $15^{\circ}--------------------50$

APPENDIX C: CORRECTIONS FOR TRUE EOTTOM SLOPES

GREATFR TUAN $15^{\circ}--------------------$

REFERENCES CITED -

INITIAL DISTRIBUTION LIST ---

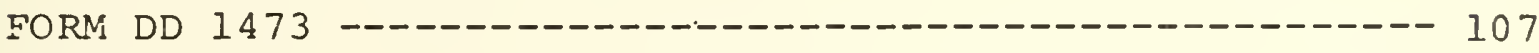




\section{LIST OF TABLES}

\section{TABLE}

I Sounding Line Spacing for $100 \%$ Coverage -------- 17

II Control Point Data --------------------22

II Instrument Errors - 



\section{LIST OF FIGUPES}

\section{FIGURE}

1. Location Map of Carmel Bay (from C\&GS 5476) ----- 12

2. Definition of $100 \%$ Coverage --- 16

3. Sounding Lines Steamed and Sounding Iines Not Completed ----------------------------- 20

4. Construction of Track Preplot ---------------- 24

5. Track Preplot and Ship's Actual Track----------- 26

6. Slope Correction for Slope Angles Less Than $15^{\circ}$

7. Slope Correction for Slope Angles Greater Than $15^{\circ}----------------------------\quad 35$

8. Cross Slope Correction

9. Ambiguity of ' $V$ ' Shaped Depression ------------ 43 10. Comparison of 1933 and 1971 Bathymetric 



\section{LIST OF PLATES}

\section{PLATE}

I. Bathymetric Chart of Carmel Bay,

California

Folded in back 



\section{ACKNOWLEDGEMENTS}

The author wishes to express his gratitude to Professor R.S. Andrews for his patience and encouragement throughout the course of this project. Thanks are also due to CDR. W.C. Knodle, USN, for his advice on conducting hydrographic surveys, to Mr. L.G. Nolan, Jr., for his help in surveying, to Mr. Don Rich for having the kelp cut performed off Carmel River Beach, and to LT. J.P. Simpson, USN, and LT. L.S. Carter, USN, for their assistance in manning the research vessel during the survey. Mr. Frederick A. Meyer of the California Department of Parks and Recreation: Mr. Ear? Smith of the Monterey County Dark Departinent, and Mr. Thompson J. Hudson provided land access for the navigation transponder locations.

Partial funding for this study was provided to Dr. Andrews by the Naval Postgraduate School Research Foundation under an Office of Naval Research grant. Funds for the leasing of the hydrographic research vesseI were provided by the Naval Postgraduate School Department of Oceanography. Further sincere appreciation is given to my mother, Mrs. A.P. Zardeskas, who forced me to study as a youth and whom I have never thanked. Thank You. 



\section{INTRODUCTION}

This paper presents the results of a hydrographic survey of Carmel Bay, California, performe 3 using a 12-kHz fathometer and a $3.5-\mathrm{kHz}$ high resolution reflection profiler. Navigation was accomplished with a two-station range-range positioning system.

The survey was conducted on March 10-12, 1971, from a 52-ft chartered oceanographic survey boat, R/V DAWN STAR, owned and operated by General Oceanographics, Inc., of Newport Beach, California.

\section{A. OBJECTIVE}

The objective of this study was to create a bathymetric chart of Carmel Bay, California, which accurately represented the bottom topography. This completed chart, far more detailed than a standard navigational chart, provides a valuable tool to those interested in studying Carmel Bay.

The hydrographic survey was conducted using the best positioning and echo-sounding systems economically available. Corrections were applied to the bathymetric data so as to reproduce faithfully the topographic features of the bottom. During the course of reducing the bathymetric data, equations were derived to handle corrections for the steep bottom slopes encountered in the bay. 

The contours on the final chart will not necessarily be the depths that a ship using a standard fathometer would find. The depth corrections were in places very large due to the steep-walled submarine canyon and would cause a vessel to read considerably shallower depths than those indicated on the chart (the depths on the chart being the actual depths).

\section{B. DESCRIPTION OF AREA}

Carmel Bay, situated on the central California coast (Fig. 1), is an embayment cut by Carmel submarine Canyon (a principle tributary of Monterey Submarine Canyon to the north). The head of Carmel Canyon is located close to the beach in the southeastern sector of the bay.

Carmel Bay is protected to the north and south by Cypress Point and Point Lobos, both of which are composed of Cretaceous Santa Lucia granodiorite. Granite Point, Pescadero Point, and the southern half of Abalone Point are also made up of granodiorite. Arrowhead Point and the northern side of Abalone Point are made up of Miocene volcanics.

Carmel Beach, Pebble Beach, Stillwater Cove, and Whaler's Cove have been formed by the weathering of Paleocene carmelo pebble conglomerate. Dune sands can be found at the north end of Carmel Beach.

Carmel Submarine Canyon is formed by subaerial erosion in solid rock along a possible fault trace (Martin, 1964, p. 54). The major sources of sediment into Carmel Bay 



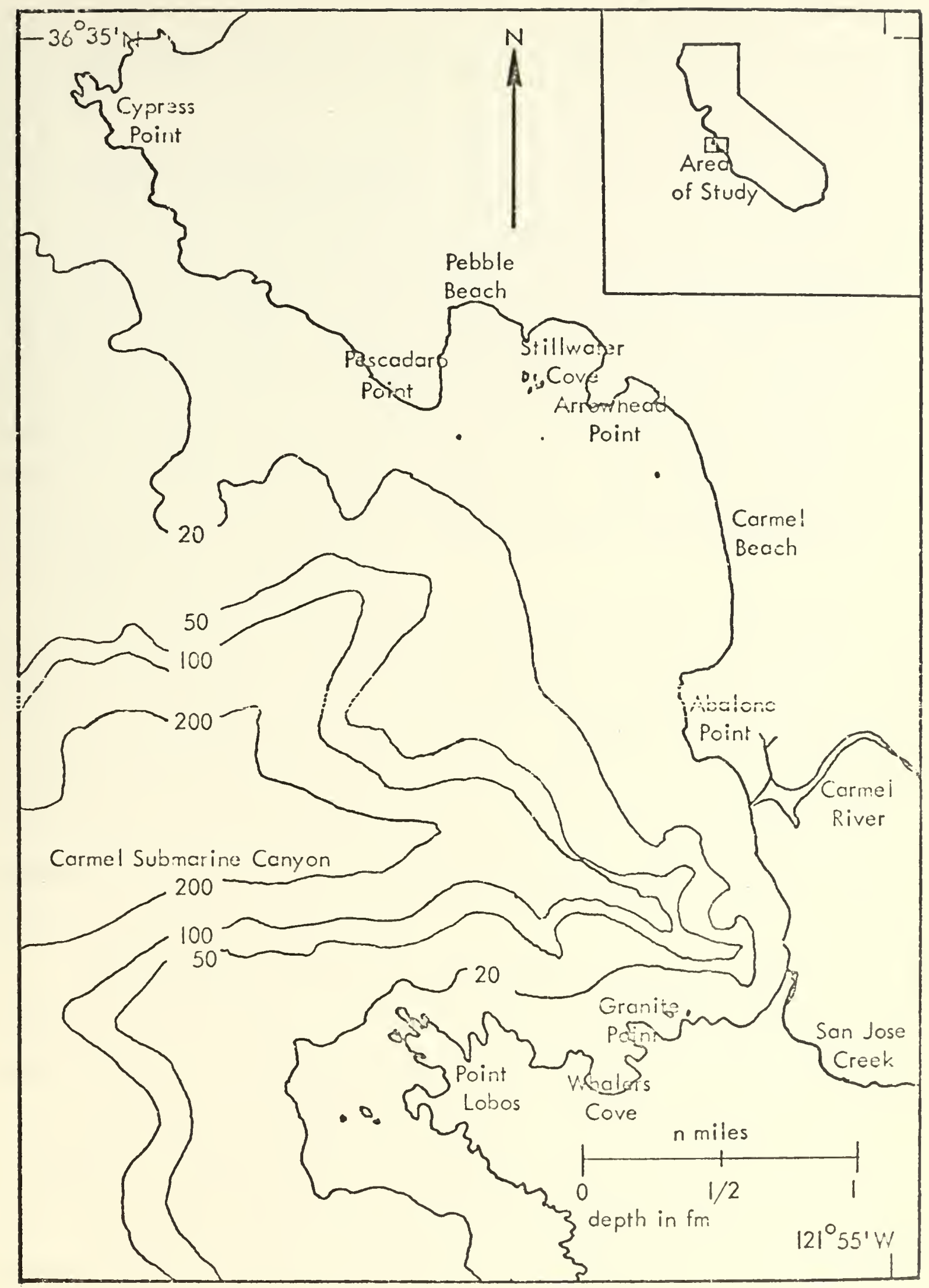

Figure 1. Location Map of Carmel Bay (from C\&GS 5476). 

are the Carmel River and San Jose Creek, plus some shoreline erosion.

\section{PREVIOUS INVESTIGATIONS}

Prior to this study, a hydrographic survey of Carmel Bay had been conducted in 1933 by the U.S. Coast and Geodetic Survey (C\&GS) (1933). Also, the head of Carmel Canyon had been charted in 1934 by Shepard and Emery (1941). These surveys were conducted using lead line soundings and horizontal sextant angles for positioning. The 1933 survey of C\&GS serves as the basis for the present navigation chart of Carmel Bay (C\&GS 5476).

The sounding line spacing of the C\&GS 1933 survey was 600 ft for depths greater than approximately 20 fm and $300 \mathrm{ft}$ for depths less than $20 \mathrm{fm}$. Soundings were taken along the lines about every 400 ft in the deeper water and every 200 ft in the shallows. As no more detail than necessary for safe navigation was desired, the deeper areas of the bay lack definition.

The sounding line spacing for the Shepard and Emery survey of the canyon head was $200 \mathrm{ft}$ with soundings taken every $50 \mathrm{ft}$. This survey was very accurate when accomplished, but this area is subject to variation in deptr due to slumping of sediment down the steep canyon walls. It is safe to assume that some bathymetric changes have occurred since 1934

Lead line soundings give true depths and need only be corrected for tide and wire angles, but suffer from a lack 

of continuity. Because lead-line soundings are noncontinuous, small-scale features such as rock pinnacles and small channels are difficult to correlate with the overall bottom topography. In addition, wire line soundings cannot be precisely contoured as the depth intervals cannot be accurately interpolated between obtained soundings for areas of rugged and highly variabie bathymetry. 



\section{PROCUREMENT OF DATA}

\section{A. SOUNDING LINES}

\section{Echo-Sounding Equipment}

As the ship tracked, $12-\mathrm{kHz}$ fathometer and $3.5-\mathrm{kHz}$ reflection profiling data were taken simultaneously. Both systems utilized $30^{\circ}$ transducer cones.

a. Fathometer

A standard hull-mountea Raytheon 12-kHz ship fathometer was used, the data being recorded on standard 7-inch fathometer recorder paper.

b. 3.5-kHz High Resolution Reflection Profiler Utilizing a towed streanined tranducer 'fish,'

the $3.5-\mathrm{kHz}$ profiling system provided the best bathymetric records of the survey. The record was maintained on a modified Gifft GDR precision depth recorder using 18-inch wide wet paper.

\section{Sounding Line Spacing}

Optimumly when conducting hydrographic surveys using echo sounders, the incident sound cones of the transducers for parallel adjacent sounding lines should be tangert at the ocean bottom so as to provide 100\% coverage of the bottom (Fig. 2). Closer spacing of sounding lines is necessary to obtain this coverage in shallow water due to truncation of the sound cone by the bottom. Some representative sound-line spacings for a $30^{\circ}$ cone are shown ir: Table I. 

TABLE I

SOUNDING LINE SPACING FOR 100\% COVERAGE

\begin{tabular}{cc}
\hline $\begin{array}{c}\text { Depth } \\
\mathrm{fm}\end{array}$ & $\begin{array}{l}\text { Sounding Line Spacing } \\
\text { for } 100 \% \text { Coverage, ft }\end{array}$ \\
10 & 32.4 \\
50 & 161.6 \\
80 & 258.0 \\
100 & 323.6 \\
200 & 649.2 \\
\hline
\end{tabular}



It is estimated that for a hydrographic survey of

Carmel Bay to be accomplished with $100 \%$ coverage, over $250 \mathrm{n}$ miles of sounding lines would be necessary. This is a large amount considering that Carmel Bay covers less than 6 square miles. The large amount of track is necessary because the northern half of the bay is relatively shallow, requiring a high track density. In addition, the bathymetry of Carmel Bay is very complex, including many rugged rock outcrops on the bottom and a submarine canyon.

Originally proposed sounding line spacings were $250 \mathrm{ft}$ for expected depths less than $80 \mathrm{fm}$ and $500 \mathrm{ft}$ for expected depths greater than $80 \mathrm{fm}$. These spacings were determined as a compromise between available resources (ship time, navigation net, and acoustic equipment) and desirabie track density.

\section{Sounding Line Layout}

When planning the sounding lines to be steamed in performing a hydrographic survey, the following items were considered:

- Make each line as long as possible to cut down on non-productive time in turns and to provide continuity in the bathymetric records.

- Wider sounding line spacing can be used in deep water without a loss in coverage because the incident sound cone is wider.

- Check-lines should be provided to run at right angles to the tracks to ensure that the depth measurements agree at track intersections.

- Plan sounding lines to run normal to major siope contours so as to avoid cross slope error (ciscussed in a later section). 

The north-south sounding lines of this survey (Fig. 3) were used because they were generally parallel to the major bottom slopes and were the longest tracks possible. These lines were spaced $250 \mathrm{ft}$ apart, with every other north-south sounding line terminated when the expected depth exceeded $80 \mathrm{fm}$. East-west cross lines were included to check these tracks.

Segmented sounding lines were used around Point Lobos so as to get the maximum resolution of what was known to be an extremely irregular bottom made up primarily of jointed massive igneous rock. The Point Lobos sounding lines were checked with the north-south sounding lines.

\section{Sounding Lines Accomplished}

The originaliy plarncd soundirg lines lotaled 137 in

miles. Due to equipment fajlure and severe weather limiting the survey to $2 \frac{1}{2}$ days of daylight operations, $85 \mathrm{n}$ miles were actually steamed. It is anticipated that the sounding lines not completed will be àone at some future date. Figure 3 shows the sounding lines that were steamed and those planned but not completed.

\section{B. NAVIGATION}

\section{Navigation Equipment}

Navigation was accomplished by use of a HIREX positioning system owned and operated by Offshore Navigation, Inc. (ONI), New Orleans, La. Stated accuracy was 5 to $10 \mathrm{ft}$ at ranges of less than 3 miles from the shore stations 



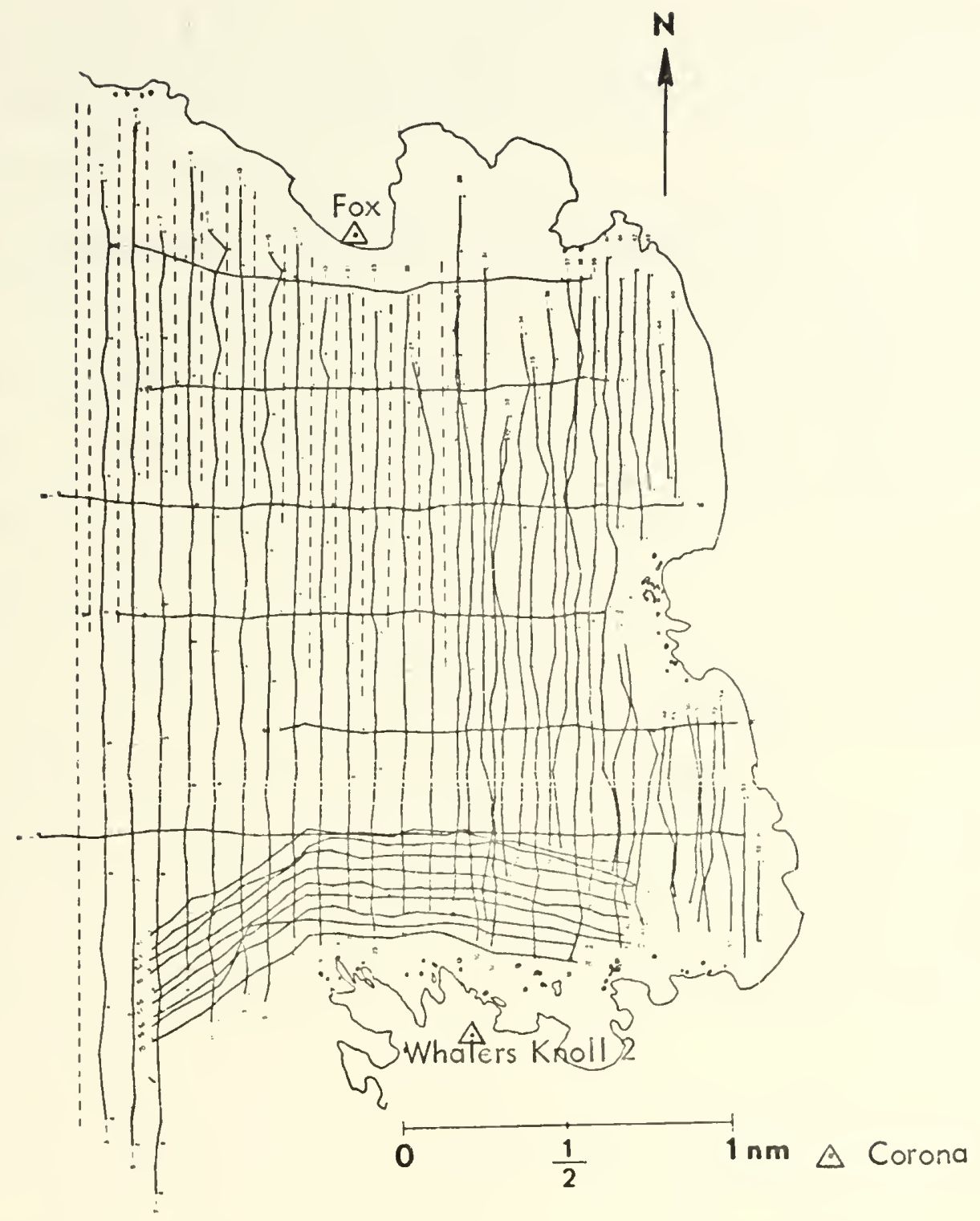

Sounding Lines Planned Buf Not Completed

Sounding Lines Compleied

Figure 3. Sounding Lines steamed and Sounding Lines Not Completed. 

(J.W. Vernon, General Oceanographics, Inc., personal communication).

HIREX operates in the $\mathrm{x}$-band frequency range and consists of two land-situated transponders powered by batteries and two shipboard receivers.

2. Transponder Positioning Reguirements It was required that the land-situated transponders be placed within line-of-sight to as much of Carmel Bay as possible and that a base line between the two transponders be offset from the bay. In addition, the positions of the transponders had to be accurately known.

Line-of-sight positioning was necessary because the $\mathrm{x}$-band signal transmitted by the transponders is readily interrupted by obstrlictions such as trees.

The line between the transponders had to be offset because the accuracy of the system is degraded when the area of operation approaches the base line connecting the two transponders.

The position of the transponders had to be precisely known so that the track preplots and post-plots of fixes taken could be accurately made.

\section{Transponder Positioning}

For the Carmel Bay survey, the northern transponder was placed on C\&GS Horizontal Control Point Loma Alta (Table II). The southern transponder was placed on an offset control point, subsequently named Corona, which was surveyed in by the author by land transit tria gulation 



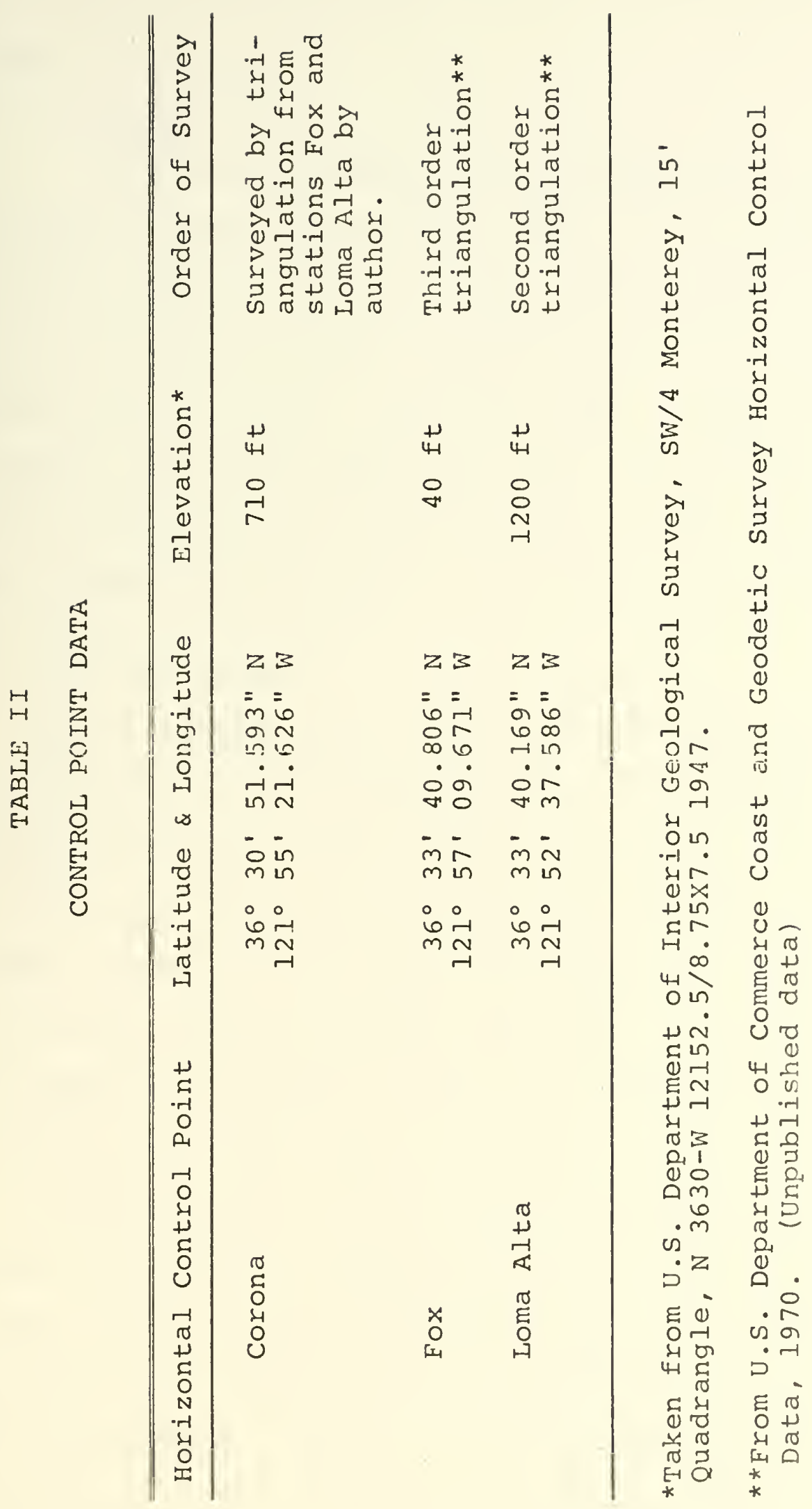



from C\&GS Horizontal Control Points Fox and Loma Alta

(Fig. 4)

\section{4. $\quad$ Fixes}

Fixes were obtained by simultaneously receiving the omni-directional range signals from the two transponders and recording them for post-plotting. Fixes were taken at the start and finish of each sounding line and at 3-min intervals along the lines. Since the ship averaged a speed of 5 knots, the 3 -min fixes were about 500 ft apart. Each time a fix was taken, the fathometer and 3.5-kHz profiler records were marked and annotated to coincide with the fix number.

\section{TRACK MAINTENANCE}

The contracted navigation firm (ONI) was provided before the survey with the desired tracks to be steamed. Given these tracks and the fix spacing, the ranges from the two land-based transponders for each anticipated fix were computed. Plotting the ranges from each point on the sounding line to the Station Corona transponder as the abscissa and the ranges to the Station Loma Alta transpondex as the ordinate gave a hyperbola segment (Fig. 4).

In this manner, ONI fabricated computerized track preplots consisting of segments of hyperbolas with the proposed 3-min fixes along each line indicated. The preplotted track hyperbola for a given line was placed in an X-Y recorder on the ship's bridge prior to steaming the line. The helmsman maintained track by keeping the recorder stylus, ariven by 


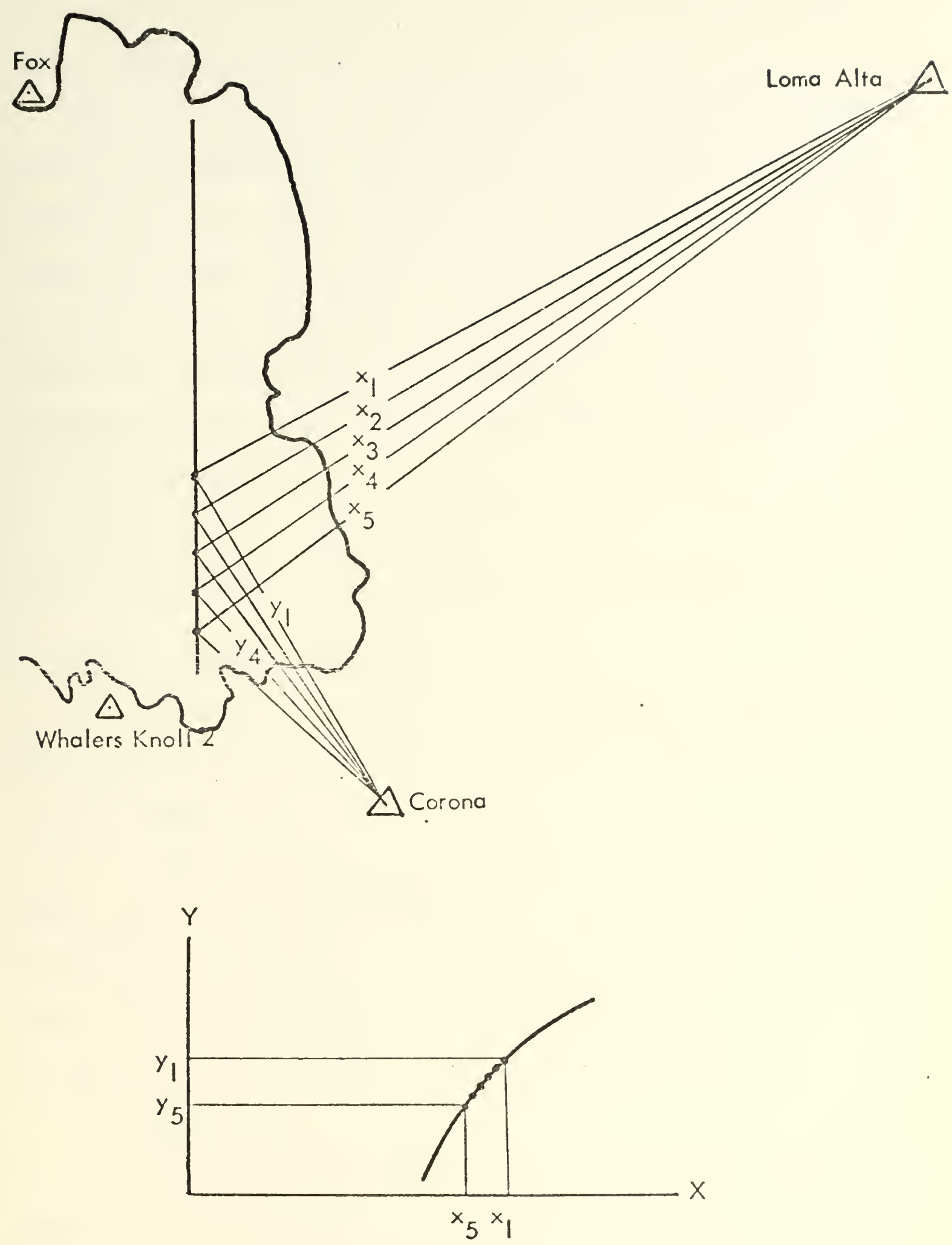

Figure 4. Construction of Track Pres tot.

24 

the navigation system, on the preplotted hyperbolas; the stylus represented the ship's position.

The actual fixes were made by hand recording the ranges from the transponder read-outs at 3-min intervais (approximately at the preplotted fixes). A post-plot of the fixes taken along each line with their assigned fix numbers was provided by the contractor. The preplot and post-plot fixes were corrected for transponder elevation because the recorded ranges were actually slant distances from the ship to the transponders.

Figure 5 is a sample preplot showing the ship's actual track superimposed over the precalculated hyperbola.

D. AREA OF SURVEY COVERAGE

The factors limiting the areas covered by this survey were shallows, kelp beds, and equipment limitations.

1. Shallows

Although the relatively small size of the vessel used (52 ft in length) allowed for work in shallow water, it was often necessary to stand well off shore due to shoaling waves and/or the presence of submerged rocks because the 3.5-kHz transducer was towed at a depth of 20 It.

2. Kelp Beds

In Carmel Bay, large dense beds of kelp (Macrocystis pyrifera) extend for a considerable distance off shore and occasionally caused the premature termination of, or departure from, the planned sounding lines. The kelp beds were 



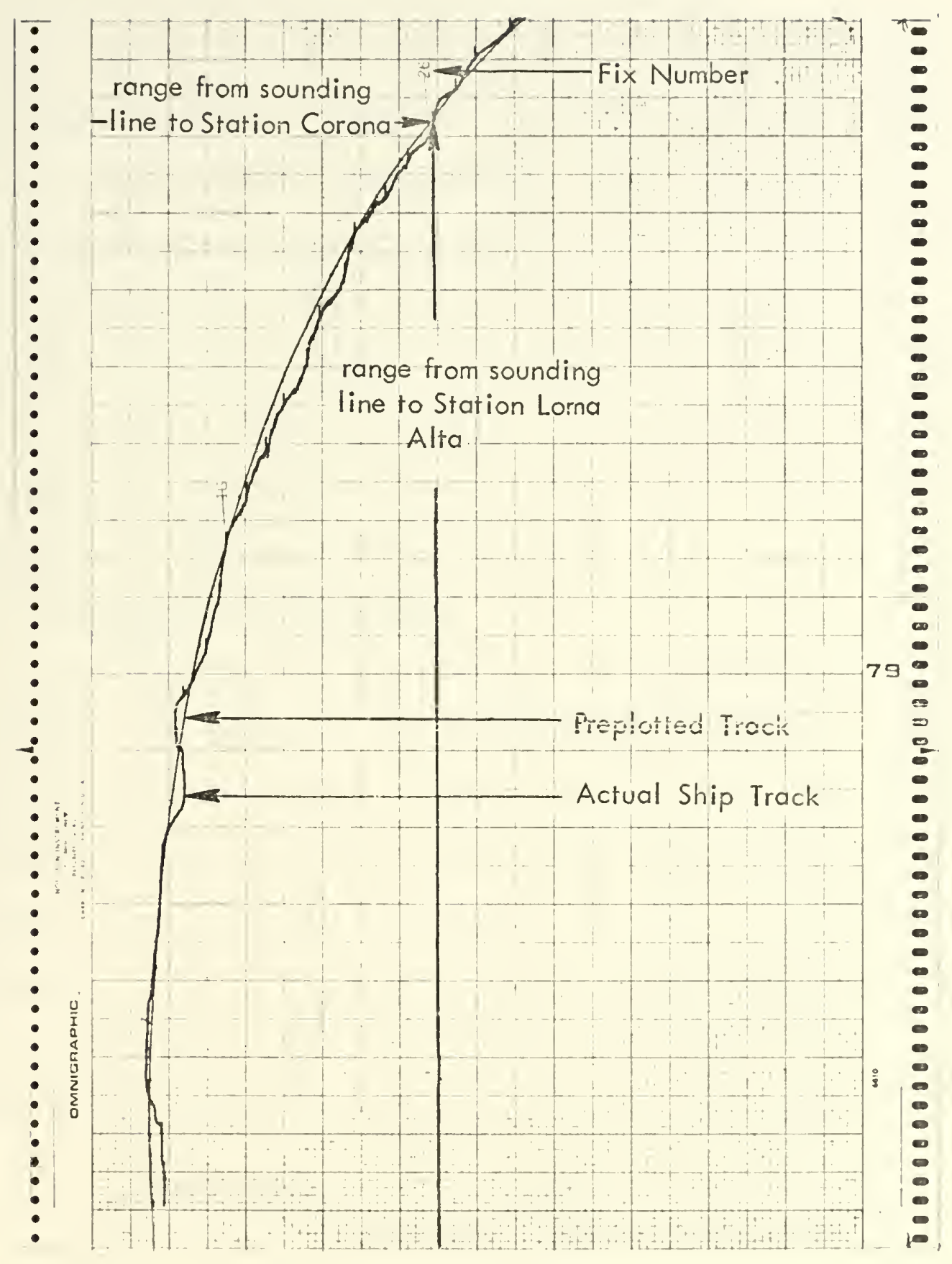

Figure 5. Track Preplot and Ship's Actual Track. 

not crossed because the towed instrumentation became fouled and the quality of data obtained deteriorated.

Under the auspices of Mr. Don Rich, Ranger of Point Lobos State Reserve, a kelp cut was heid by diving clubs in the area around Carmel River Beach. The elimination of kelp in this area allowed for near shore work in the area of the sewage outfall under construction and at the head of a tributary to Carmel Canyon. Data collected in these areas will be used for baseline studies to show future changes in the bathymetry due to sand deposition from the Carmel River and sediment slumping down the canyon.

3. Equipment Limitations

As mentioned previously, it was necessary for the navigation transponüers to be piaced on horizontel control points with a clear line of sight to most of Carmel Bay. The sites selected were thought to meet these requirements. However, some blanking of stations did occur in the northernmost part of the bay forcing premature track line cut-off. The blanking was attributed to the tall trees close to Carmel Beach interrupting the $\mathrm{X}$-band signal of the HIREX transponders.

\section{E. DATA COLLECTION}

Fathometer and $3.5-\mathrm{kHz}$ transducer data were collected simultaneously as the ship tracked. Both records were marked and annotated at the start and finish of each line and at 3-min intervals coinciding with the navigation system fixes. In addition, a cruise log was kept noting the line number, 

the time of start and finish of each line, depth of the towed transducer 'fish', sweep rate of the recorders, firing rate of the $3.5-\mathrm{kHz}$ system, sea state, course, speed, and general remarks. 



\section{CORRECTIONS APPIIED}

Several corrections should be applied to bathymetric data obtained using echo-sounders in order to reproauce an accurate chart of true depths. The errors considered and the corrections to be made are discussed in this section. The actual application of the corrections to the bathymetric records is discussed in the section on data resolution.

\section{A. TRANSDUCER DEPTH}

The scales automatically marked on bathymetric records are referenced to the transducer. Since hull-mounted transducers are never at the waterline of the survey vessel, a correction to account for the distance below the waterline must be determined and applied. Towed transducers must have their depths recorded for each line steamed so that the proper correction can be made. The fathometer transducer depth was determined and the towed transducer depth was measured for each line.

B. TIDE CORRECTION

Corrections for tidal variations can be obtained either from a tide gage or from tide tables. The tide gage is the most accurate as it will reflect tidal fluctuations due to meteorological disturbances and swell, whereas tide tables will not. 

Tide records were obtained from the tide gage maintained by the Naval Postgraduate School at Monterey Harbor in Monterey Bay. It has been found from experience that these tide records seldom vary by more than $0.5 \mathrm{ft}$ from tides in Carmel Bay (Dr. W.C. Thompson, personal communication).

\section{INSTRUMENT ERROR}

Instrument error does not vary with depth. That is, a fathometer with an error of $2 \mathrm{ft}$ in $1 \mathrm{fm}$ of water will have the same error in $200 \mathrm{fm}$ of water. To calibrate the fathometer and $3.5-\mathrm{kHz}$ profiling equipments, lead line soundings were made during operation of the acoustic equipment. The errors found on the lead line casts are shown in Table III.

\section{SOUND VELOCITY CORRECTIONS}

Depth sounding recorders are calibrated to give accurate readings when the transmitted and reflected sound pulses travel through sea water with a speed of $800 \mathrm{fm} / \mathrm{sec}$. Deviations of the mean vertical sounding speed (MVSS) from this value will result in the recorder scale giving incorrect readings.

For depths encountered, the MVSS is chiefly dependent on the thermal structure. In order to determine the thermal structure of Carmel Bay, expendable bathythermograph data was collected. 

TABLE III

INSTRUMENT ERRORS

\begin{tabular}{ccc}
\hline Test & $\begin{array}{c}\text { Fathometer } \\
\mathrm{ft}\end{array}$ & $\begin{array}{c}3.5 \mathrm{kHz} \text { Seismic } \\
\mathrm{ft}\end{array}$ \\
1 & +2 & +2 \\
3 & +4 & +2 \\
& +4 & +2 \\
\hline
\end{tabular}



1. Computation of Mean Vertical Sounding Speed

Temperatures were taken off the bathythermograph at $10-\mathrm{m}(32.8-\mathrm{ft})$ intervals and the mean temperature at each depth was found by averaging the temperature at that depth with the shallower temperatures. Using tables of sound velocity in sea water prepared by the U.S. Naval Oceanographic Office (1962), a MVSS was found at each depth. A nearly constant MVSS of $1,487 \mathrm{~m} / \mathrm{sec}(812.9 \mathrm{fm} / \mathrm{sec})$ was found to exist in Carmel Bay for the period of this survey.

2. Computation of Sound Speed Error

True depth relates to fathometer depth by the expression:

$$
\text { true depth }=\frac{\text { MVSS } \times \text { fathometer depth }}{\text { fathometer calibrated sounding speed }}
$$

for: $\quad$ MVSS $=1487 \mathrm{~m} / \mathrm{sec}$, and

fathometer calibration $=1,463 \mathrm{~m} / \mathrm{sec}$

true depth $=1.01640 \mathrm{x}$ fathometer recorder depth.

Therefore, the fathometer was reading shallow by a factor of $1.64 \%$.

This error was compensated for by manufacturing acetate overlays of depth scales compressed $1.64 \%$ to be used instead of the existing scales automatically marked on the bathymetric records.

\section{E. SLOPE CORRECTIONS}

1. Statement of the Problem

The sound wave front of a transducer sreads spherically. The ship will receive an echo from any part 

of the sea floor that is intercepted by the spherical wave front as long as the reflection occurs within the sound cone of the transducer and any projection above the sea floor will give a hyperbolic echo trace.

Where the sea floor is sloping at an angle less than half of the transducer cone angle, the first reflection will not be detected from vertically beneath the ship, but will return from the part of the slope which is perpendicular to the ray (Fig. 6).

If the angle of sea floor slope is greater than half the transducer cone angle, the first reflection will return from the half angle of the transducer cone (Fig. 7).

2. Corrections for Slope Angles Less Than $15^{\circ}$ Krause (1962) has shown that the relationship between the echo slope angle $(\phi)$ and true bottom siope angle $(\theta)$ is :

$$
\sin \theta=\tan \phi .
$$

In addition, the relationship between true depth ( $Z$ ) and echo depth (R) is:

$$
z=\frac{R}{\cos \theta}
$$

Tabulated values of the true depth for true bottom slope angles from $0^{\circ}$ to $15^{\circ}$ and echo depths from 0 to $300 \mathrm{fm}$ are given in Appendix B.

\section{Corrections for Slope Angles Greater Than $15^{\circ}$} The equations given by Krause fail at echo slope angles greater than $15^{\circ}$ when using a transducer with a $30^{\circ}$ 



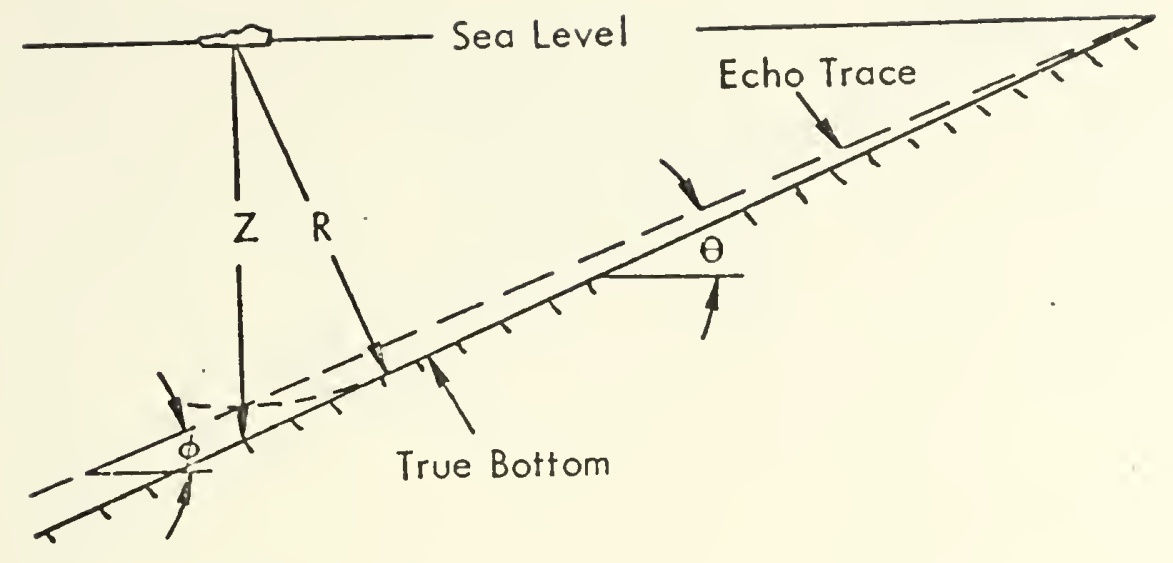

$\mathrm{R}=$ echo trace depth

$Z$ = true depth

$\phi=$ echo trace slope angle

$\theta=$ true botion siope angle

From Krause (1962):

$\sin \theta=\tan \phi$

$Z=R / \cos \theta$ Figure 6. Slope Correction for Slope
Angles Less than $15^{\circ}$. 



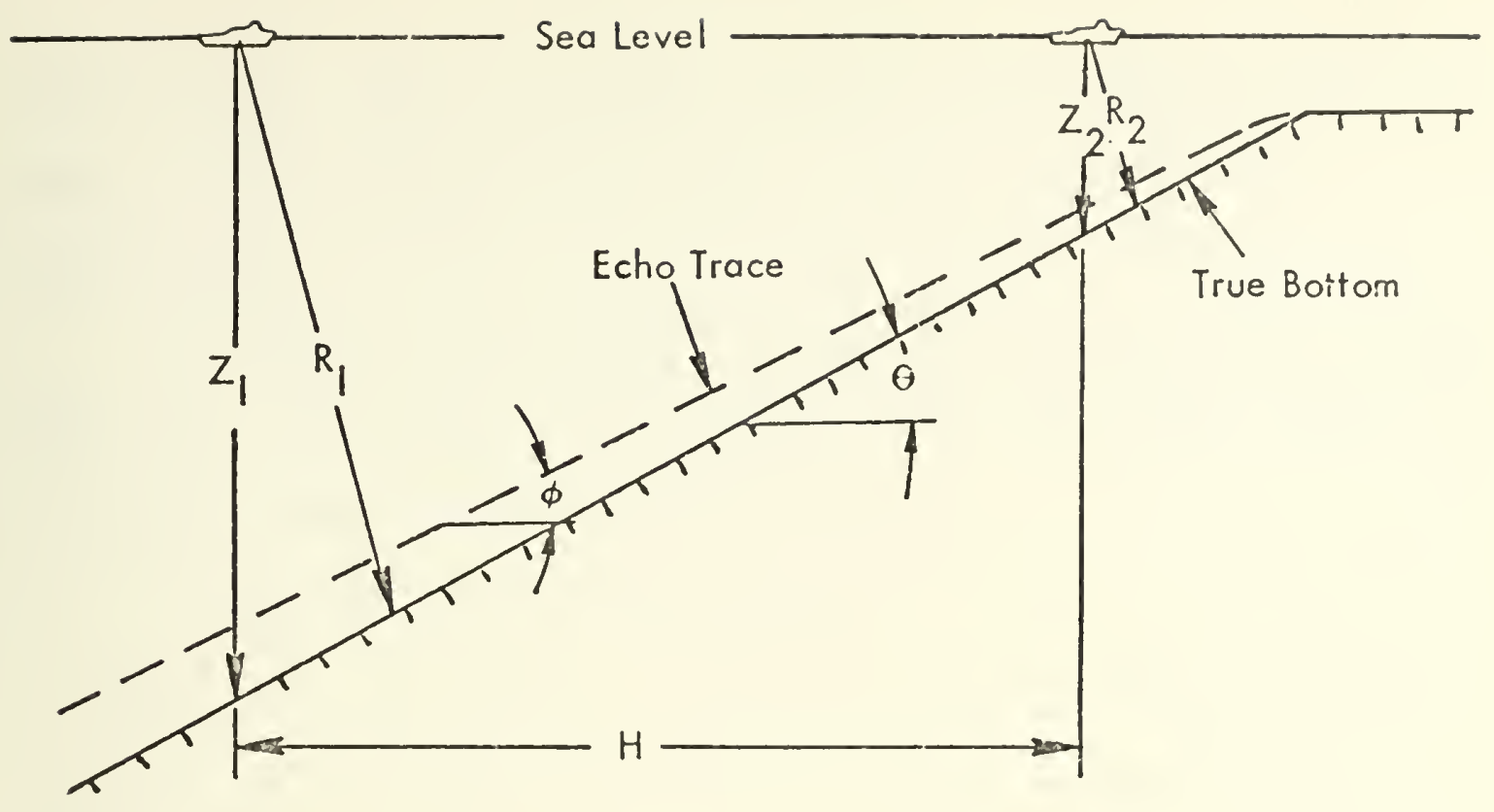

$$
\begin{gathered}
\tan \phi=\left(R_{1}-R_{2}\right) / H \\
\tan \theta=\tan \theta=\left(Z_{1}-Z_{2}\right) / H \\
\left.Z_{1} /\left[\sin \left(75^{\circ}+\theta\right)\right]=R_{1} /\left[\sin \left(90^{\circ}-\theta\right)\right]=Z_{2} / \cos \theta ;\left(R_{1}-R_{2}\right)\right] \\
Z_{2} /\left[\sin \left(75^{\circ}+\theta\right)\right]=R_{1} \sin \left(75^{\circ}+\theta\right) / \cos \theta \\
\therefore \sin \theta=\tan \phi \sin \left(75^{\circ}+\theta\right) \\
Z=R\left(\cos 15^{\circ}+\sin 15^{\circ} \tan \theta\right)
\end{gathered}
$$

Figure 7. Slope Correction for Slope Angles Greater than $15^{\circ}$. 

sound cone. This is because his work was intended for use only in the deep sea where steep slopes are rarely encountered.

It may be seen from Fig. 7 that the relationship between the echo slope angle $(\phi)$ and the true bottom slope angle $(\theta)$ for echo slope angles over $15^{\circ}$ is:

$$
\sin \theta=\tan \phi \sin \left(75^{\circ}+\theta\right) .
$$

The solutions of this transcendental equation for echo slope angles of $15^{\circ}$ up to $45^{\circ}$ are shown in Appendix $A$. The solutions given in Appendix A were obtained by iterating $\theta$ so that left and right hand sides of the above equation agreed to within \pm 0.00005 .

It may also be seen from Fig. 7 that the relationship between the true depth ( $Z$ ) and echo depth $(R)$ is:

$$
z=R\left(\cos 15^{\circ}+\sin 15^{\circ} \tan \theta\right) .
$$

Tabulated values of the true depths for true bottom slope angles from $15^{\circ}$ to $50^{\circ}$ and echo depths from 0 to $300 \mathrm{fm}$ are given in Appendix $C$.

\section{F. CROSS SLOPE CORRECTION}

\section{Statement of the Problem}

The slope corrections previously discussed assume that the ship's track is parallel to the maximum bottom slope. If the ship's track is not parallel to the siope, the track of the point of reflection across the slope does not correspond with the vertical projection of the ship's 

track on the sea floor, but lies upslope of the projection of the shif's track (Fig. 8).

2. Correction for Cross slope

Krause (1962) has shown that the relationship

between the true bottom slope angle $(\theta)$, the apparent bottom: slope angle $\left(\theta_{a}\right)$, and the angle between the ship's track and a line parallel to the bottom contour $(\beta)$ to be:

$$
\tan \theta=\frac{\tan \theta_{a}}{\sin \beta}
$$

This relationship is good for all values of apparent bottom slope. 



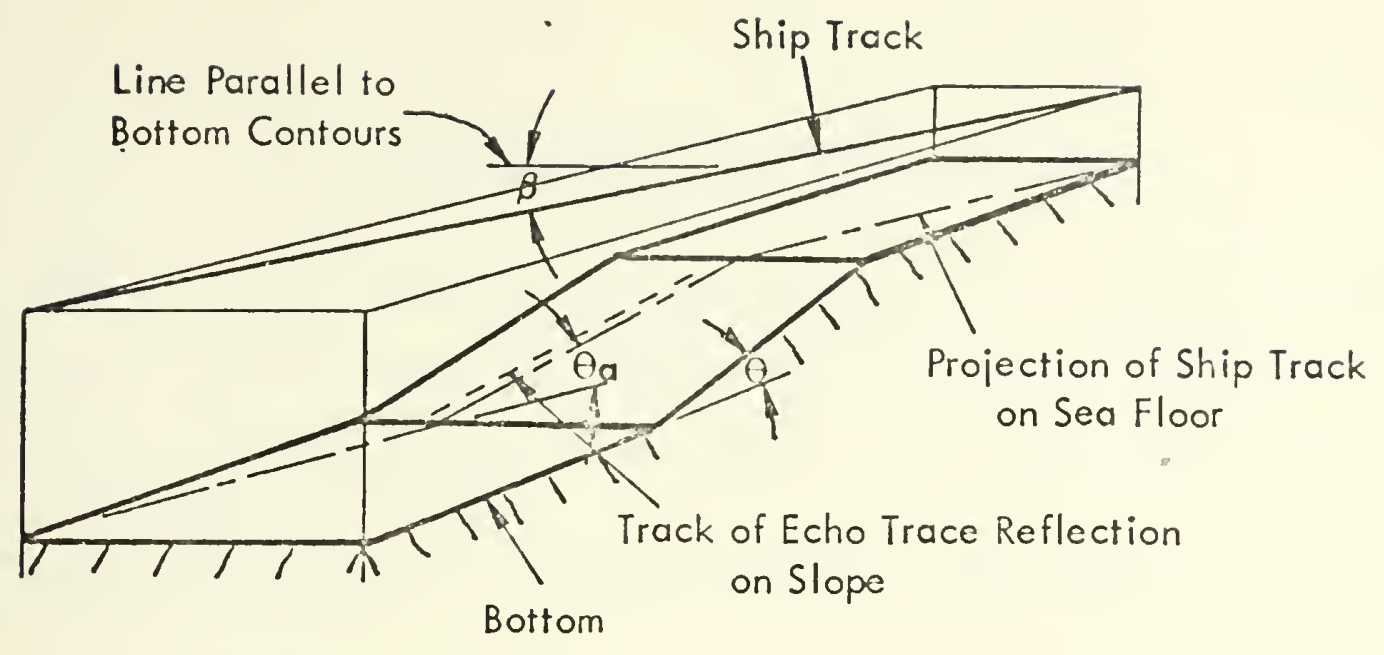

$\theta_{a}=$ apparent bottom slope angle

$\theta^{\circ}=$ true bottom slope angle

$B=$ angie between ship track and line patalle! to bottom contcuts

From Krause (1962):

$\tan \theta=\tan \theta_{a} / \sin \beta$

Figure 8. Cross Slope Correction. 



\section{RESOLUTION OF BATHYMETRIC DATA}

The $3.5-\mathrm{kHz}$ profiler records were used to make the Carmel

Bay chart rather than the fathometer bathymetry because:

-the $3.5-\mathrm{kHz}$ records had better resolution than the fathometer records,

- the wide precision depth recorder paper was easier to work on, and

-the $3.5-\mathrm{kHz}$ records were better on the steep slopes of the canyon walls.

The fathometer records were used to validate the $3.5-\mathrm{kHz}$ profiler records so that if any penetration of the bottom sediments had occurred, the true bottom could still be determined.

\section{A. DATA REDUCTION}

1. Calculation of the Mean Lower Low Water Datum The datum plane from which depths are recorded on hydrographic charts for the West Coast of North America is mean lower low water (MLLW). It is necessary to locate the MLLW datum on the bathymetric records so as to use it as the zero level for subsequent depth determinations. Considered in the determination of MLLW datum are transducer depth, instrument error, and the height of the tide above MLLW.

In the cruise logbook were noted the date and time that each sounding line was steamed, the instrument error determined from the most recent lead line test and the transducer 

depths. The height of the tide from the MLLW datum is obtained from the tide gage records using the date and time that the line was run.

A typical calculation of the MLLW for the tide $3.0 \mathrm{ft}$ above MLLW, a $3.5-\mathrm{kHz}$ profiling system reading too deep by $2.0 \mathrm{ft}$, and a $3.5-\mathrm{kHz}$ transducer towed $20.0 \mathrm{ft}$ below the surface would total 15.0 ft $(-3.0-2.0+20.0)$. The MLLW datum is therefore located $2.5 \mathrm{fm}$ above the zero scale line marked on the $3.5-\mathrm{kHz}$ profiler records.

2. Preliminary Annotation of Bathymetric Records Acetate scales (corrected for deviations of MVSS from the calibrated fathometer sounding speed) were fabricated and used to mark depth intervals on the bathymetric records. The depths should be marked at the contour ine interval to be used on the completed chart. As the overlay is moved across the record, the zero line of the acetate scale must be held on the calculated zero line on the record. This is to assure that the marked depths will be taken from the MLLW datum.

Major pinnacles and troughs should be marked by some consistent convention. The pinnacles and troughs of the small scale bottom structure may or may not be annotated depending upon the intended use for the finished chart.

\section{Application of Slope Corrections}

The depths now on the record are corrected for tide, instrument, and sounding speed errors. The depths marked on approximately level portions of the echo trace are correct 

and need no more work. Corrections still need to be applied to the depths marked on the slopes.

a. Calculation of Apparent Echo Slope Angle

The apparent echo slope angle $\left(\phi_{a}\right)$ is expressed by the relationship:

$$
\tan \phi_{a}=\frac{\text { change in depth }(f t)}{\text { distance traveled }(f t)} .
$$

The change in depth is that change which occurs between any two fixes on the same slope. The distance traveled is obtained from the track post-plot by measuring the distance between the fixes used to get the change in depth.

b. Calculation of Apparent Bottom Slope Angle

(1) Echo Slope Angles Less Than $15^{\circ}$. The relationship between the apparent bottom siope angle $\left(\hat{\theta}_{a}\right.$ ' and the apparent echo slope angle $\left(\phi_{a}\right)$ for echo slope angles less than $15^{\circ}$ is:

$$
\sin \theta_{a}=\tan \phi_{a} .
$$

Since $\phi_{a}$ is already known, i.t is only necessary to find the angle whose sine equals the tangent of $\phi_{a}$ to find $\theta_{a}$.

\section{(2) Echo Slope Angles Greater Than $15^{\circ}$. For} apparent echo slope angles greater than $15^{\circ}, \theta_{a}$ may be obtained directly from Appendix A.

c. Calculation of True Bottom Slope The relationship between true bottom slope angle $(\theta)$, apparent bottom slope angle $\left(\theta_{a}\right)$, and the angle between the ship's track and a line parallel to the bottom contour (B) is: 

$\tan \theta=\frac{\tan \theta_{a}}{\sin \beta}$.

The angle $\beta$ need not be exact. For the carmel Bay survey, $\beta$ was obtained from previously existing hydrographic charts.

d. Final Annotation of Bathymetric Records

With the true bottom slope angle known, the true depth may be obtainea for every echo depth (up to $300 \mathrm{fm}$ ) from Appendix B $\left(\theta \leq 15^{\circ}\right)$ or Appendix $C\left(\theta \geq 15^{\circ}\right)$.

If the corrected depths are plotted below every echo depth on the records and connected, the profile of the true bottom will be seen. Again, using the acetate scales, even depth intervals can be marked on the true bottom.

e. Ambjguity of ' $V$ ' Shaped Depressions

Extending the true bottom profiles of both sides of a ' $V$ ' shaped depression until they irtersect will give a very rough approximation of the bottom of the depression. An ambiguity exists as to the actual shape of the bottom since the echo trace would appear the same for a variety of depression cross sections (Fig. 9). This ambiguity causes the Carmel Bay chart to be inaccurate along the canyon axis. Shepard and Emery (1941, p. 76), using lead lines, found that the carmel Canyon head had a narrow, comparatively flat base. The wide $\left(30^{\circ}\right)$ transducer sound cones employed on the echo sounding equipments of this survey would completely mask this feature of the canyon profile. 


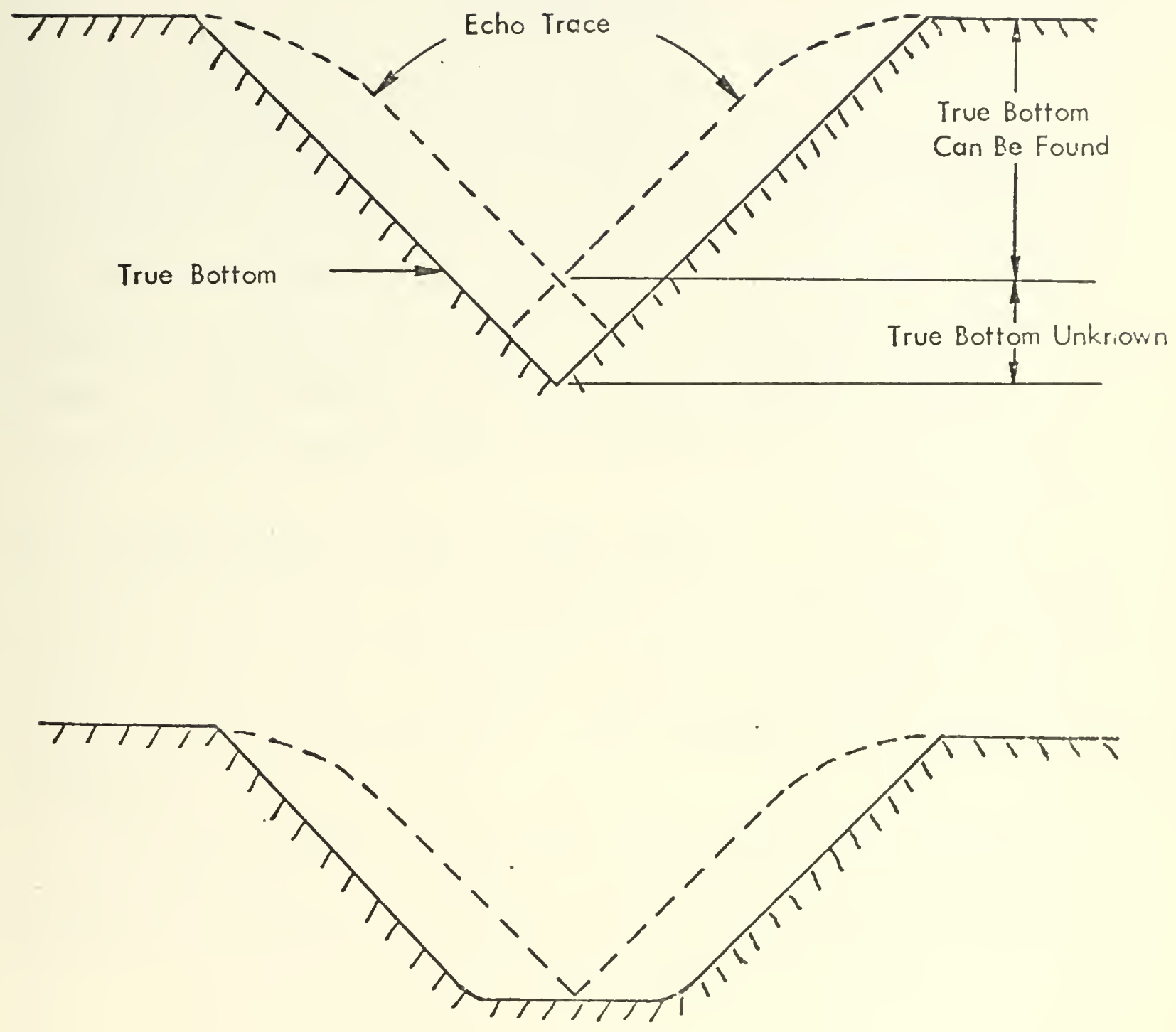

Note the identical echo traces (first reflection) for both troughs.

Figure 9. Ambiguity of ' $V$ ' Shaped Depression. 



\section{CARTOGRAPHY}

\section{A. CONSTRUCtion OF the SMGoth SHEET}

The true depths on the bathymetric records were next transposed to the post-plot of the fixes taken. Every mark on the record had a coinciding fix on the post-plot. Proportional dividers were used to locate the positions of useful contour depths on the post-plot between fixes. Pinnacles and troughs were also located.

B. CONSTRUCTION OF THE FINISHED CHART

The last step in the manufacture of a hydrographic chart is the contouring of the smooth sheet. Contouring of depths was done on tracing paper, as many erasures were often necessary.

The shoreline for the Carmel Bay chart was taken from the 1933 hydrographic survey smooth sheet made by C\&GS. 



\section{SUMMARY}

The completed chart of Carmel Bay is enclosed as Plate I. Every precaution has been taken to insure the accuracy of the contours. Unfortinately, the $30^{\circ}$ transducer cones did not allow for the bottom of the canyon to be properly surveyed and the chart j.s not exact in these areas.

Figure 10 shows the depth contours from the current navigation chart of Carmel Bay (based on the 1933 C\&GS survey) as compared with the contours obtained by this survey. It may be seen that although the 1933 survey provided the generai trends uf the bottom topography, chis study is more specific.

It is hoped that this study can be used as a guide for those interested in conducting bathymetric surveys of areas similar to Carmel Bay. 



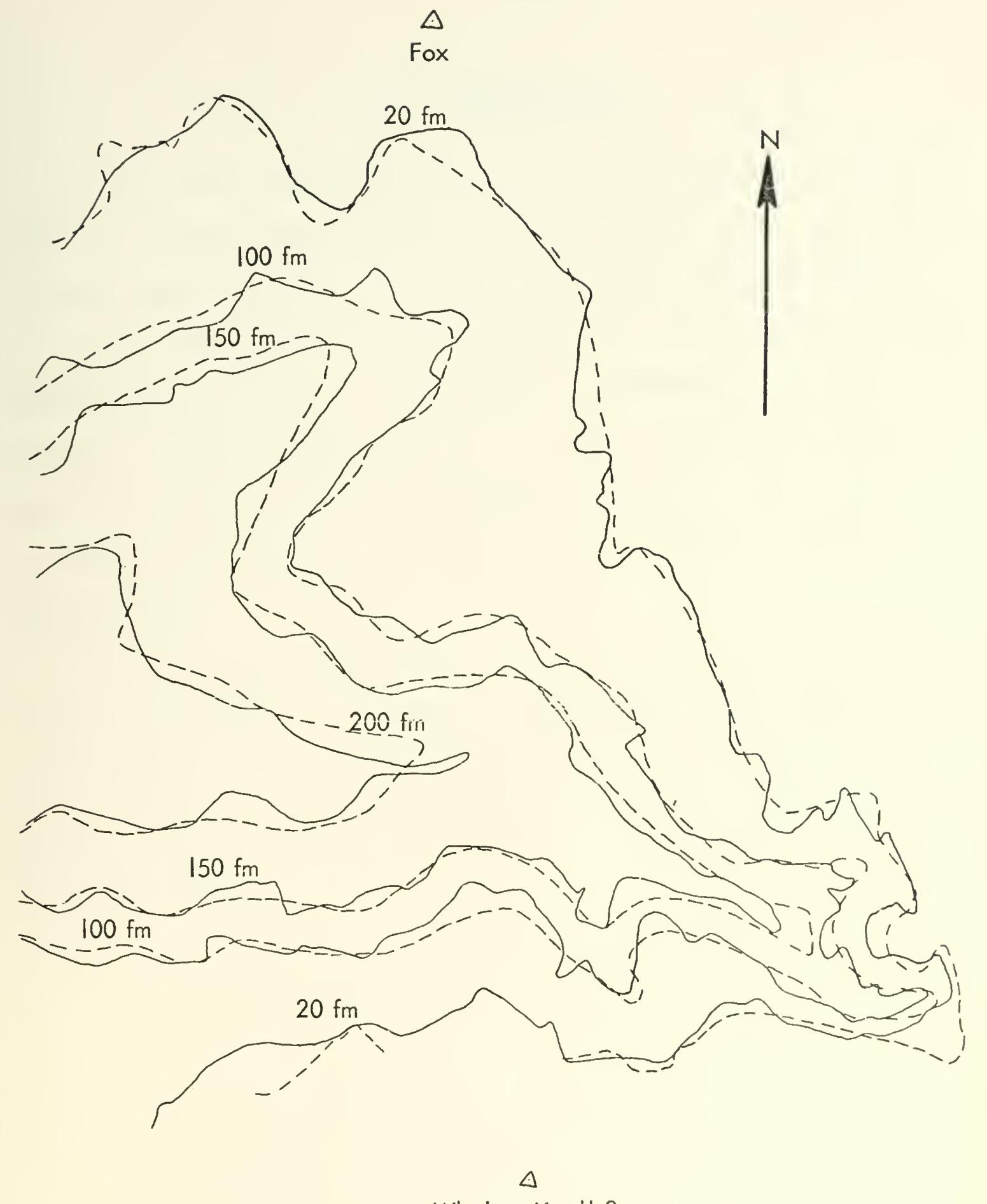

Whalers Knoll 2

1971 Survey (this report)

- - - 1933 C\&GS Survey

Figure 10. Comparison of 1933 and 1971 Bathymetric Surveys. 



\section{FUTURE WORK}

It is anticipated that the sounding lines not completed will be accomplished at some future date so that the contours in this region (Fig. 3) can be drawn with more certainty.

Carmel submarine Canyon should be surveyed with a narrow beam profiler so as to accurately determine the cross-section profile of the entire canyon. If this profiling could be done on regular intervals, every few years or so, the slumping at the head of Carmel canyon could be closely documented.

Work is presently under way at the Naval Postgraduate School to define the texturai and mineraiogical distribution and basins of the bottom sediments of Carmel Bay. Also, a careful study is being conducted of the shoreline geology of Carmel Bay. 

THIS PACGRAM SJLVES THE EQUATION -

$$
\text { SIN(THETA) =SIN }(75+T H E T A) \approx T A N(P H I)
$$

FOR EACH VALUE OF PHI EROM 15 TO 45 DESE EES

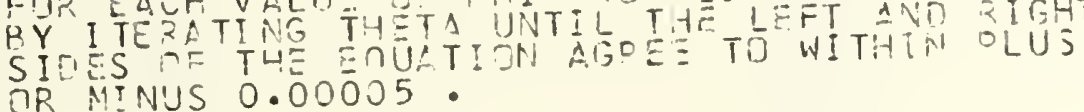

$$
K=14
$$

FHI $=0.017453 \div 14.0$

WRITE $(6,98)$

98 CERMTI (11,1//)

99 WOIT (B,99)

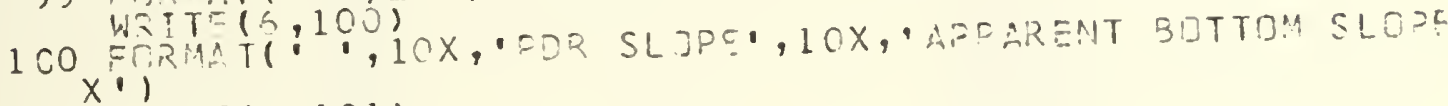

101 WRTTE(t,101)

$2 K=K+1$

$P 4 i=F \mathrm{H}+0.017453$

I E (K.Cn. 46$)^{1-} \in \mathrm{T}$ Tว 3

THET $A=F+1 T$

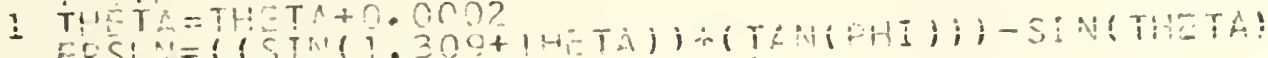

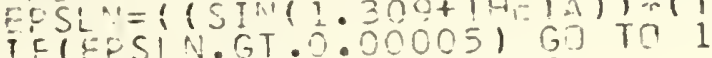

$A=(T H F T=57.296)+0.0 C 5$

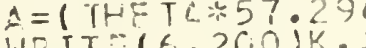

200 EDPMAT; $, 14 \hat{x}, 12,21 x,=6.2)$

$3 \stackrel{3}{S T O P P}$ 



\section{PDR SLDPE \\ (DEGREES)}

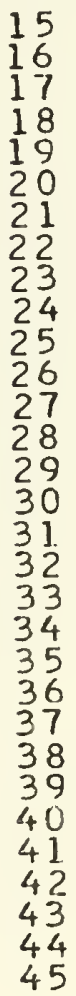

\section{APPARENT BOTTOM SLCPE} (DEGR.EES)

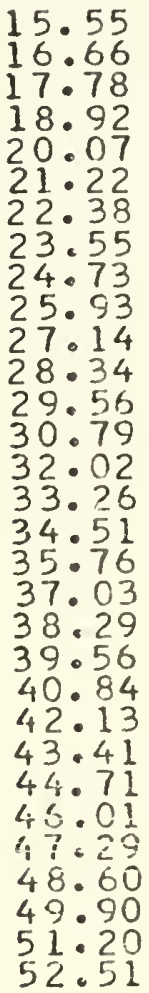





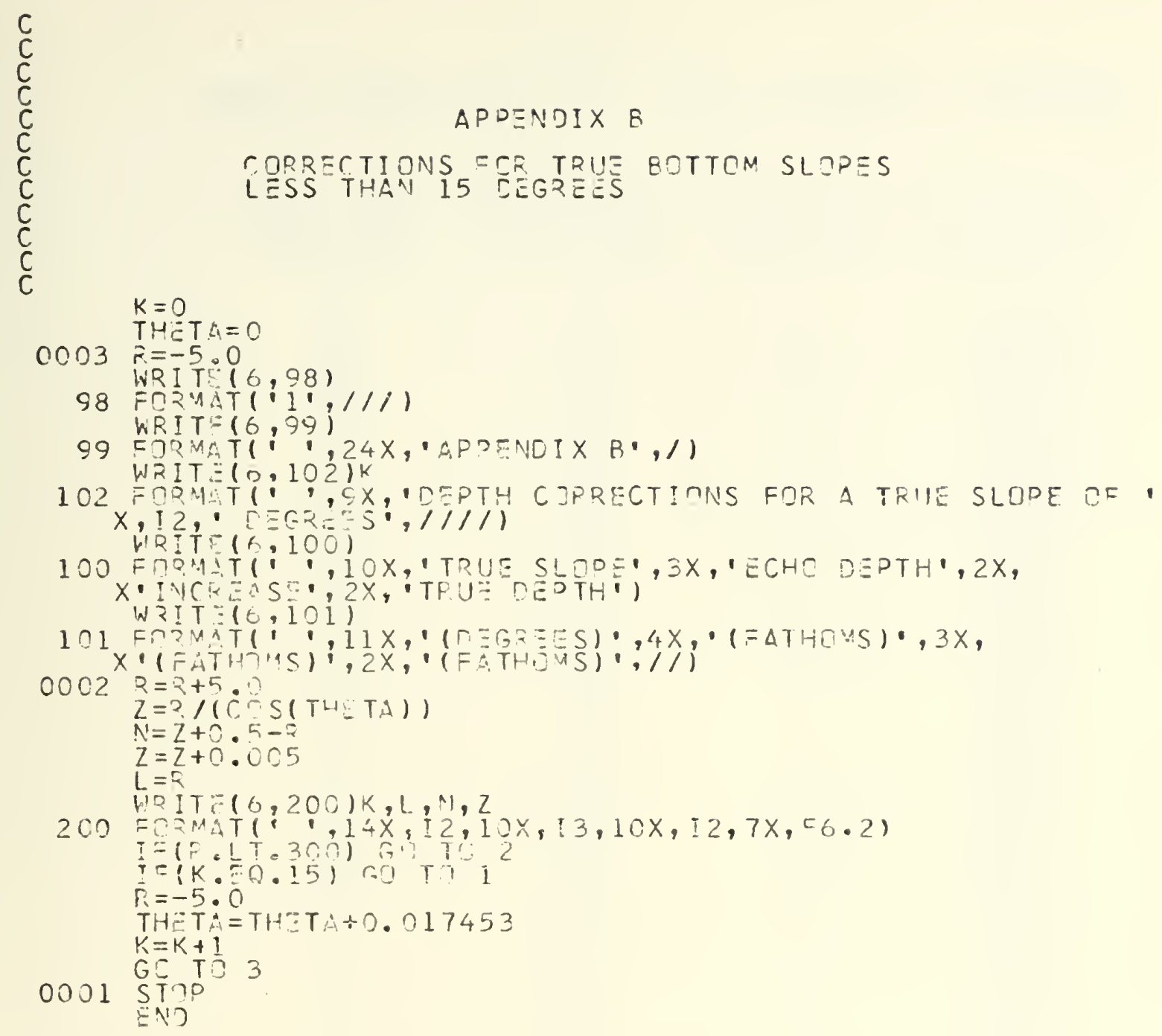



DEPTH CORRECTIINS FOR A TRUE SLCPE GF O DEGREES

TRUE SLOPE
(DEGREES) (FATHEPTH INCREASE TRUE DEPTH
(FATHOMS)
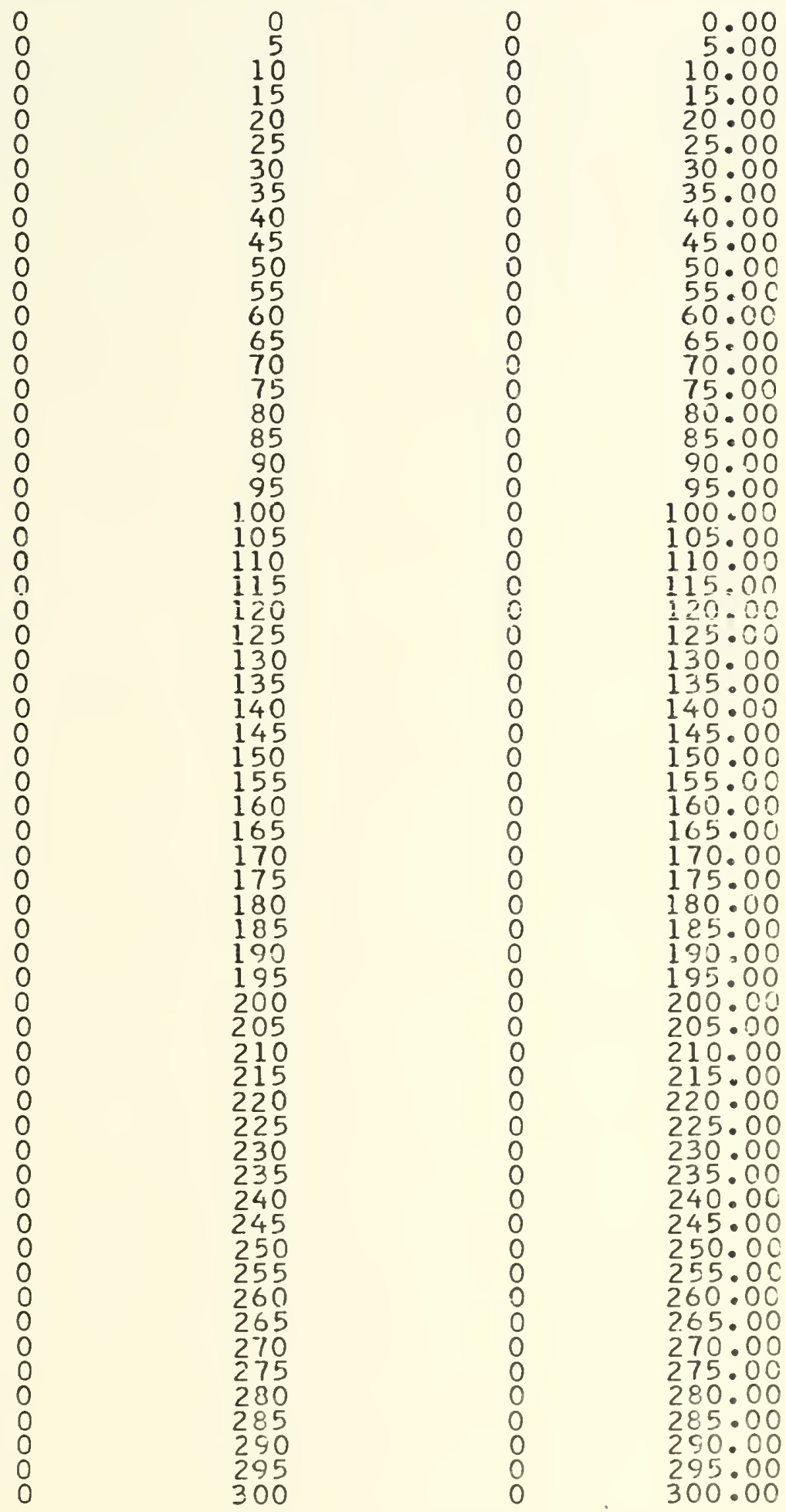


TRUE SLOPE ECHO OEPTH INCREASE TRUE DEPTH
(DEGRESI (FATHOMS) (FATHCMS) (FATHOMS)
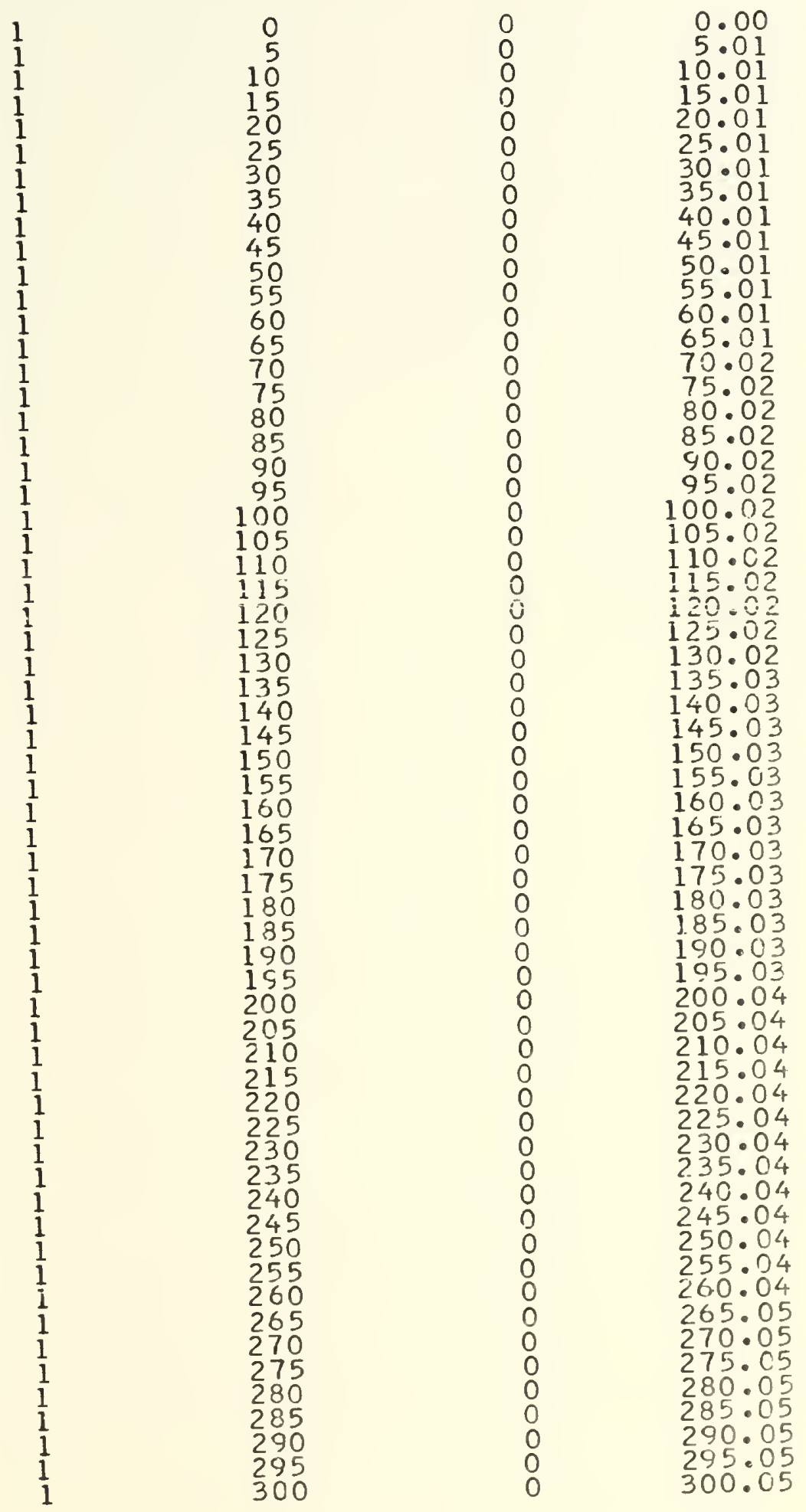

APPENDIX $B$

DEPTH CORRECTIONS FOR A TRUE SLOPE OF 2 DEGREES

TRUE SLOPE ECHE DEPTH INCREASE, TRUE DEPTH
(DEGREES) (FATHOMS) (FATHCMS) (FATHOMS)
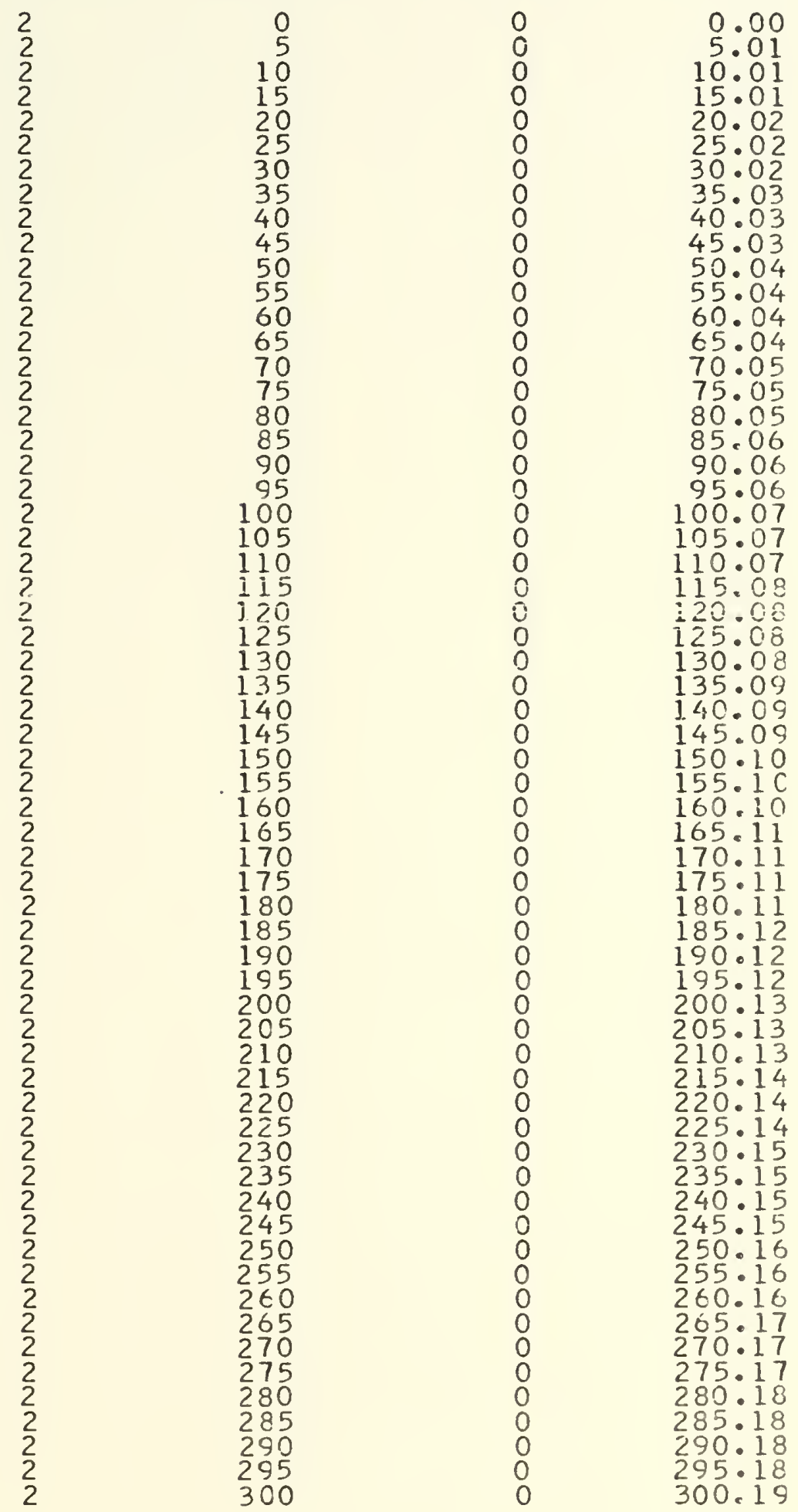

DEPTH CORRECTIONS FOR A TF.UE SLOPE OF 3 DEGREES

TRUE SLOFE ECHC DEPTH INCREASE, TRUE DEPTH
(DEGRES) (FATHCMS)
(FATHOMS) (FATHOMS)
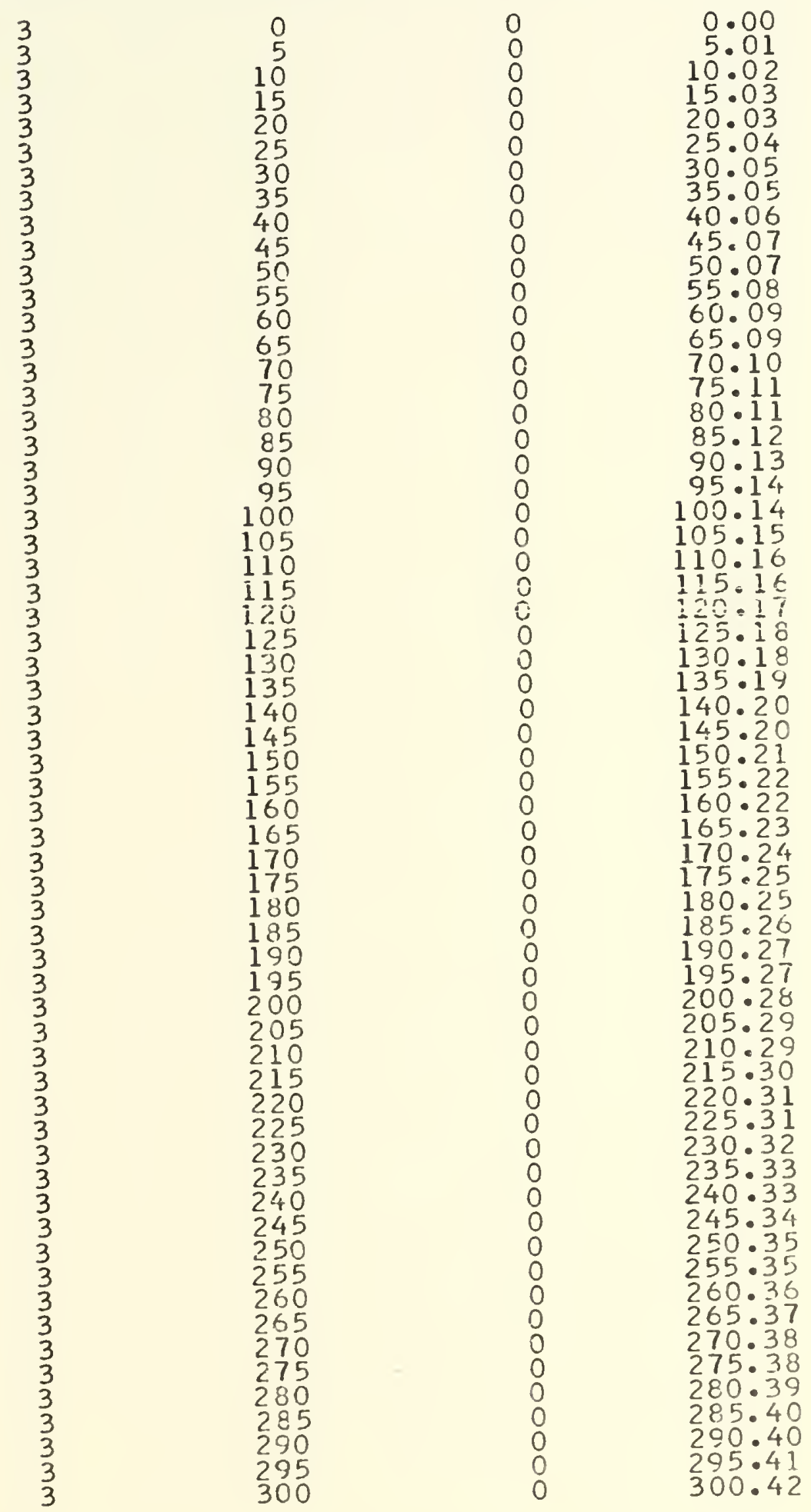

DEPTH CORRECTIINNS FOR A TPUE SLOPE OF 4 DEGREES

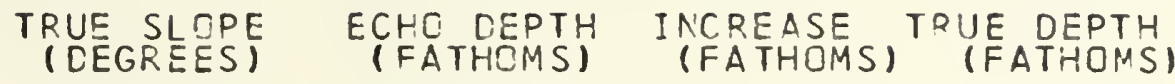
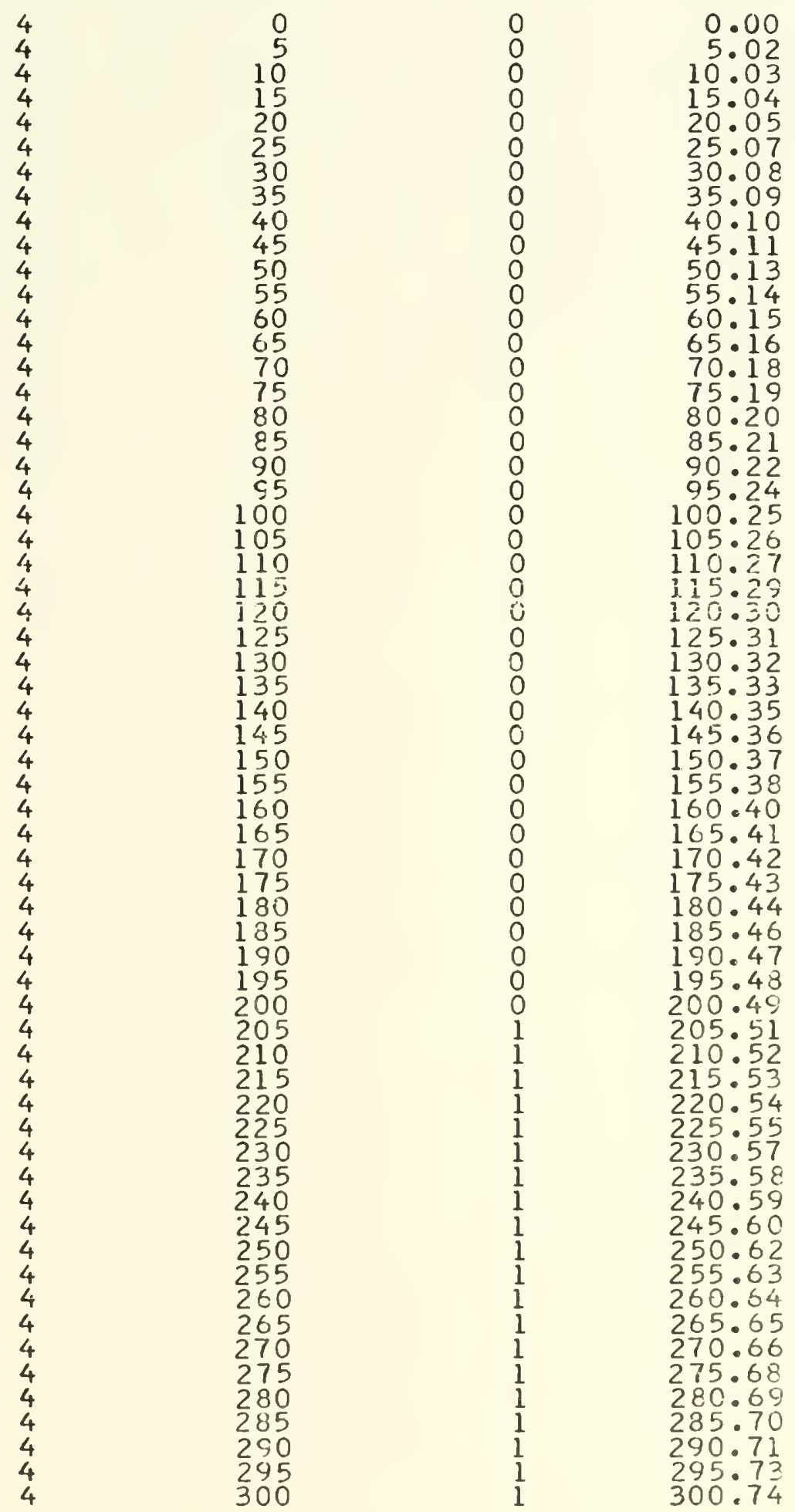

DEPTH CORRECTIONS FOR A TRUE SLCPE CF 5 DEGREES TRUE SLOPE ECHO DEPTH INCREASE TRUE DEPTH
(DEGREES) (FATHOMS!
(FATHOMS) (FATHOMS)
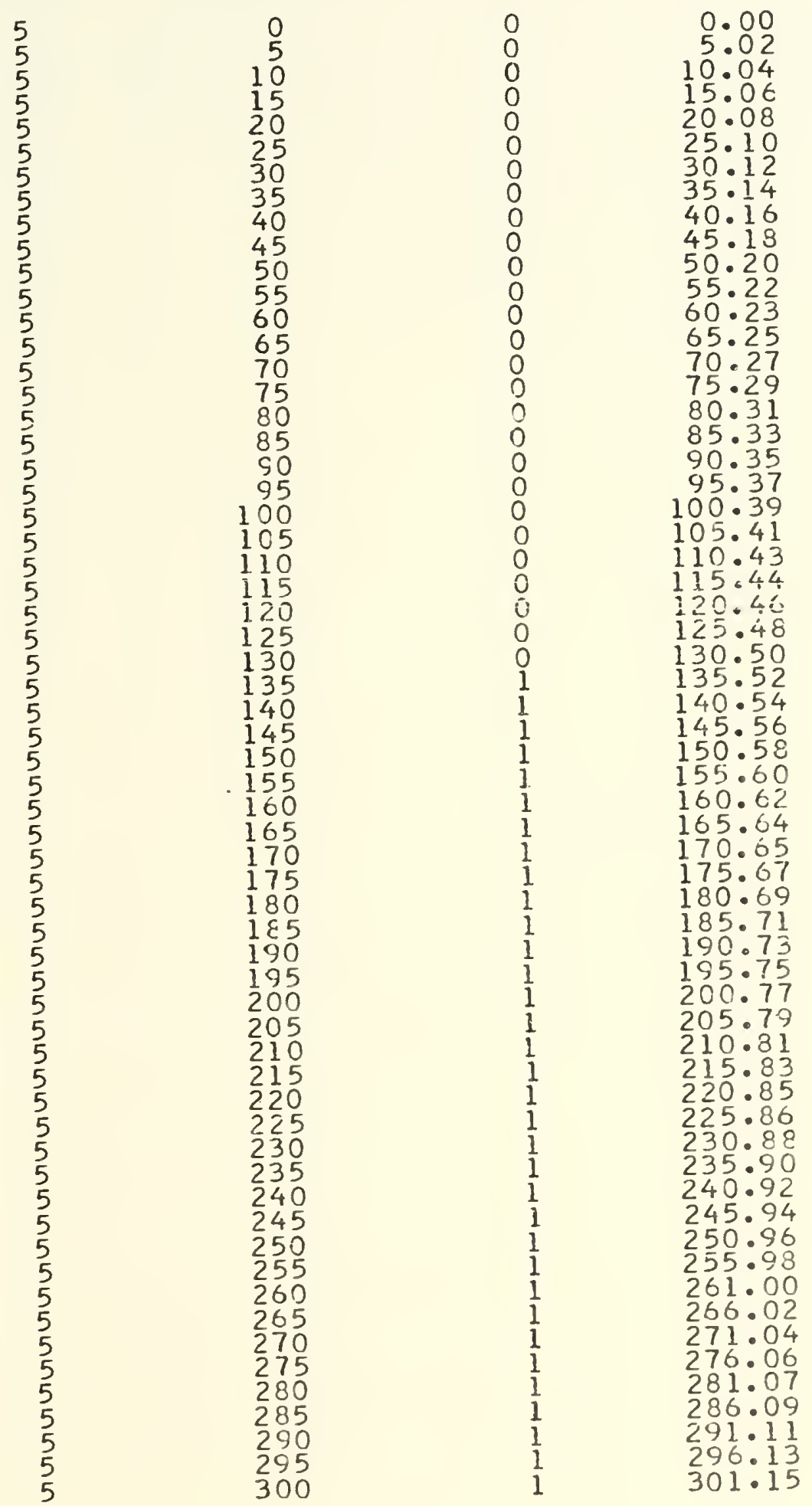

DEPTH CORRECTIONS FDR A TRUE SLCPE OF 6 DEGREES

TRUE SLOPE ECHODEPTH INCREASE TRUE DEPTH
(DEGREES) (FATHOMS)
(FATHOMS) (FATHOMS
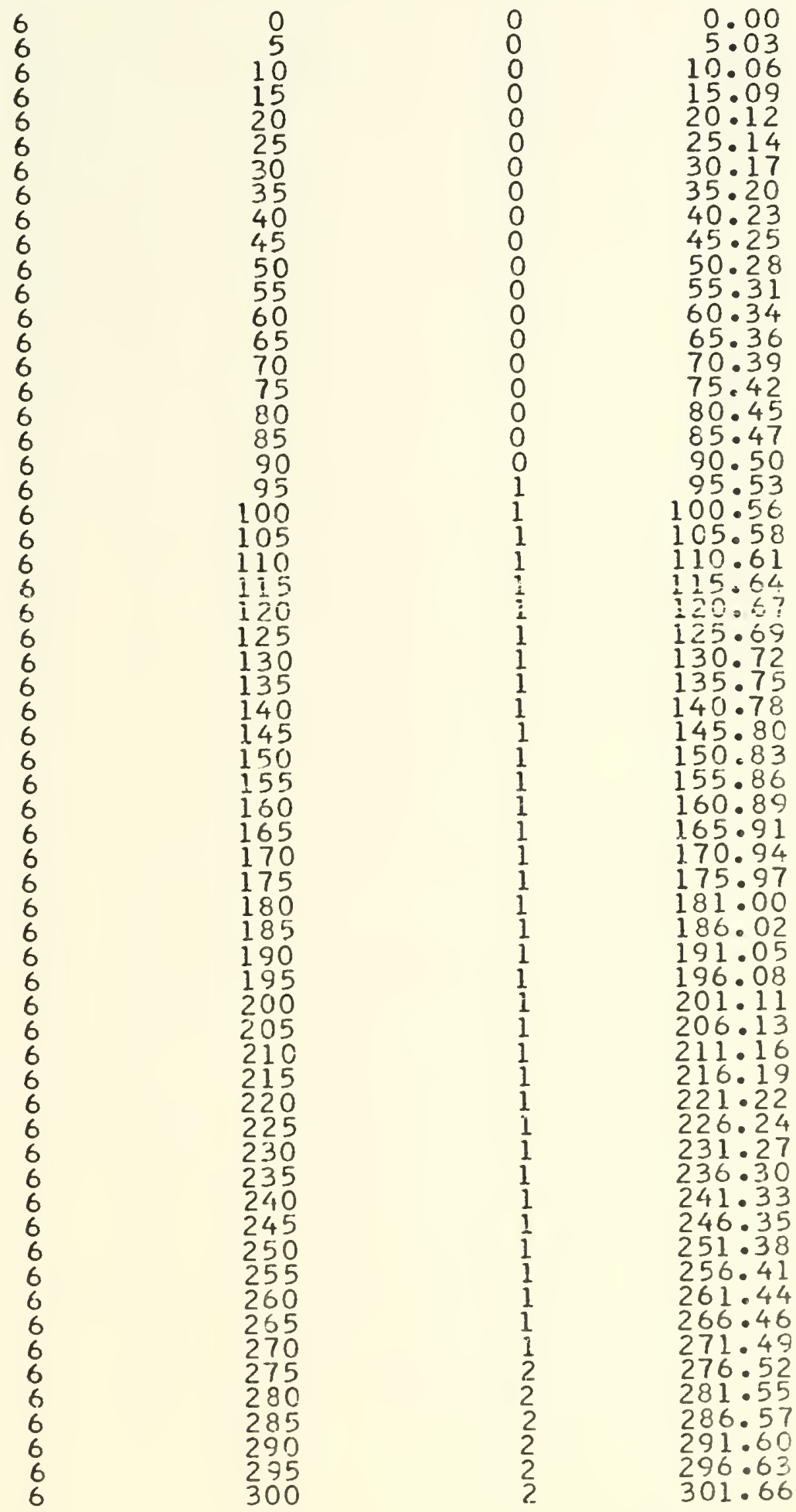

$\begin{array}{lll}\text { TRUE SLCPE } & \text { ECHC DEPTH } & \text { INCREASE TRUE DEPTH } \\ \text { (DEGREES) } & \text { (FATHOMS) } & \text { (FATHOMS) } \\ \text { (FATHOMS) }\end{array}$
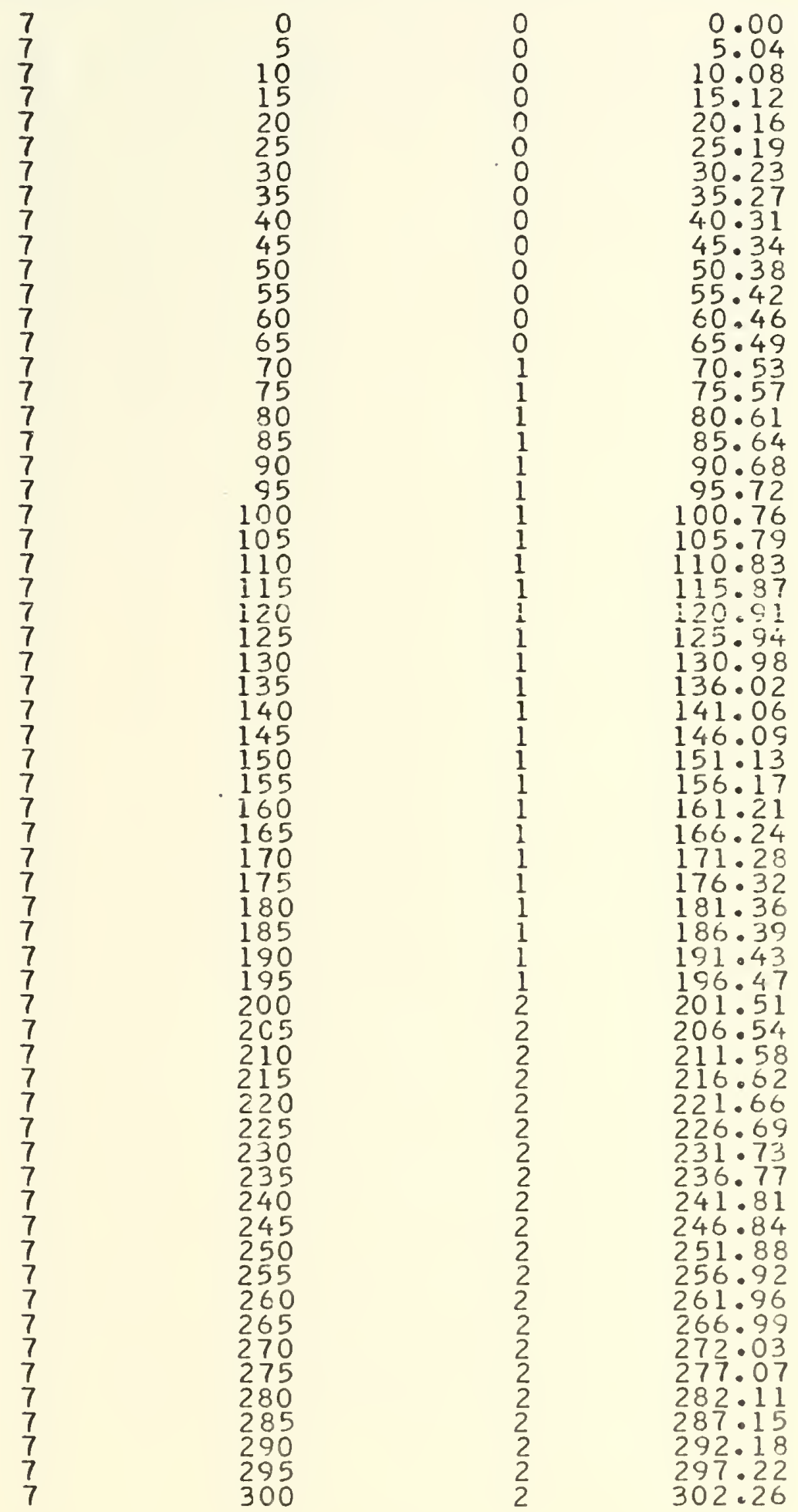

$A P P \subseteq N D I X \quad B$

DEPTH CORRECTIINS FUR A TRUE SLODE CF 8 DEGREES

$\begin{array}{lll}\text { TRUE SLOPE } & \text { ECHO DEPTH } \\ \text { (DOGREES) INCREASE TRUE DEPTH } & \text { (FATHDMS) } & \text { (FATHOMS) (FATHOMS) }\end{array}$
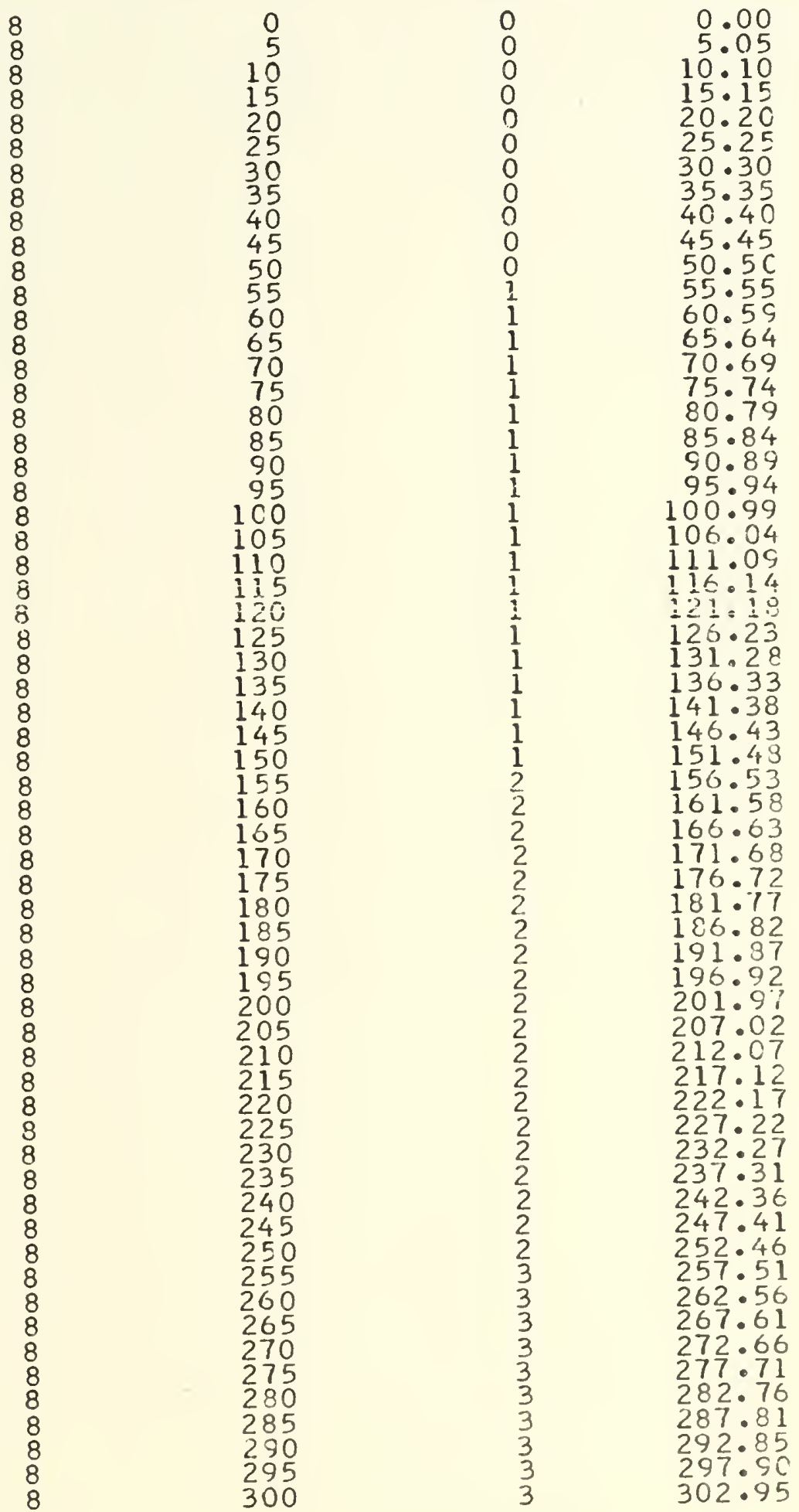

DEPTH CORRECTICNS FOR A TRUE SLCFE CF 9 DEGREES

TRUE SLOPE ECHO DEFTH INCREASE TRUE DEPTH
(DEGRESI
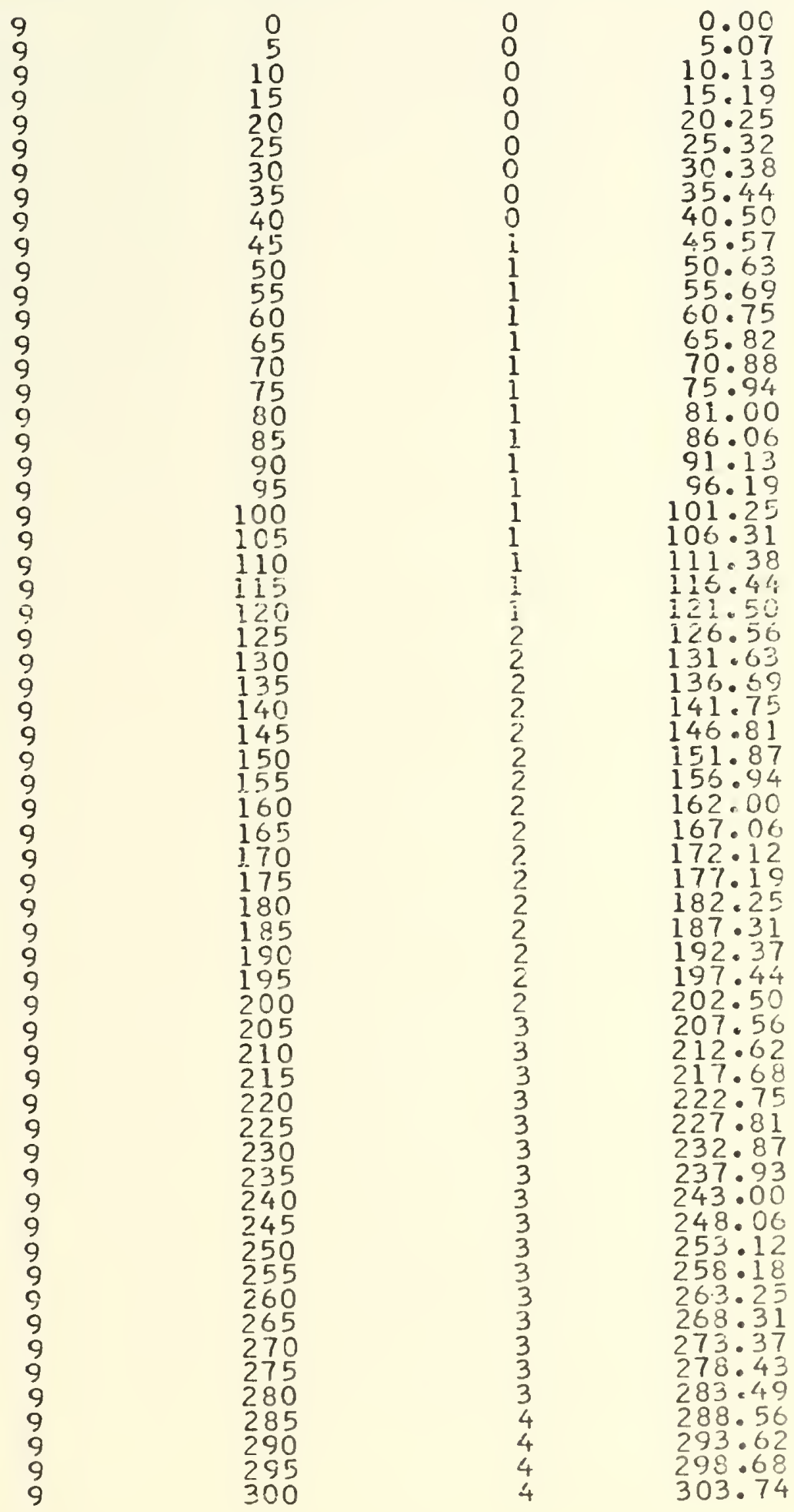

AFPENDIX $P$

DEPTH CORRECTIONS FOR A TRUE SLOPE OF 10 DEGREES TRUE SLCPE ECHC OEPTH TNCPEASE TRUE OEPTH
(DEGREES) (FATHOMS) (FATHOMS) (FATHOMS)
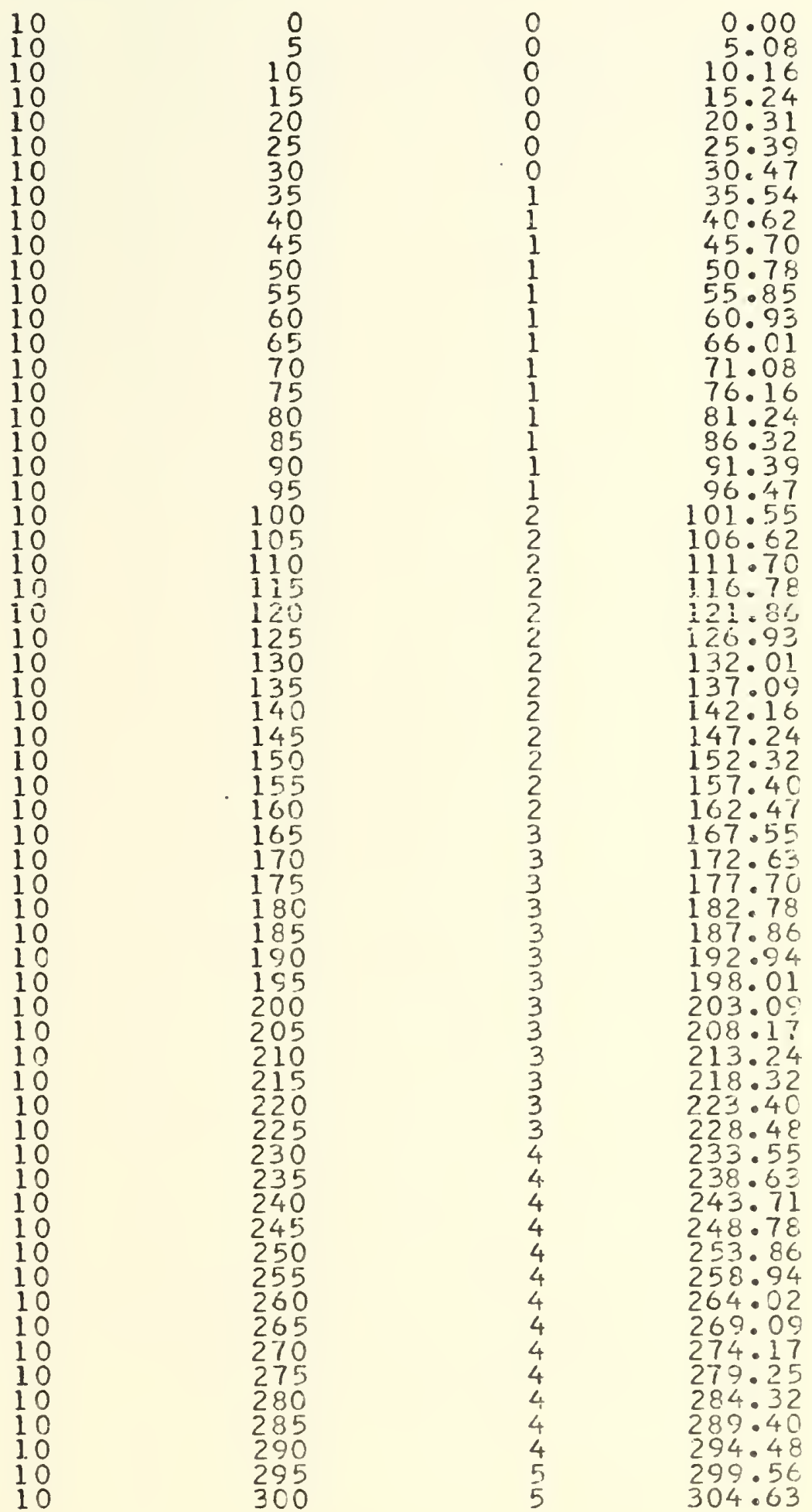

$\triangle P P E N D I X \quad B$

DEPTH CORRECTIONS FOR A TRUE SLOFE OF 11 DEGFEES

TRUE SLCPE ECHO DEPTH INCREASE, TRUE CEPTH
(DEGREES) (FATHOMS)
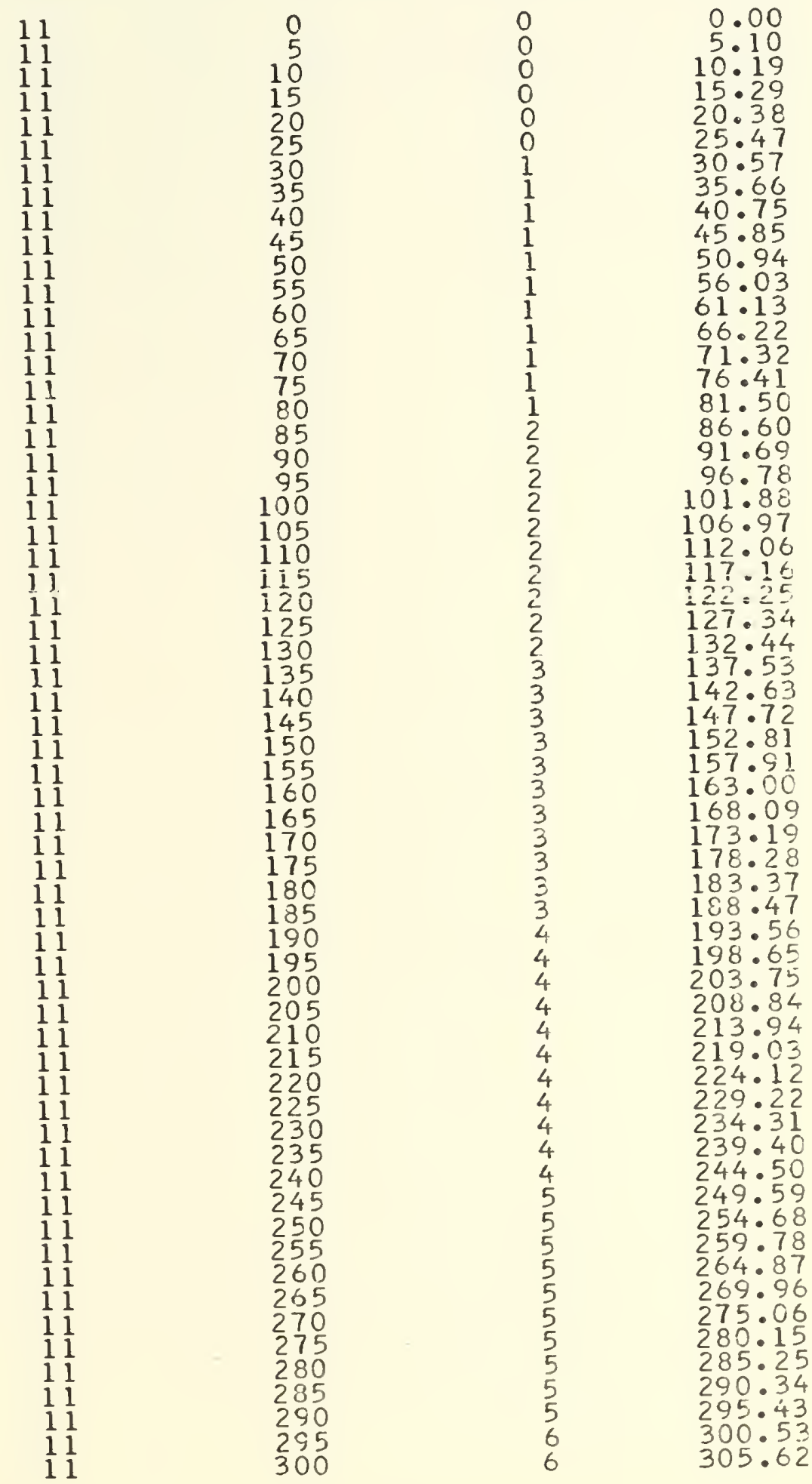

DEPTH CORRECTICNS FOR A TRUE SLCFE CF 12 DEGREES

$\begin{array}{lll}\text { TRUE SLOPE } & \text { ECHO REPTH INCREASE TRUE DEPTH } \\ \text { (DEGREES) } & \text { (FATHOMS) } & \text { (FATHOMS) (FATHOMS) }\end{array}$
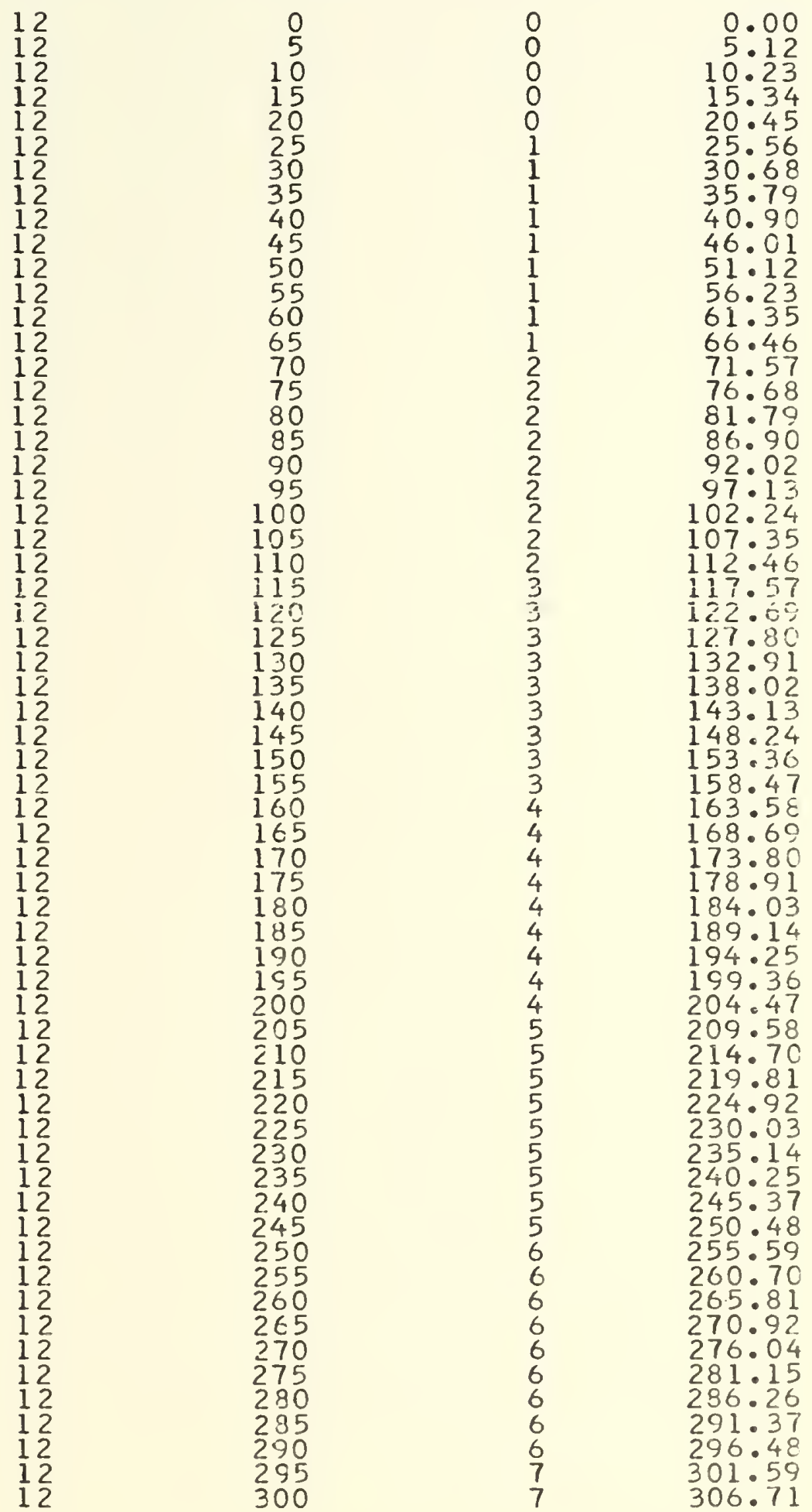



\section{APPENDIX $B$}

DEFTH CORRECTIONS FOR A TRUE SLOPE OF 13 DEGREES

TRUE SLCPE ECHC DEPTH IACREASE TRUE DEPTH
(DEGRES) (FATHOMS)
(FATHOMS) (FATHOMS)
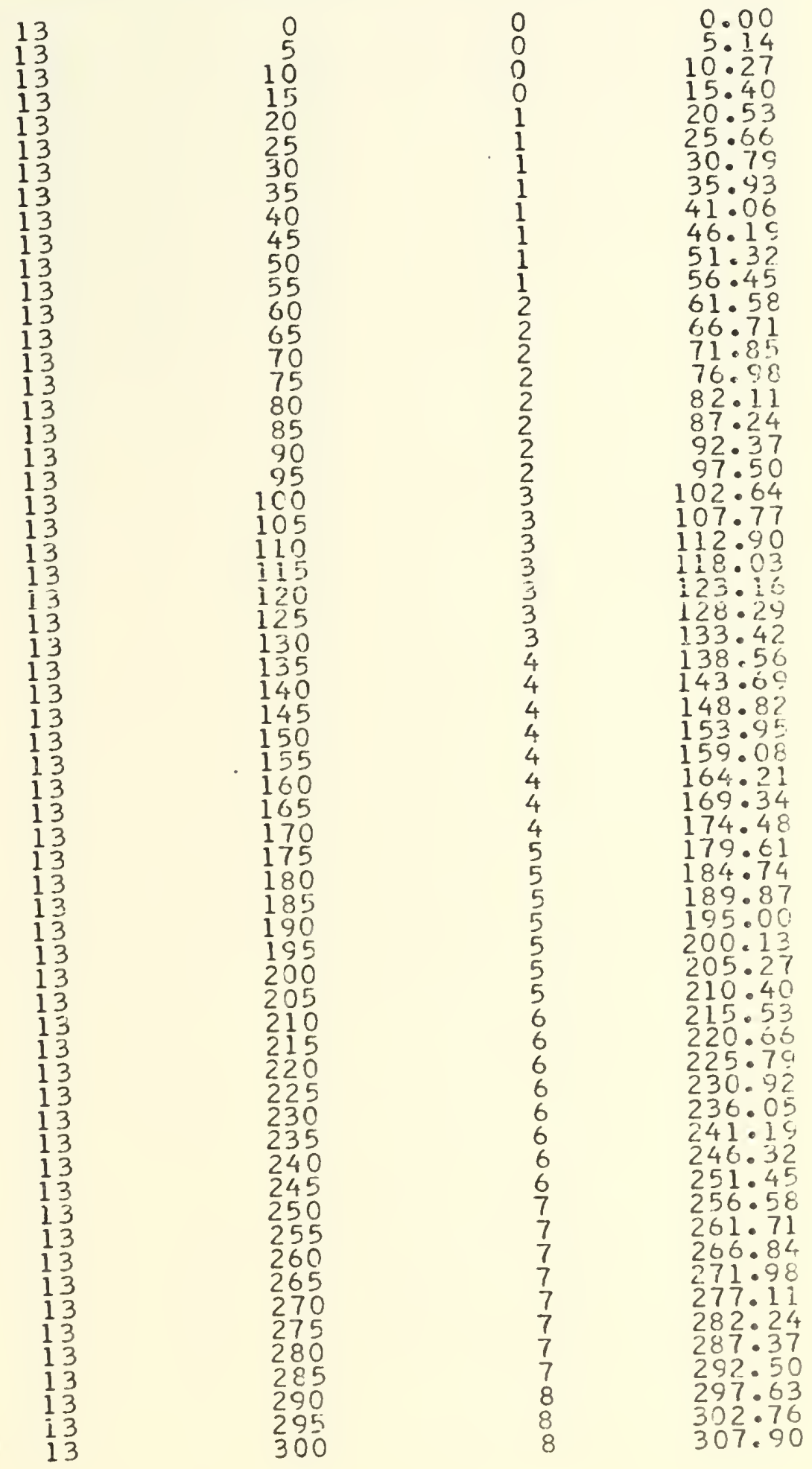

TRUE SLCPE ECHO DEPTH INCREASE TRUE DEPTH
(DERREST (FATHDMSI (FATHOMS) (FATHOMS)
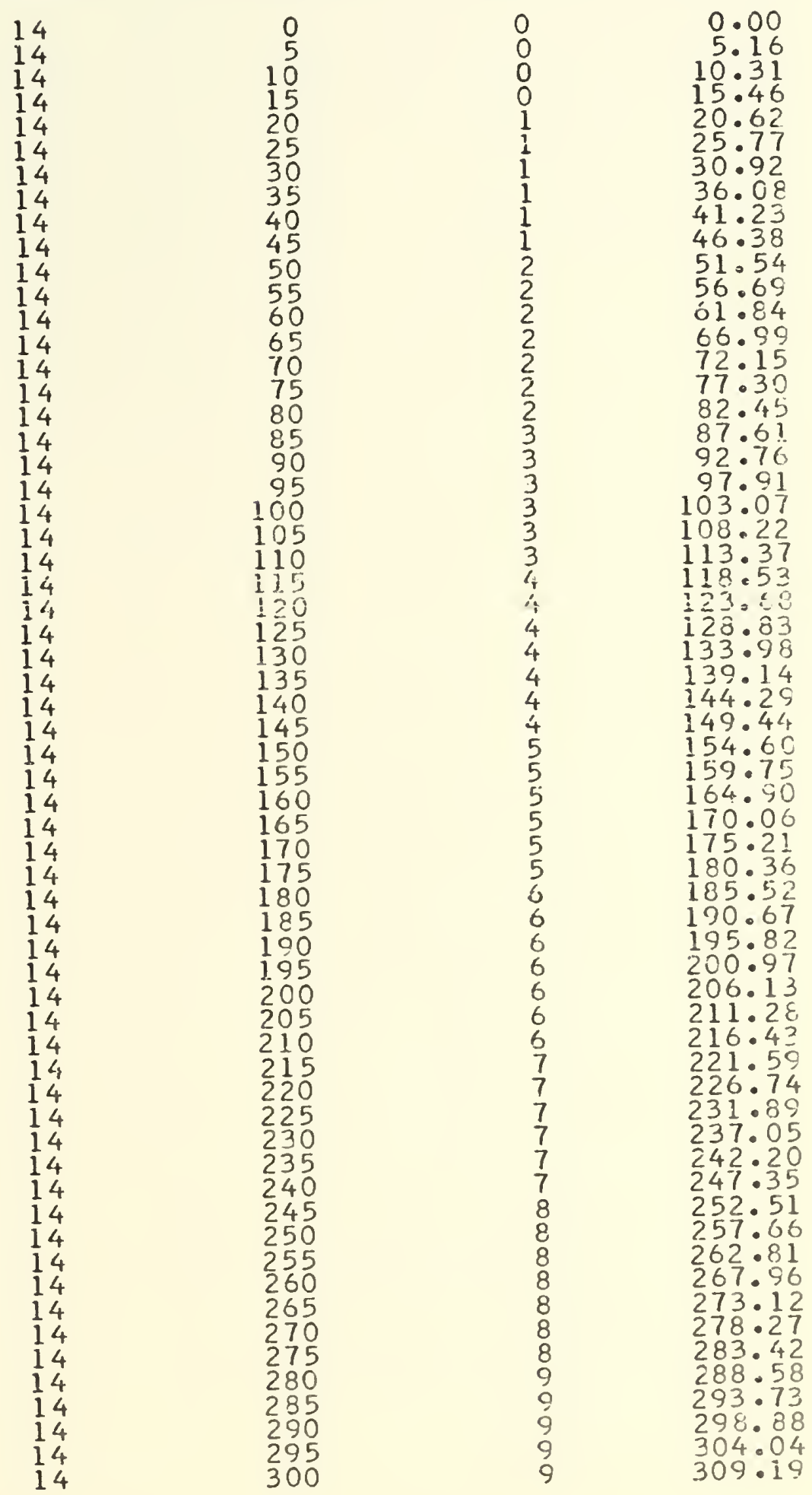


TRUE SLOPE ECHC DEPTH INCREASE TRUE OEPTH
(OEGREES) (FATHOMS)
(FATHOMS) (FATHOMS)
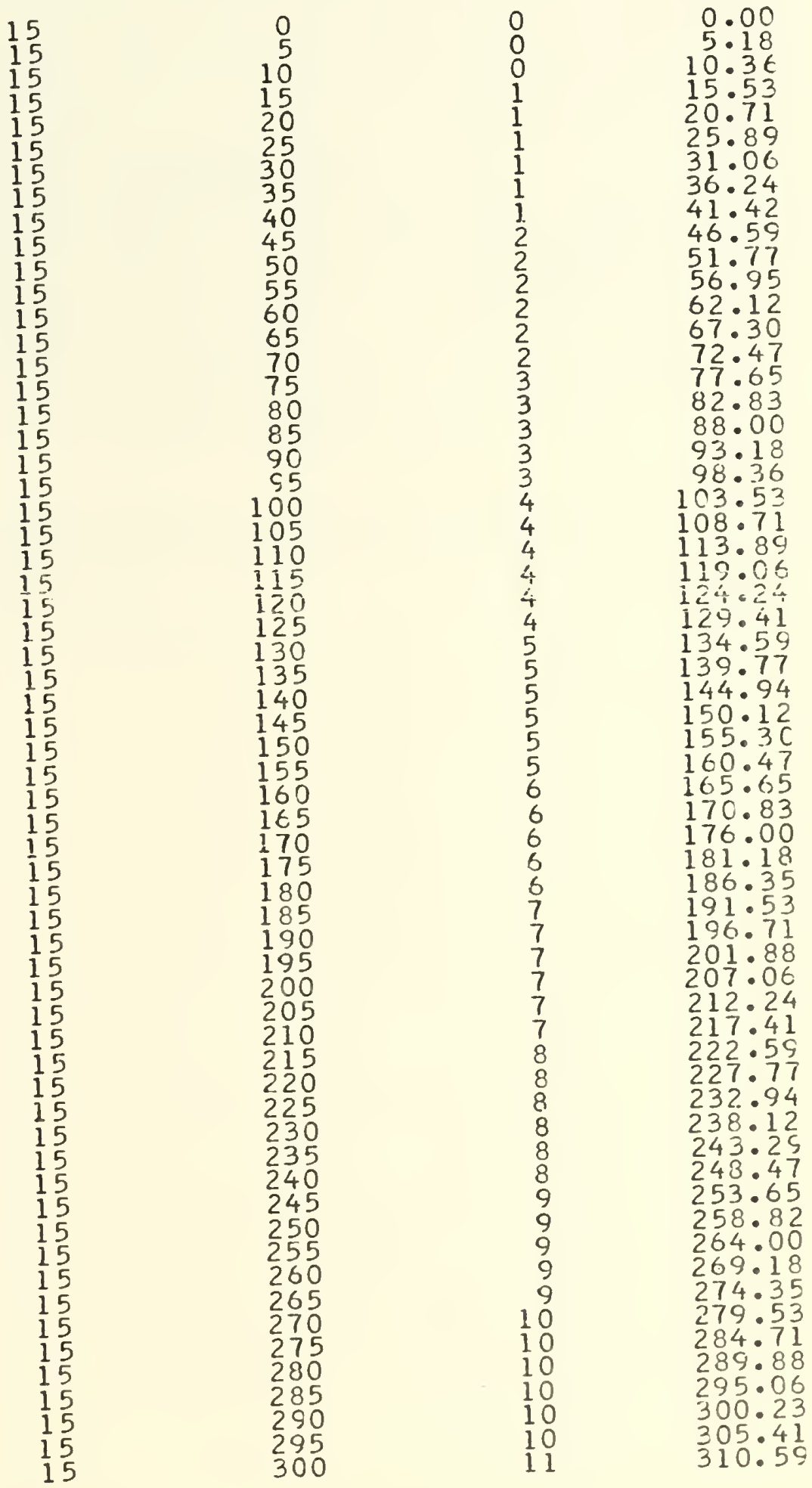



\section{APPENDIX C}

CORRCCTIONS FCR TRUE BOTTOM SLOPES
GREATEE THAN IS DEGREES

$K=15$

THETA $=0.26180$

$0003 R=-5.0$

WRIT $(6,98)$

S 8 FCRAAT( $11,1 / 1)$

99 FORMGT( 99$), 24 X, 1$, ADPENDIX C', / ) 102 WRITE(G, 102$) \mathrm{K}$, IAFTH COREECTIONS FOP A TR.UE SLOPE OF '

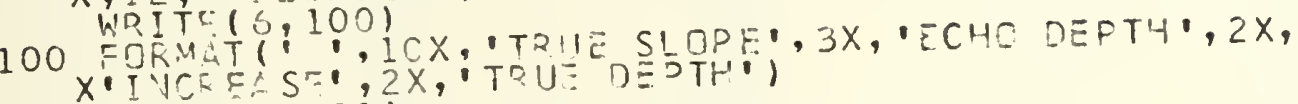
WD.IT $=(6,101)$

101 FO? T T (

$0002 P=R+5.0$

$Z=R *(0.96593+0.25882 *(T A N(T H E T A)))$

$N=Z+0.5-6$

$L=R$

WRITr: $(t, 200) \mathrm{K}, \mathrm{L}, \mathrm{N}, \mathrm{Z}$

200

ERRMAT(' '14X, 1 , 1 CX, I3, $10 \mathrm{X}, 12,7 \mathrm{X}, \mathrm{F} 6.21$

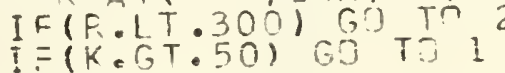

$\overline{\mathrm{k}}=-5.0$

THETA=THET +10.017453

$K=K+1$

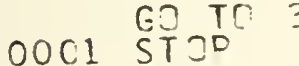

LiV 

APPENDIX C

DEPTH CORRECTICNS FOR A TRUE SLCFE OF 15 DEgREES

$\begin{array}{lll}\text { TRUE SLOPE } & \text { ECHODEPTH INCPEASE TRUE DEPTH } \\ \text { (DEGRES) } & \text { (FATHCMS) } & \text { (FATHOMS) (FATHOMS) }\end{array}$

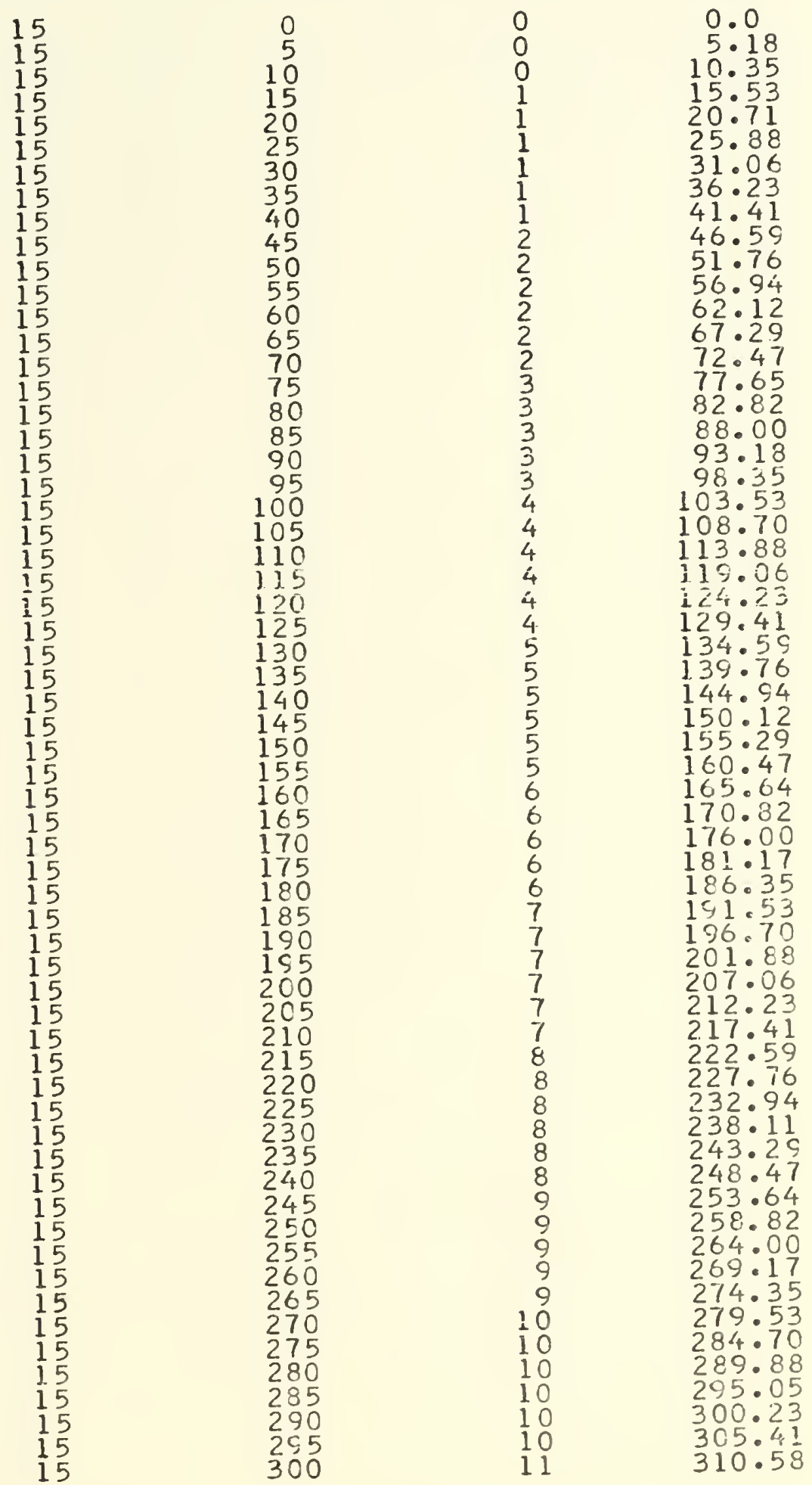



APPENDIX C

DEPTH CORRECTIONS FOR A TRUE SLCFE CF 16 DEGREES

TRUE SLOPE ECHO DEPTH INCREASE TRUE DEPTH
(DEREES) (FATHCMS)
(FATHOMS) (FATHOMS)
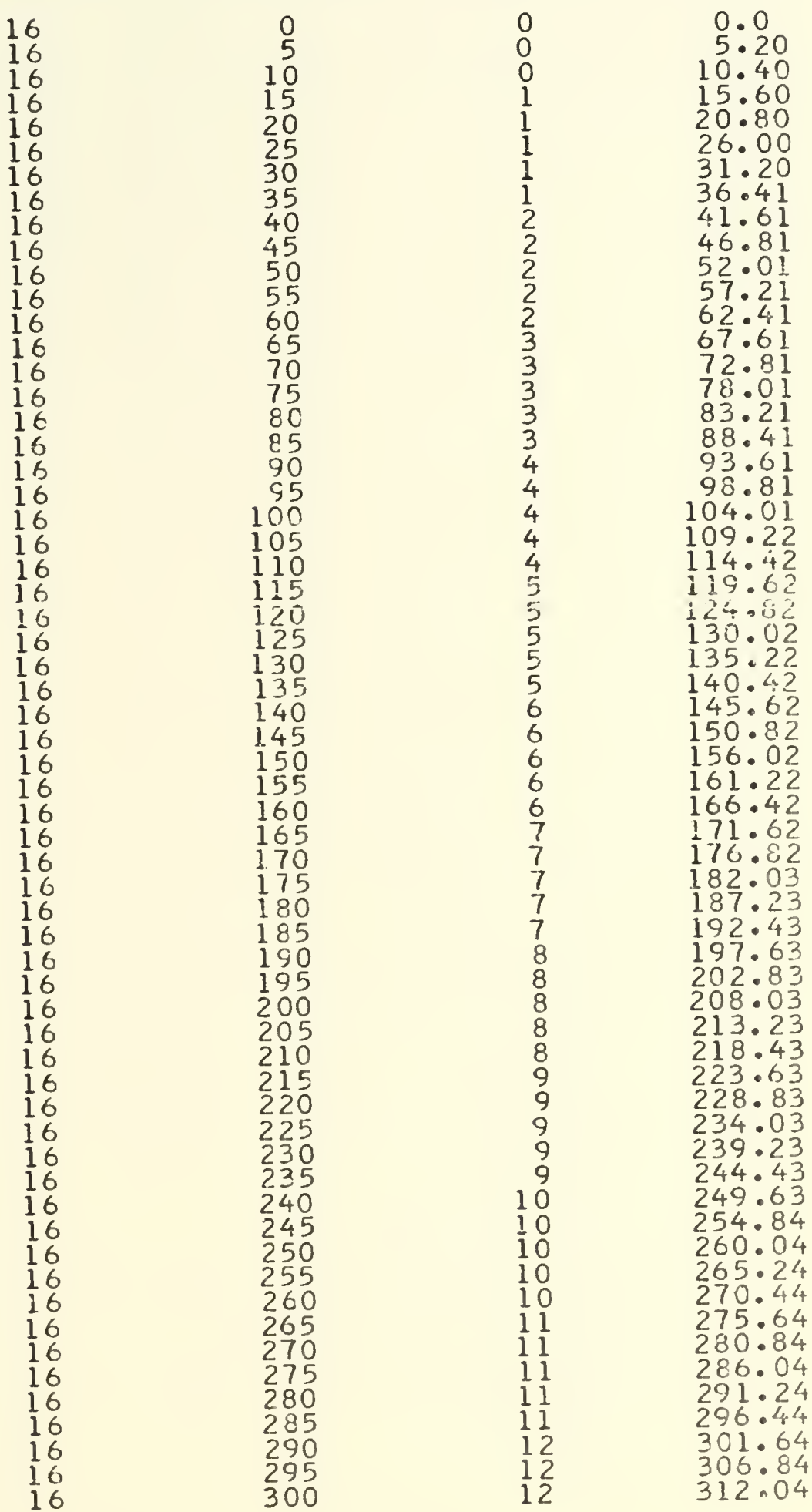

APPENDIX C

DEPTH CORRECTIONS FOR A TRUE SLCFE OF 17 DEGREES TRUE SLOFE ECHO DEPTH TNCPEASE, TRUE DEPTH
(DEGREES) (FATHCMS)
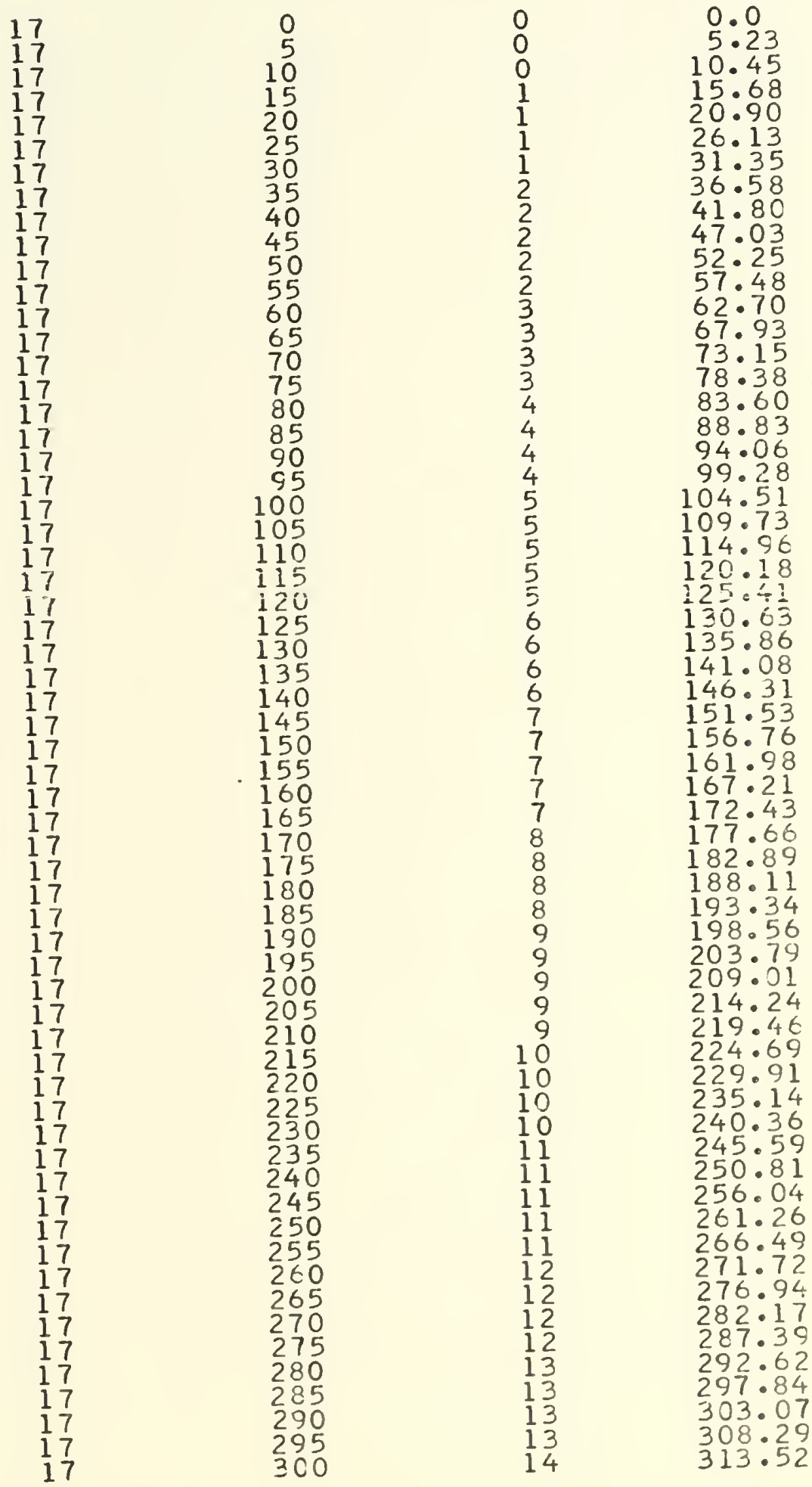

APFENDIX C

DEPTH CORRECTIONS FOR A TRUE SLOPE OF 18 DEGREES

TRUE SLCPE ECHC DEPTH INCREASE TPUE OEPTH

$\begin{array}{lr}18 & \\ 18 & 0 \\ 18 & 5 \\ 18 & 10 \\ 18 & 15 \\ 18 & 20 \\ 18 & 25 \\ 18 & 30 \\ 18 & 35 \\ 18 & 40 \\ 18 & 45 \\ 18 & 50 \\ 18 & 55 \\ 18 & 60 \\ 18 & 65 \\ 18 & 70 \\ 18 & 75 \\ 18 & 80 \\ 18 & 85 \\ 18 & 90 \\ 18 & 95 \\ 18 & 100 \\ 18 & 105 \\ 18 & 110 \\ 18 & 115 \\ 18 & 120 \\ 18 & 125 \\ 18 & 130 \\ 18 & 135 \\ 18 & 140 \\ 18 & 145 \\ 18 & 150 \\ 18 & 155 \\ 18 & 160 \\ 18 & 165 \\ 18 & 170 \\ 18 & 175 \\ 18 & 180 \\ 18 & 185 \\ 18 & 190 \\ 18 & 195 \\ 18 & 200 \\ 18 & 205 \\ 18 & 210 \\ 18 & 215 \\ 18 & 220 \\ 18 & 225 \\ 18 & 230 \\ 18 & 235 \\ 18 & 240 \\ 18 & 245 \\ 18 & 250 \\ 18 & 255 \\ 18 & 260 \\ 18 & 265 \\ 18 & 270 \\ 18 & 275 \\ 18 & 280 \\ 18 & 285 \\ 18 & 295 \\ 18 & \end{array}$

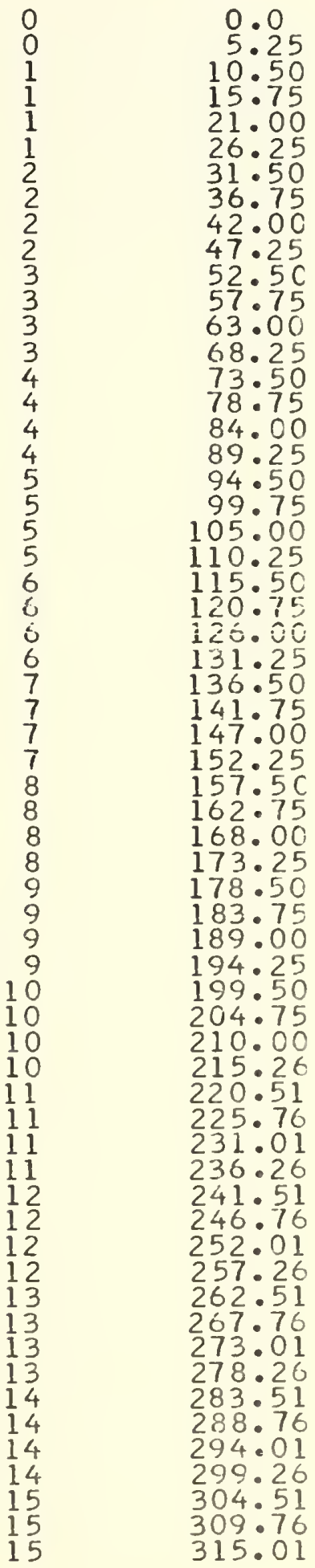



APPENDIX C

DEPTH CORRECTICNS FOR. A TRUE SLOPE OF 19 DEGREES

TRUE SLOFE ECHC DEPTH INCREASE TRUE DEPTH
(DEGREES)

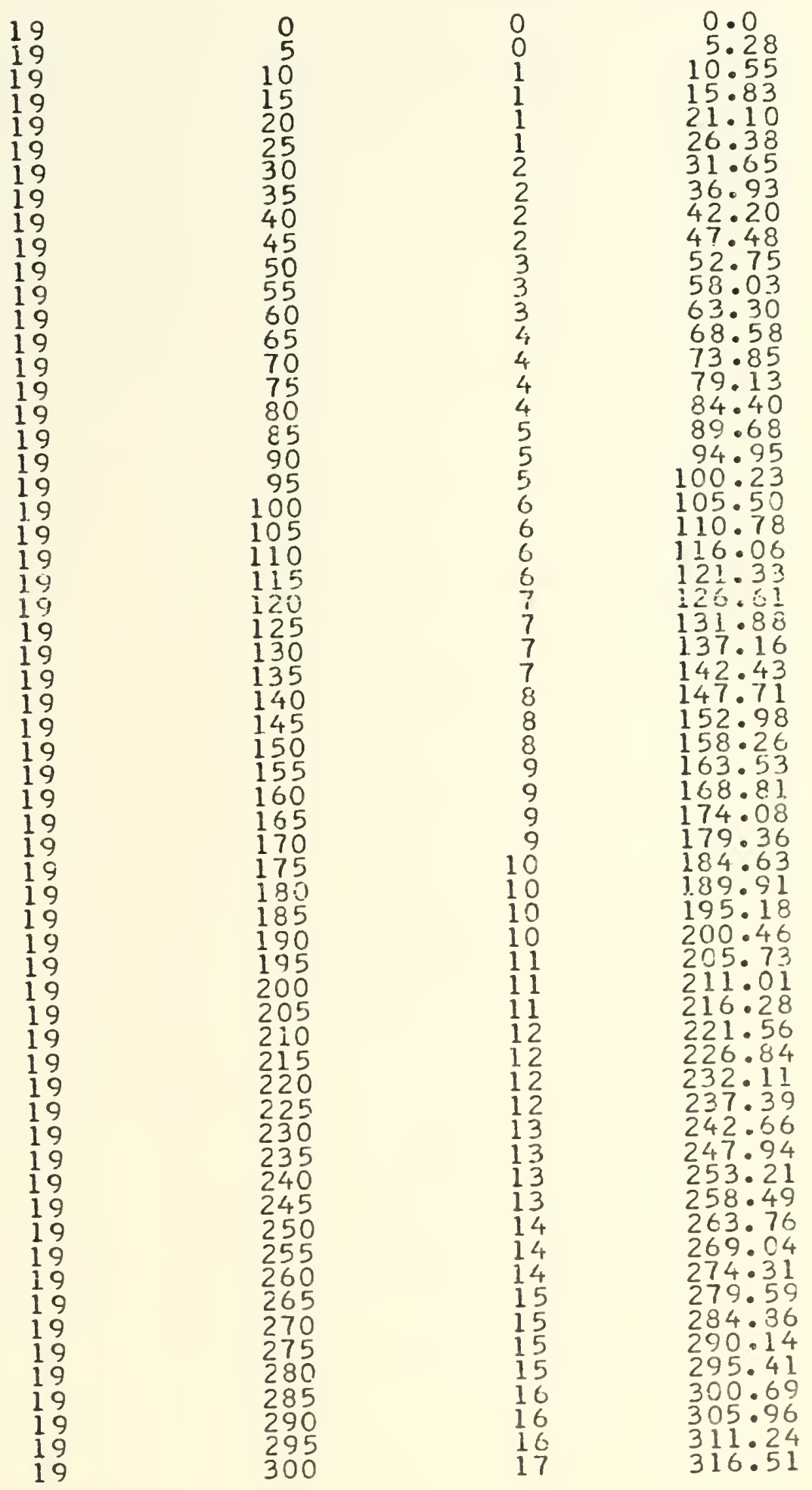



DEPTH CORRECTICNS FOR A TRUE SLCPE OF 20 DEGREES

TRUE SLOPE ECHO DEPTH INCREASE TRUE DEPTH
(OEGRES) TFATHCMS) (FATHCMS) (FATHOMS)
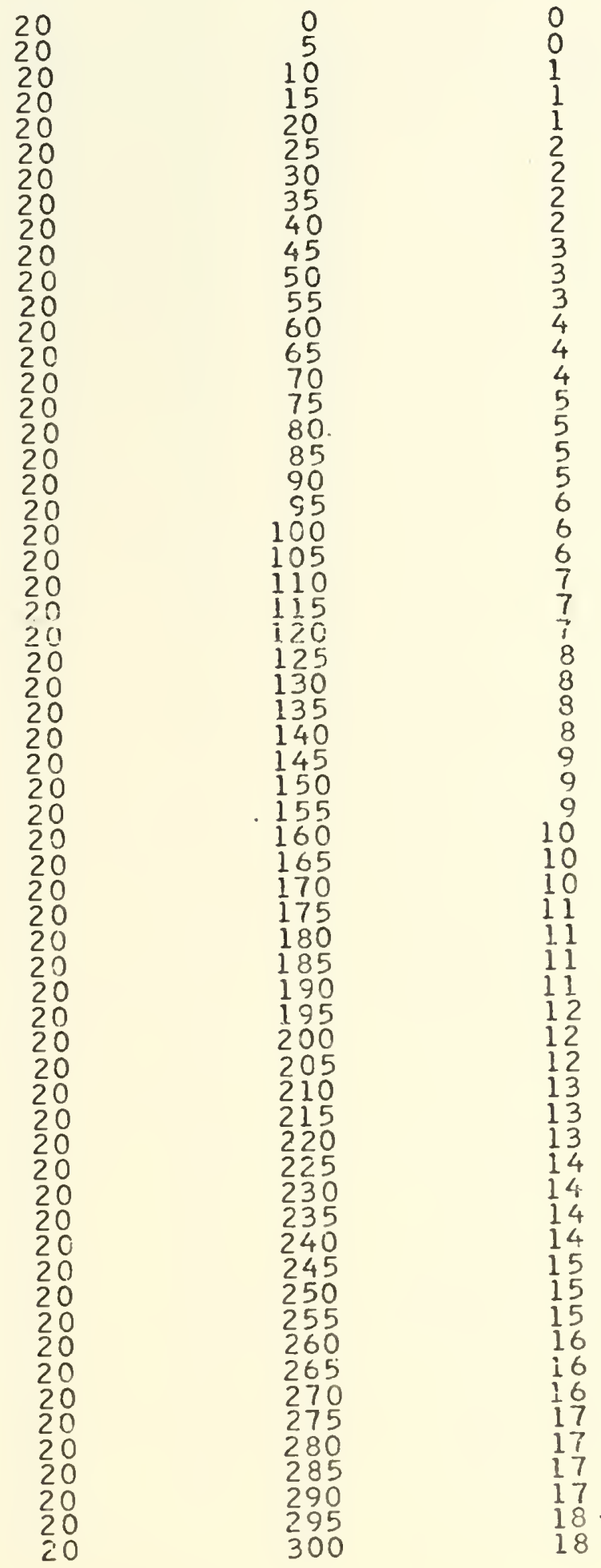

0.0
5.30
10.60
15.90

21.20

$26.5 \mathrm{C}$

31.80

$42: 41$

47.71

53.01

58.31

63.61

68.91

$74 \cdot 21$

84.81

90.11

95.41

100.71

106.01

111.31

116.61

121.92

132.52

137.82

143.12

148.42

153.72

159.0 ?

164.32

169.62

174.92

180.22

185.52

190.82

196.12

201.43

206.73

212.03

222.63

227.93

233.23

243.83

249.13

254.43

259.73

265.03

275.63

280.93

$286 \cdot 24$

291.54

302.14

307.44

312.74
318.04 

$\triangle P P E N D I X \quad C$

DEPTH CORRECTICVS FOR A TRUE SLOPE DF 21 DEGREES

TRUE SLCPE ECHC DEPTH INCREASE TRUE DEPTH
(DEGREES) (FATHOMS)
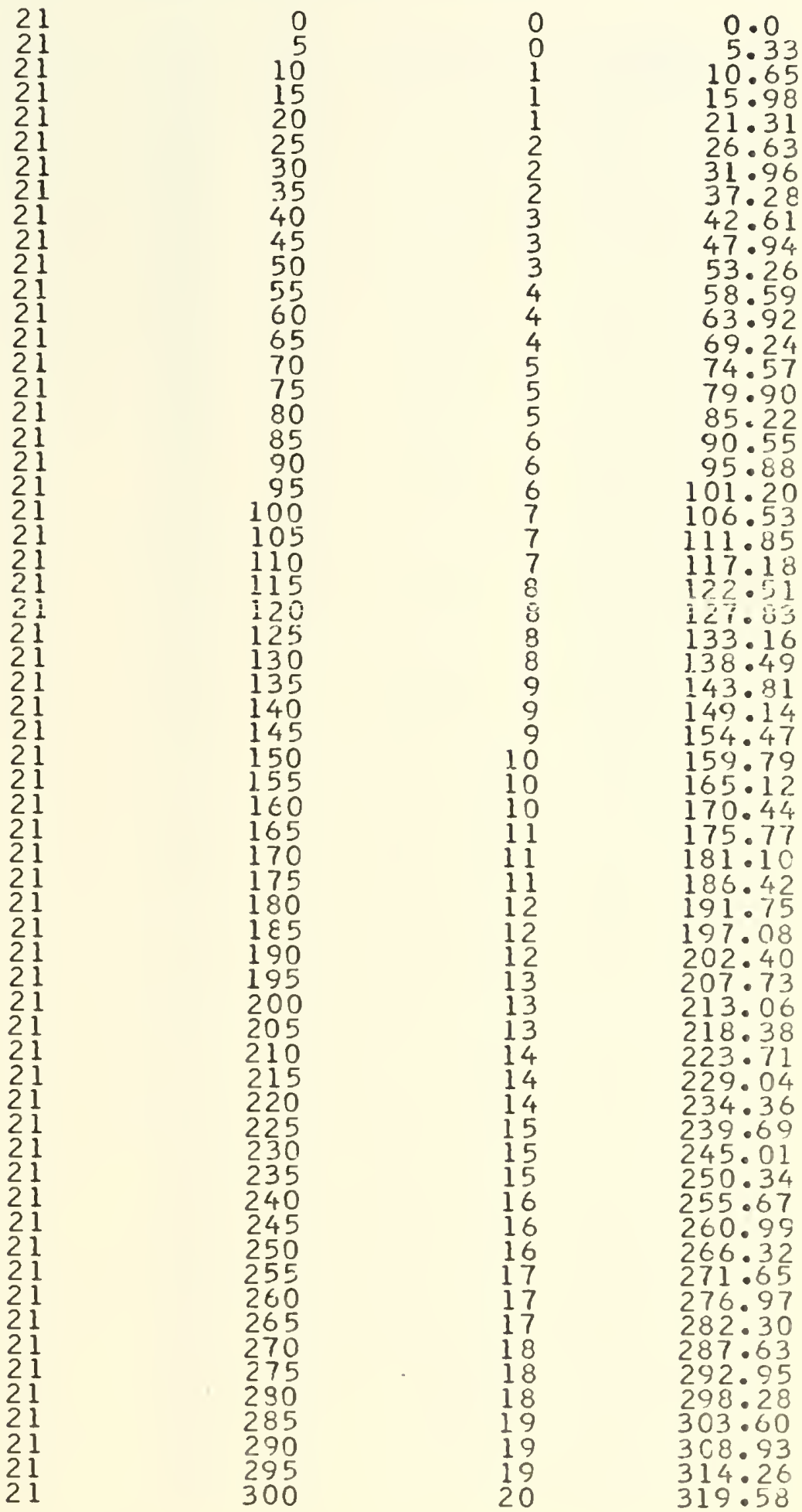


$\begin{array}{lll}\text { TRUE SLOPE } & \text { ECHO DEPTH } \\ \text { (DEGREES) INCREASE TRUE DEPTH } & \text { (FATHOMS) } & \text { (FATHOMS) (FATHOMS) }\end{array}$

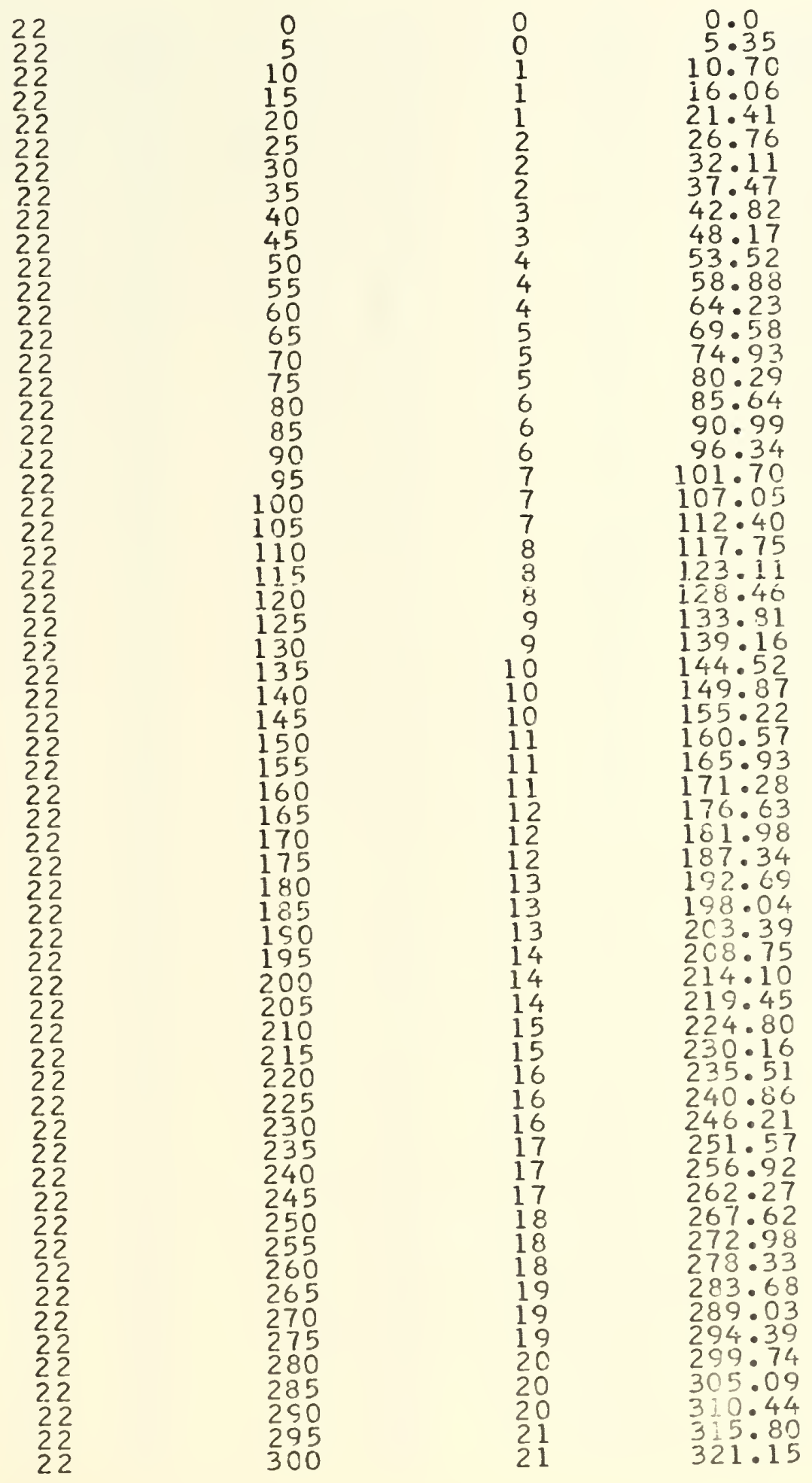



APPENDIX C

DEPTH CORRECTICNS FOR A TRUE SLOPE OF 25 DEGREES

TRUE SLOPE ECHC DEPTH IACREASE, TRUE OEPTH
(DEGREES) (FATHOMS) (FATHOMS) (FATHOMS)

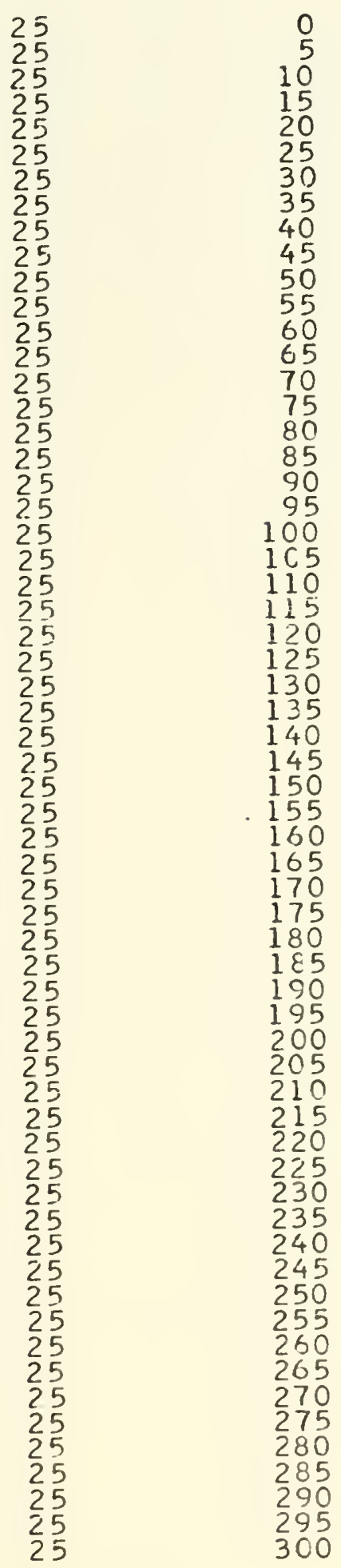

$\begin{array}{ll}0 & 0.0 \\ 0 & 5.43 \\ 1 & 10.87 \\ 1 & 16.30 \\ 2 & 21.73 \\ 2 & 27.17 \\ 3 & 32.60 \\ 3 & 38.03\end{array}$

43.46

48.90

54.33

59.76

65.20

76.06

81.50

86.93

92.36

97.80

103.23

108.66

114.09

124.96

i 30.3

135.83

$146.6 \mathrm{~s}$

$152 \cdot 13$

162.99

168.43

173.86

$\begin{array}{ll}14 & 179.29 \\ 15 & 184.73\end{array}$

190.16

16

16

16

201.02

206.46

211.89

17
18

$217 \cdot 32$

$228 \cdot 19$

233.02

239.06

19

244.49
249.92

249.92

21

21

$2 \frac{1}{2}$

60.79

266.22

271.55

282.52

287.95

293.39
298.82

304.25

309.69

315.12
320.55
$325: 95$ 

APPENDIX C

DEPTH CORRECTIONS FOR A TRUE SLOPE OF 26 DESREES

TRUE SLCPE ECHE DEPTH INCREASE TRUE DEPTH
(DEGREES) (FATHOMSI
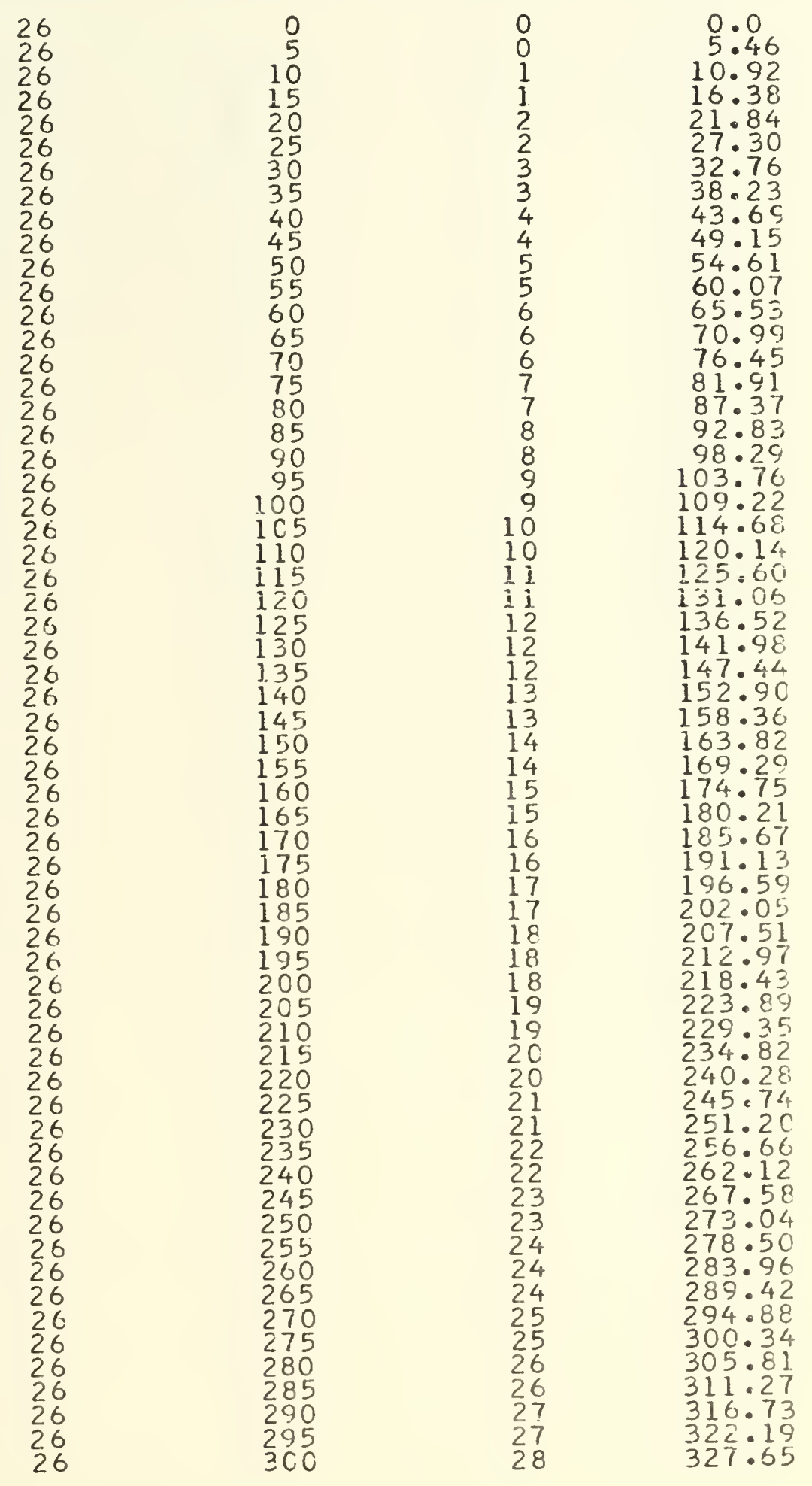



\section{APPENDIX C}

DEPTH CORRECTIONS FOR A TRUE SLOPE OF 27 DEGREES

TRUE SLOPE ECHC DEPTH INCREASE TRUE DEPTH
(OEEREES)
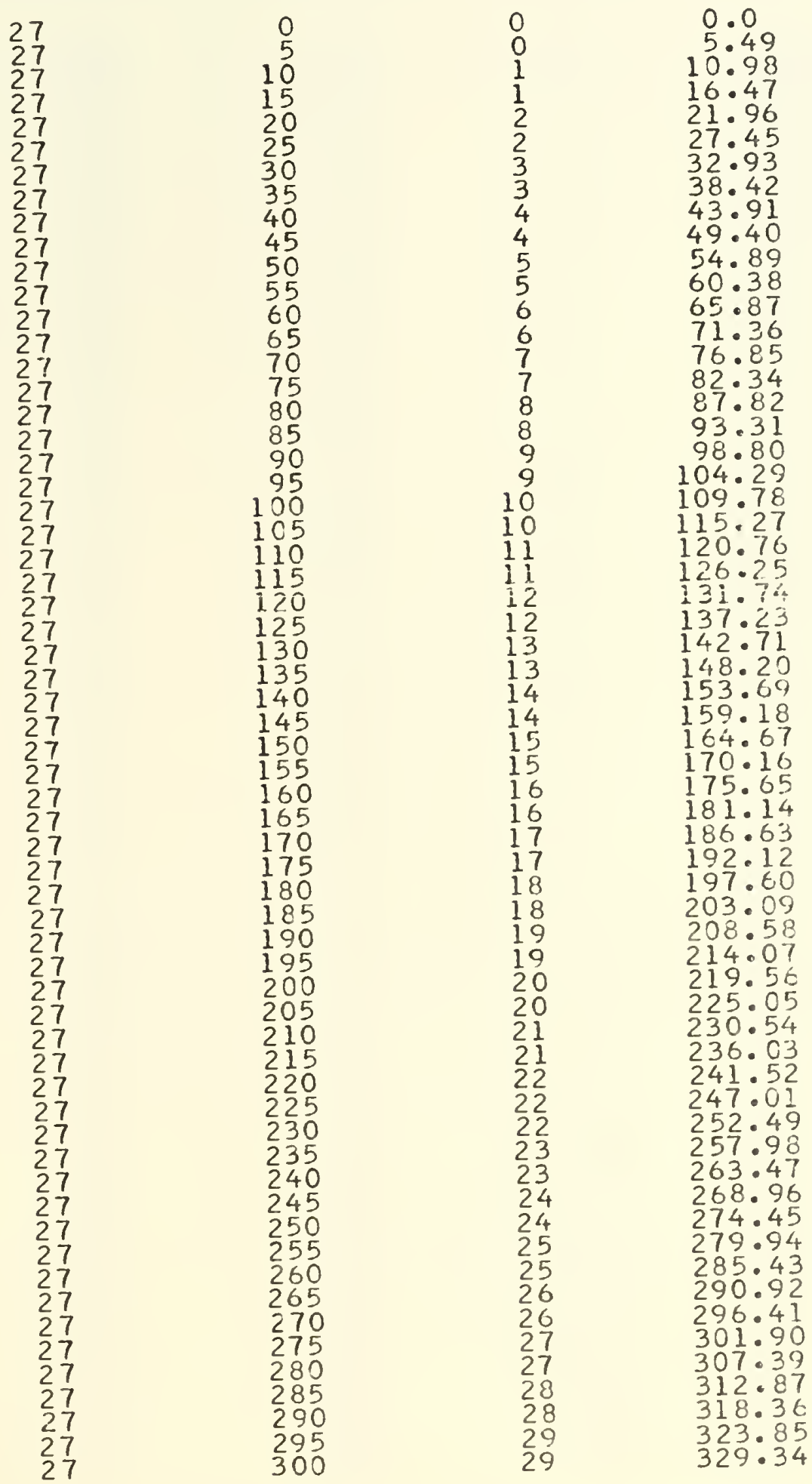

TRUE SLDPE ECHO DEPTH INCR NASE, TRUE DEPTH
(OEGREES) (FATHOMS)
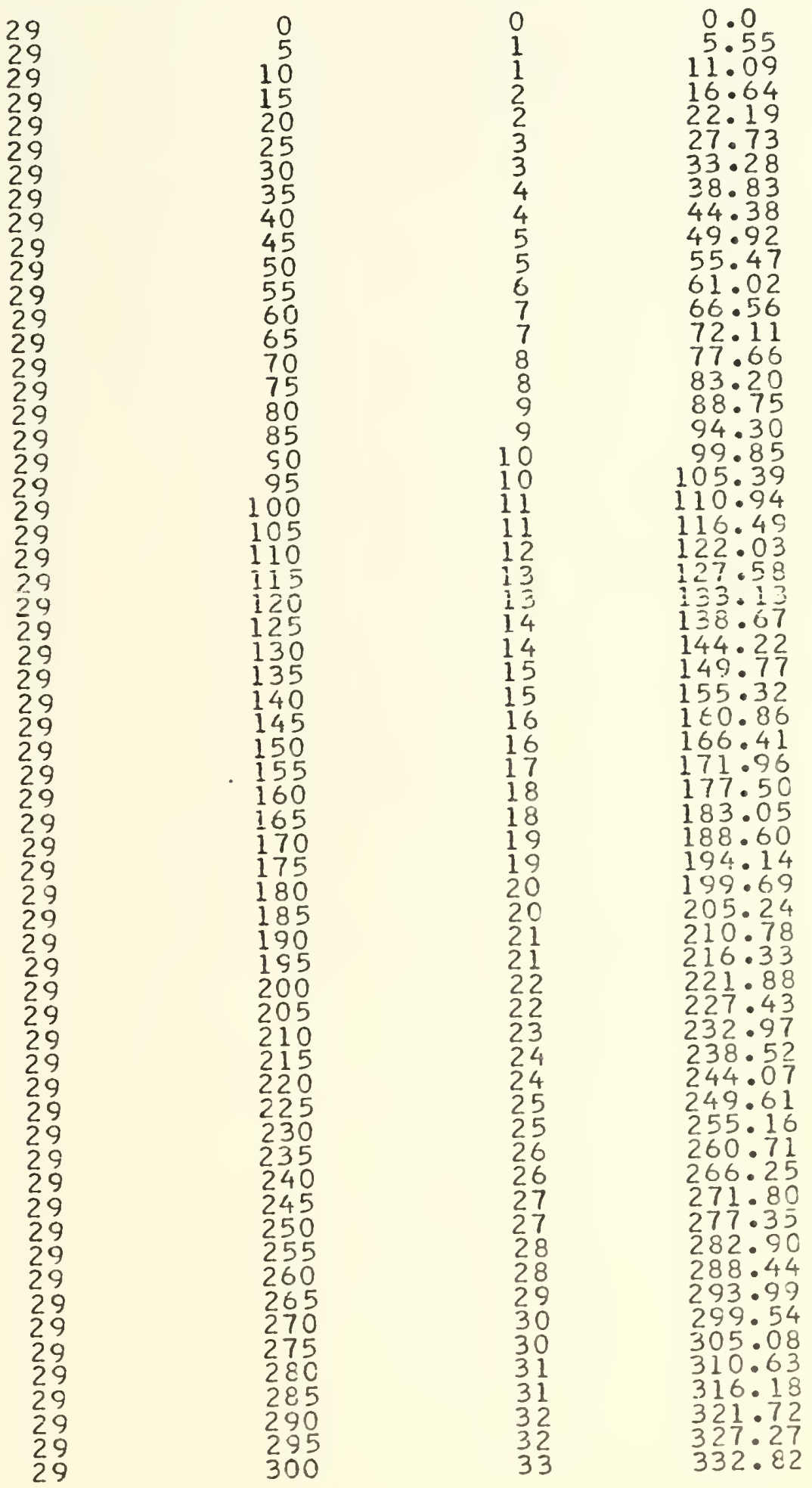

APPENDI $X \mathrm{C}$

DEFTH CORRECTIONS FUR A TRUE SLCPE OF 30 DEGREES

TRUE SLOFE ECHCDEPTH INCREASE TRUE DEPTH
(CEGREST (FATHOMS) (FATHOMS) (FATHOMS)
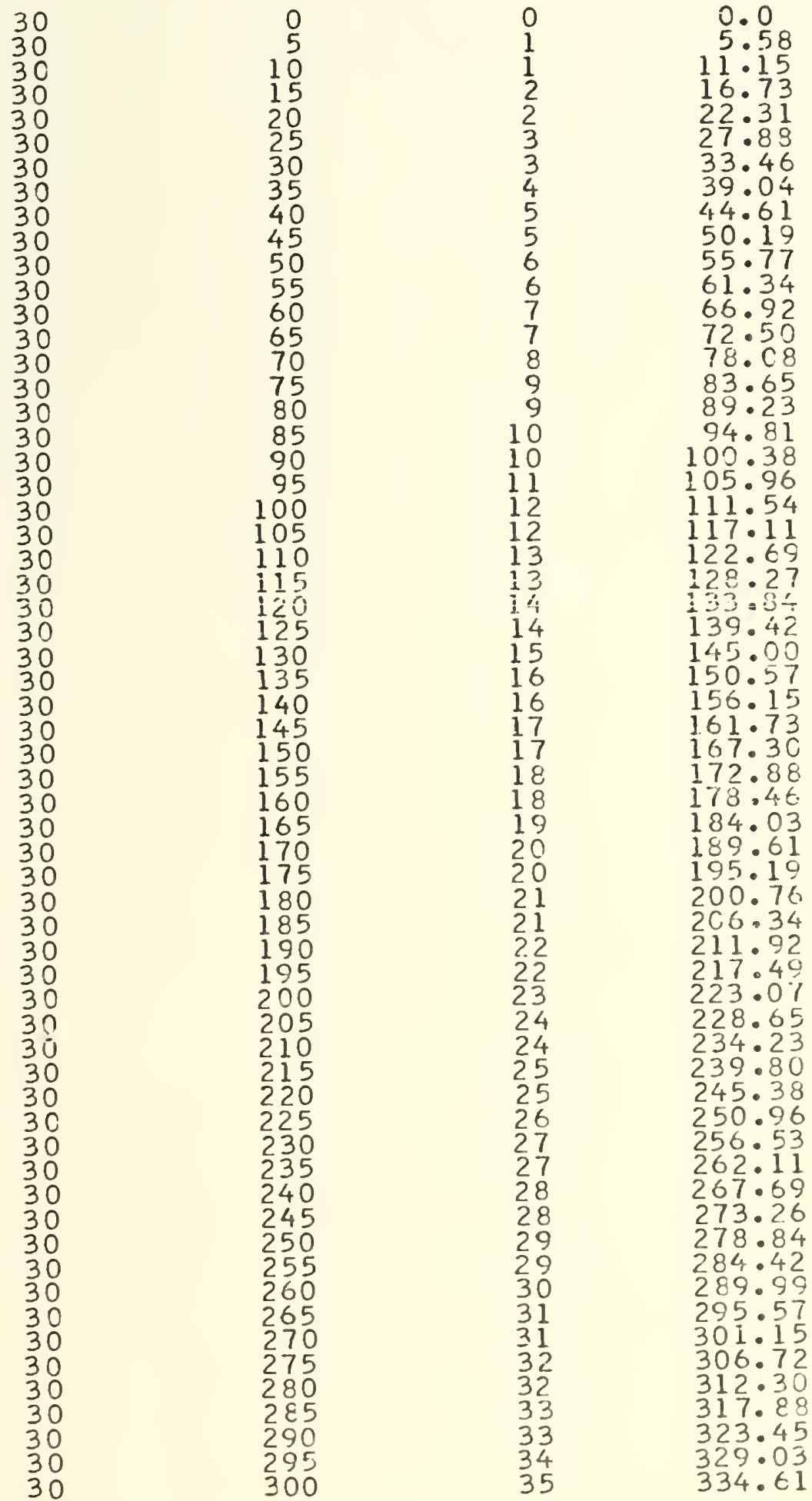

TRUE SLOPE ECHE DEPTH IACPEASE TRUE DEPTH
(DEGREST THEMS) (FATHOMS)
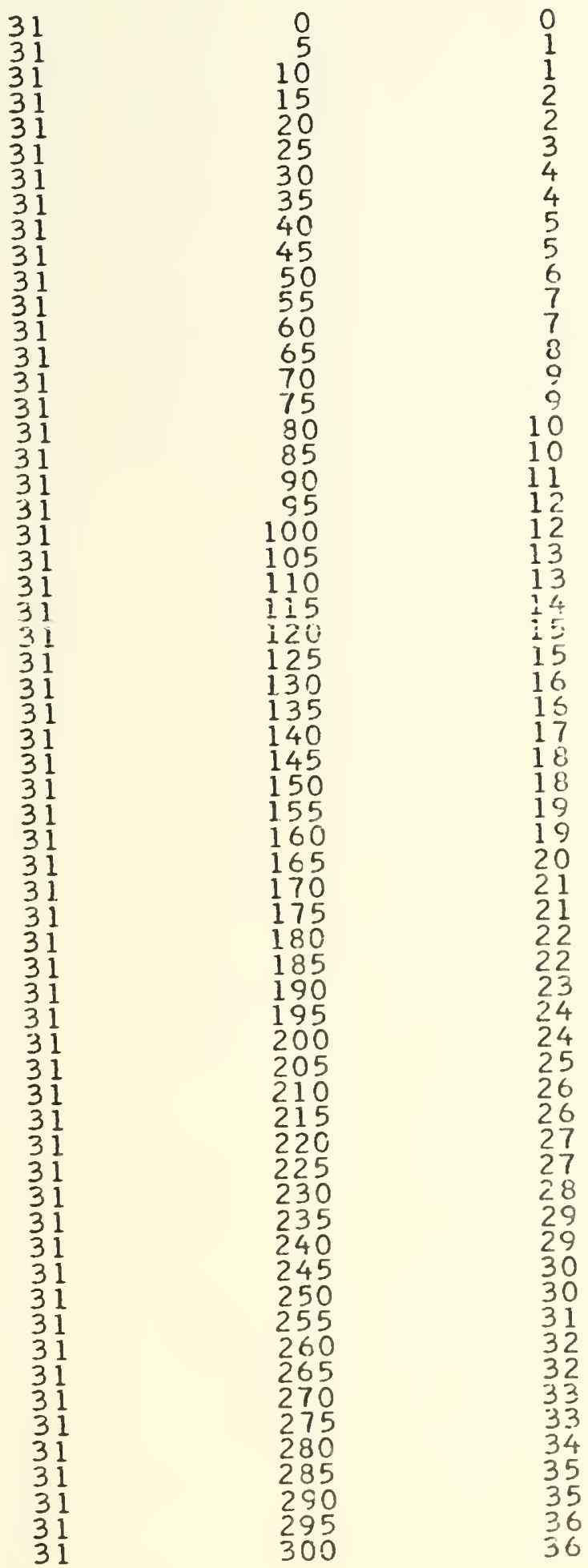

0.0
5.61
11.21
16.82
22.43
28.04
33.64
39.25
44.86

50.46

56.07

61.68

67.29

72.89

78.50

$84 \cdot 11$

89.72

100.93

1 C6.54

112.14

123.36

128.07

140.16

145.79

151.39

162.61

168.22

179.43

185.04

190.65

201.86

207.47

218.68

229.90

241.11

246.72

252.32

263.54

$269 \cdot 15$

280.35

285.57

29.1 .57

297.18

$3 \mathrm{C} 8.40$

314.00

319.61

325.22

336.43 

APPENDIX C

DEPTH CCRRECTIONS FOR A TRUE SLCPE DF 32 DEGREES

TRUE SLCPE ECHC DEPTH IACREASE TRUE OEPTH
(DEGRES) (FATHOMS)
(FATHOMS) (FATHOHS)
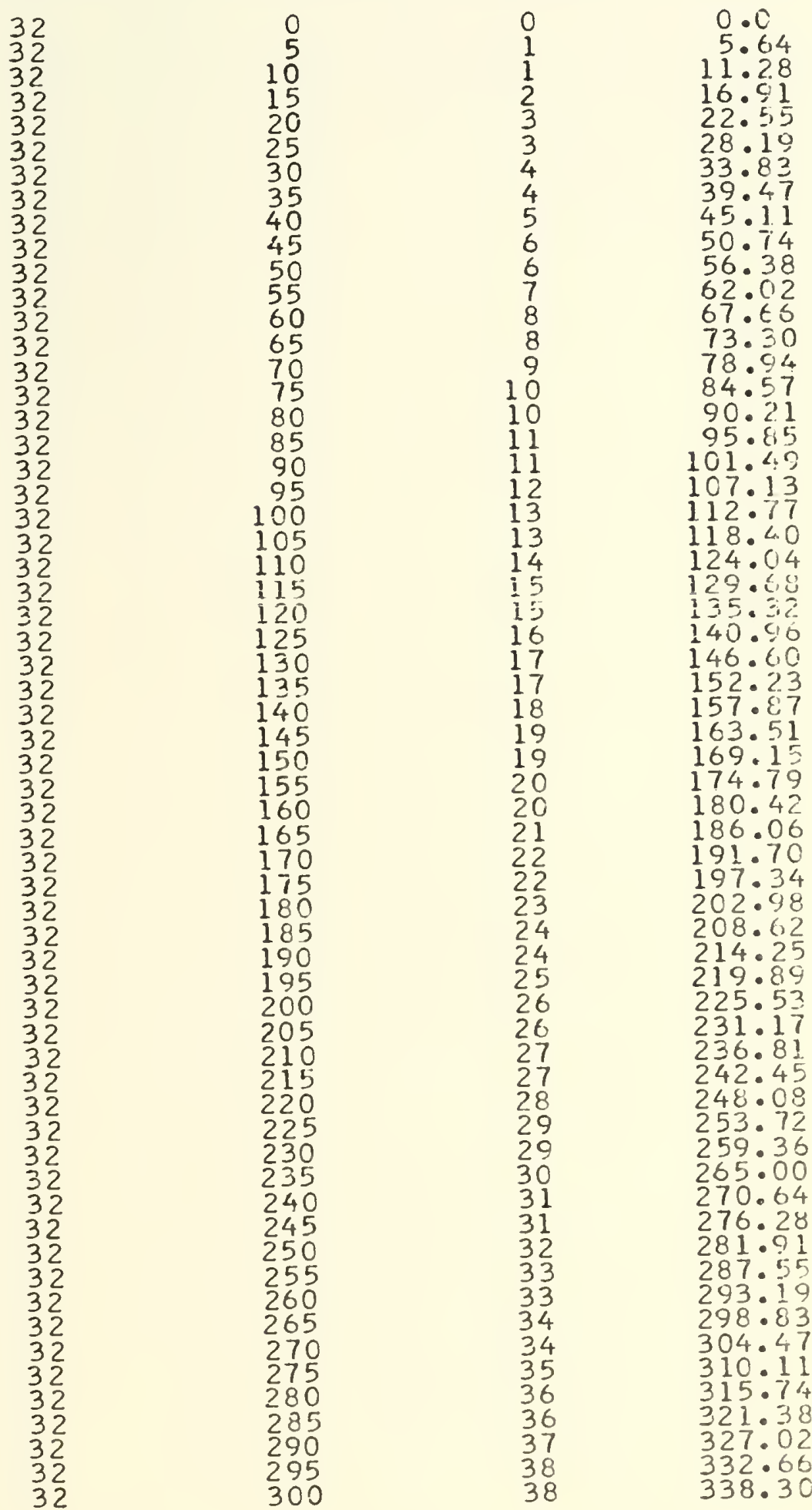

APPENDIX C

DEPTH CORRECTIONS FOR A TRUE SLOPE OF 33 DEGRE:E:S

TRUE SLOPE ECHO DEPTH INCREASE TRUE DEFTH
(OEGREES)
(FATHOMS)
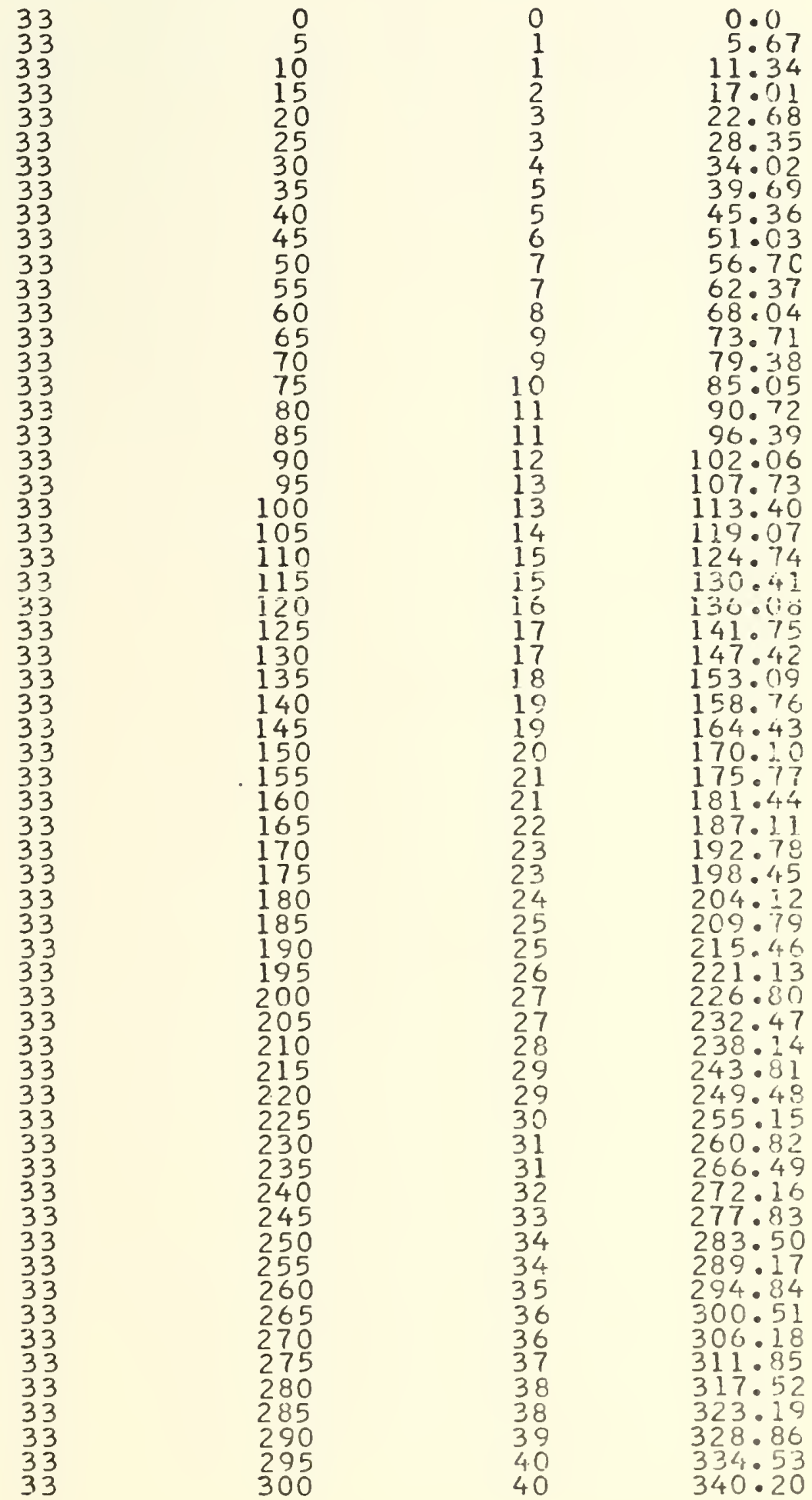

DEPTH CORRECTIONS FOR A TRUE SLOPE OF 34 DEGPEES $\begin{array}{lll}\text { TRUE SLOPE } & \text { ECHODEPTH INCREASE TRUE DEPTH } \\ \text { (DEGREES) } & \text { (FATTHOMS) } & \text { (FATHOMS) (FATHOYAS) }\end{array}$

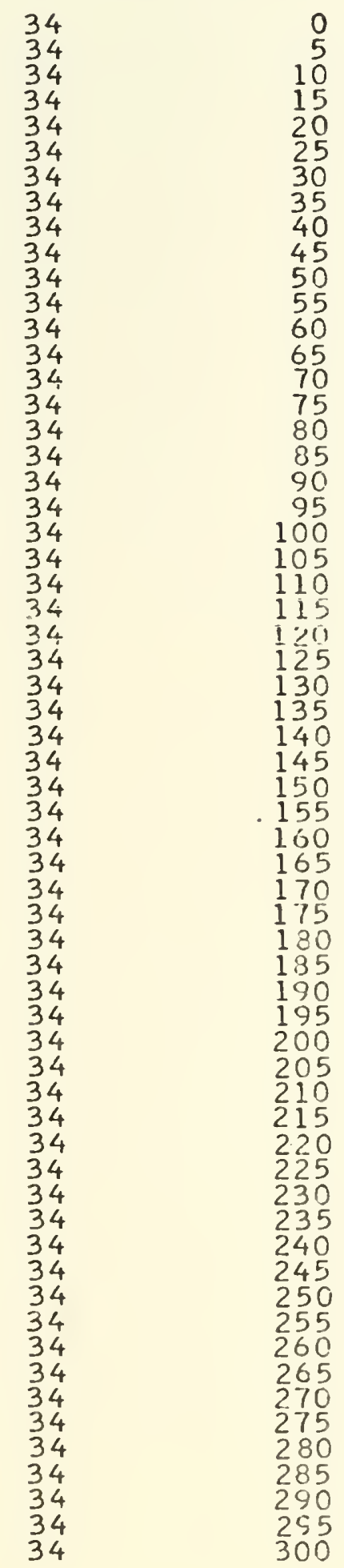

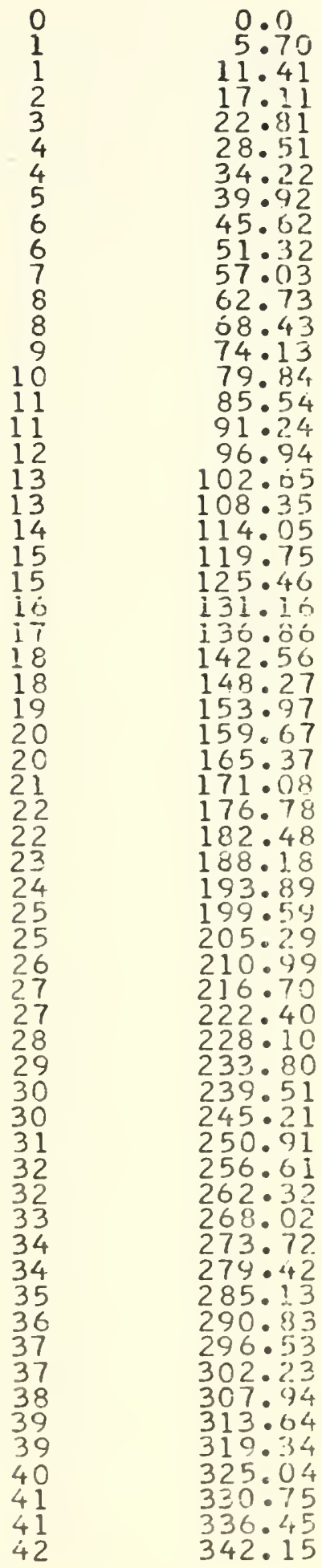



DEPTH CORFECTIONS FOR A TRUE SLOFE DF 35 DEGPEES
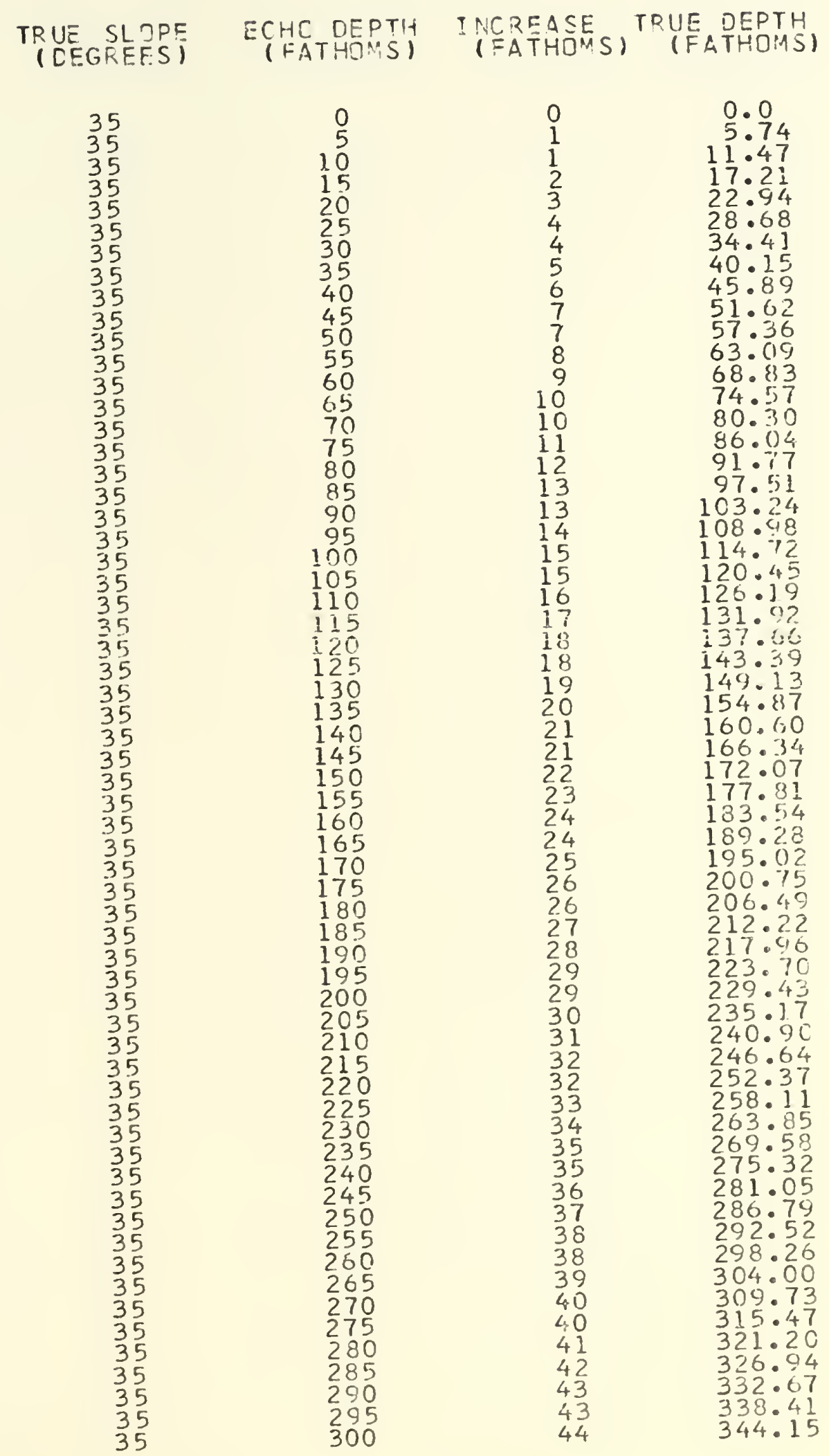

OEPTH CORDECTIONS FOR A TRUE SLCFE OF 36 DEGREFS

TRUE SLOPE ECHO DEPTH INCREASE TRUE DEFTH
(DEGREES) (FATHCMS) (FATHOMS) (FATHOMS)

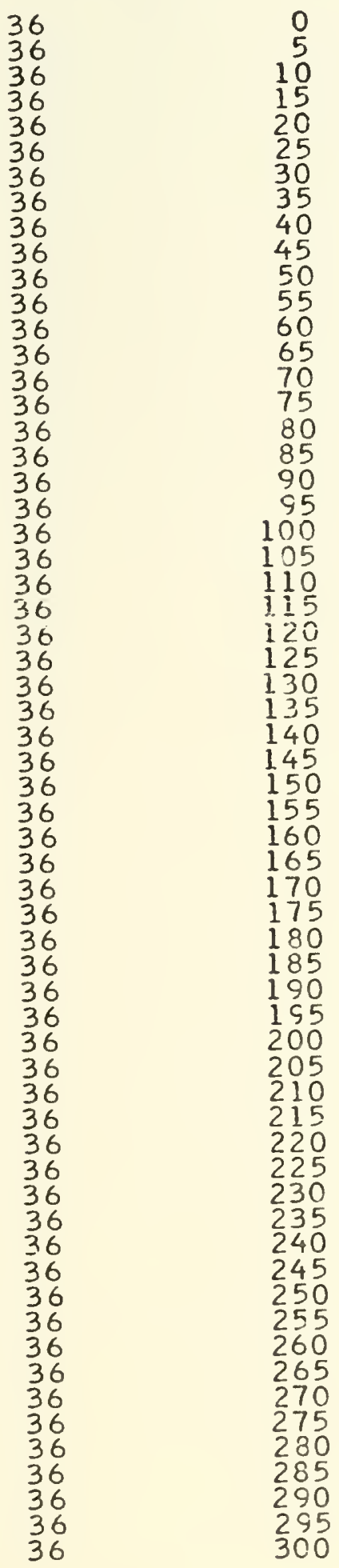

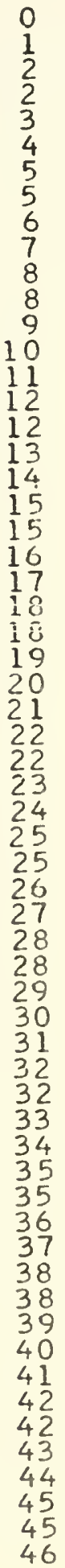

0.0

11.54

$23 \cdot 0 \frac{1}{8}$ 28.85 34.62

40.39

46.16

51.93

57
63.70
6

$69 \cdot 24$

75.01

80.78

$86 \cdot 55$

92.32

103.86

109.63

115.40

121.1 ?

126.94

132.71

132.43

144.25

150.02

161.56

167.33

173.10

178.87

184.64

190.41

196.18

$201 \cdot 94$

207.71

219.25

225.12
230.79

236.56

242.33

248.10

250.64

265.41

271.18

276.95
282.72

288.49

294.26

300.03

305.80
311.57

311.51

323.11

328.88

334.65

340.42
346.19 

APPENDI X C

DEFTH CORRECTIONS FOR A TRUE SLOFE CF 37 DEGREES

TRUE SLCPE
(DEGRERSI DEPTH TNCREASE TRUE DEFTH
(FATHOMS)
(FATHOMS) (FATHOMS)
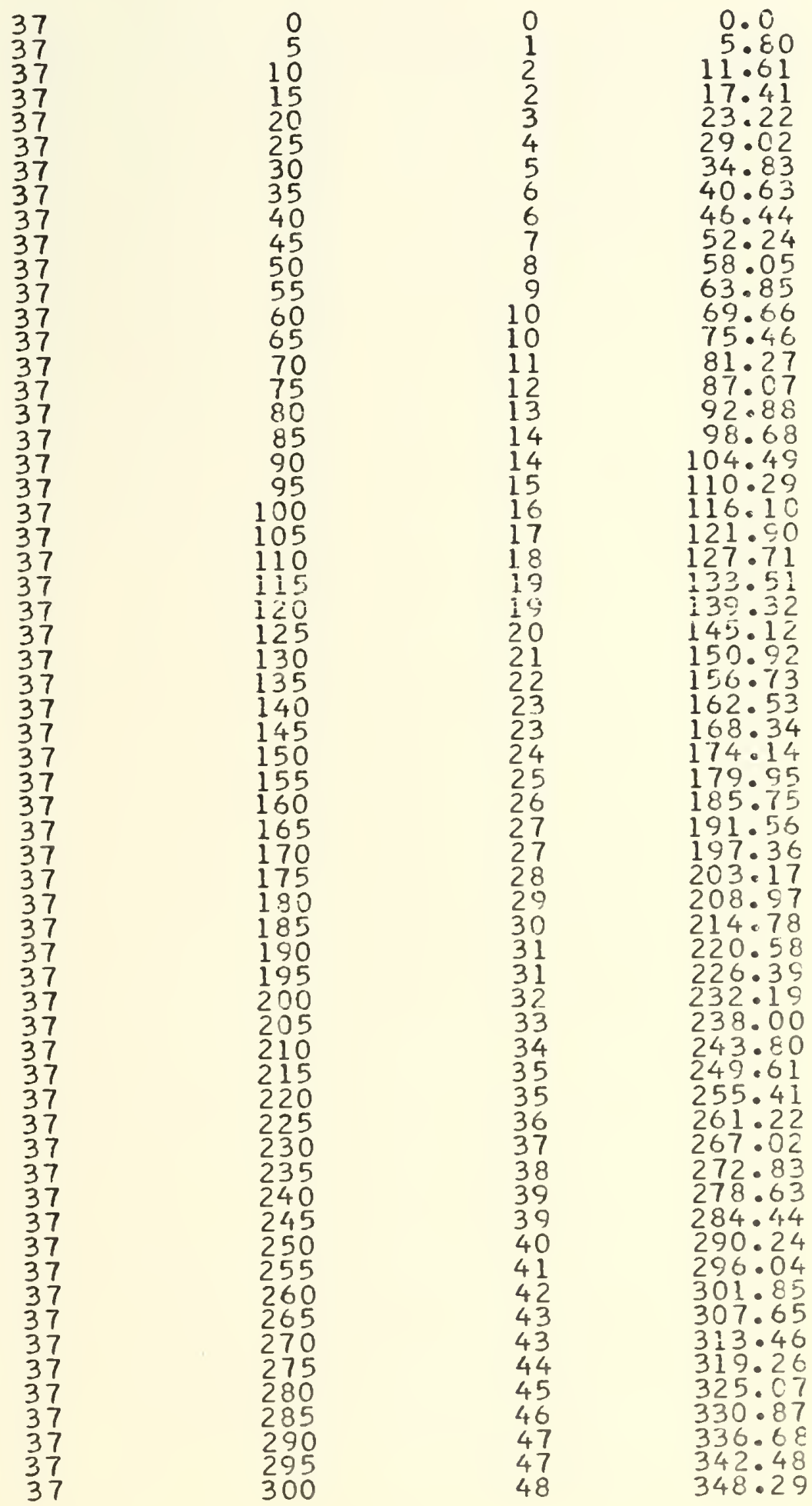

TPUE SLOPE ECHO DEPTH IACREASE TRUE DEPTH
(DEGRES) (FATHOMS)

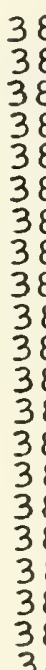

38
38
38
38
38
38
38
38
38
3
38
3
3
3
3
3
3
3
3
3
3
3

38

38

38

38

38

38

38

38

38

38

38

38

38

38

38

38

38
38

38

38

38

38

38

38

38
38

38

38

38

38

38

38
38
38

38

38

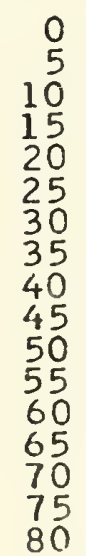

85
90

95

105

110

120

130

135

145

150

150

165

170

180

185

190

200

205

210

220

225

235

240

245

250

260

270

275

280

285

290

295
300

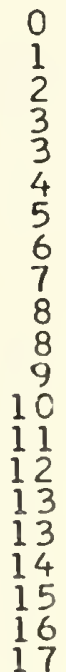

18

18

20

21

23

24

25

26

28

29

30

32

34

34

35

37

38

39

40

41

42
43

44

45

45

47

48

50
50
0.0
5.84
11.68
17.52
23.38
29.20
35.04
40.88
46.73
52.57

58.41

64.25

70.09

75.93

81.7

87.61

93.45

99.29

105.13

110.97

116.81

122.65

134.34

140.10

146.02

151.86

$157.7 \mathrm{C}$

163.54

169.38

175.22

186.90

192.74

198.58

204.42

210.26

216.11

221.95

233.63

239.47

245.31

256.99

262.83
268.67

274.51

280.35

286.19

292.03

297.88

303.72

309.56

315.40

321.24

327.08

332.92

338.78

344.60

350.44 

DEPTH CORRECTIONS FDR A TRUE SLOPE OF 39 DEGREES

TRUE SLCFE ECHODEPTH INCREASE TRUE DEPTH (DEGREES) (FATHCMS) (FATHC̈SS) (FATHCMS)
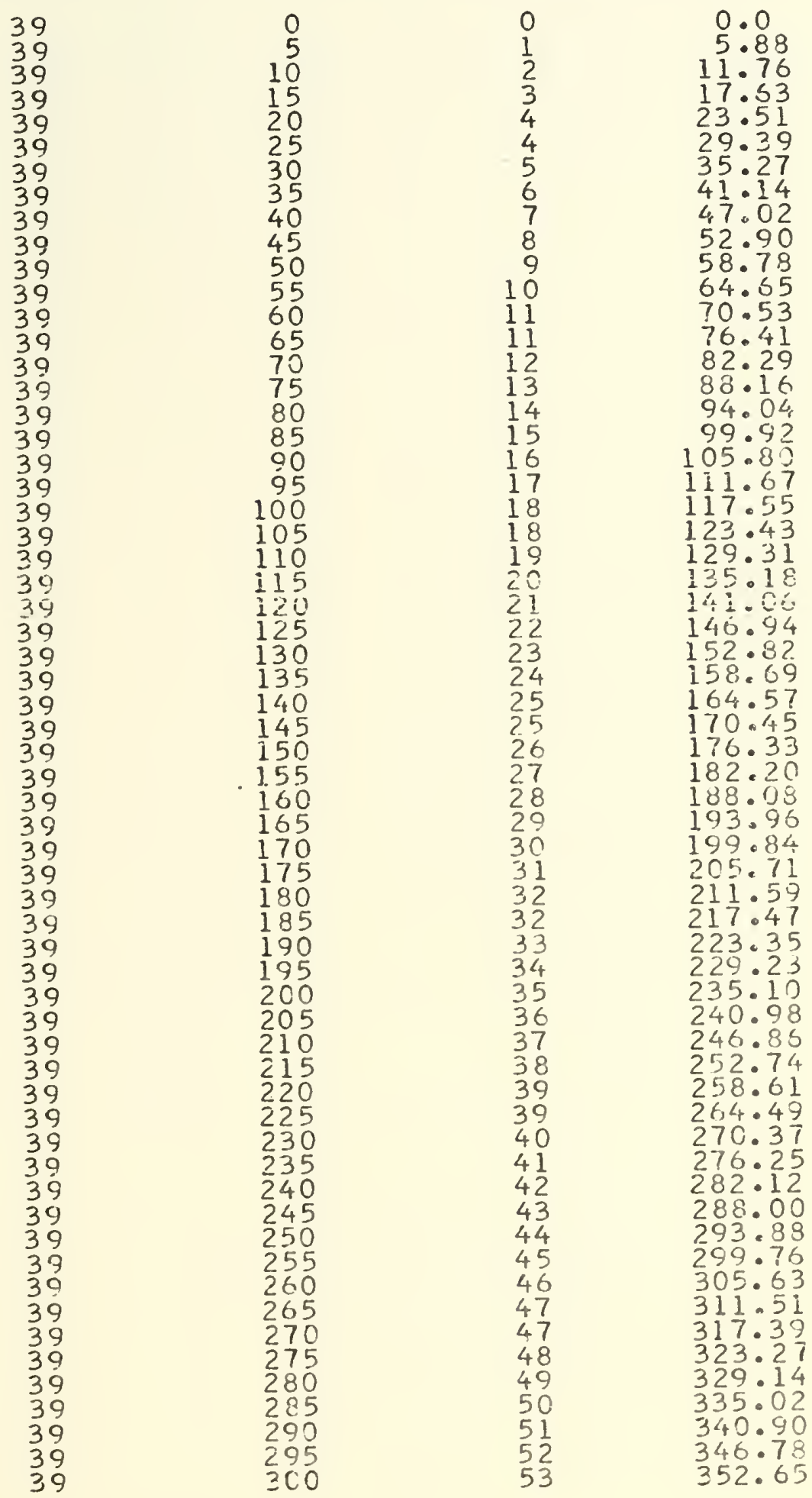



\section{APFENDIX C}

DEPTH CORFECTIONS FOR. A TRUE SLDPE OF 40 DEGREES

TRUE SLOPE ECHC DEPTH INCREASE TRUE OEPTH
(DEGREES) (FATHOMS)
(FATHOMS) (FATHOHS)
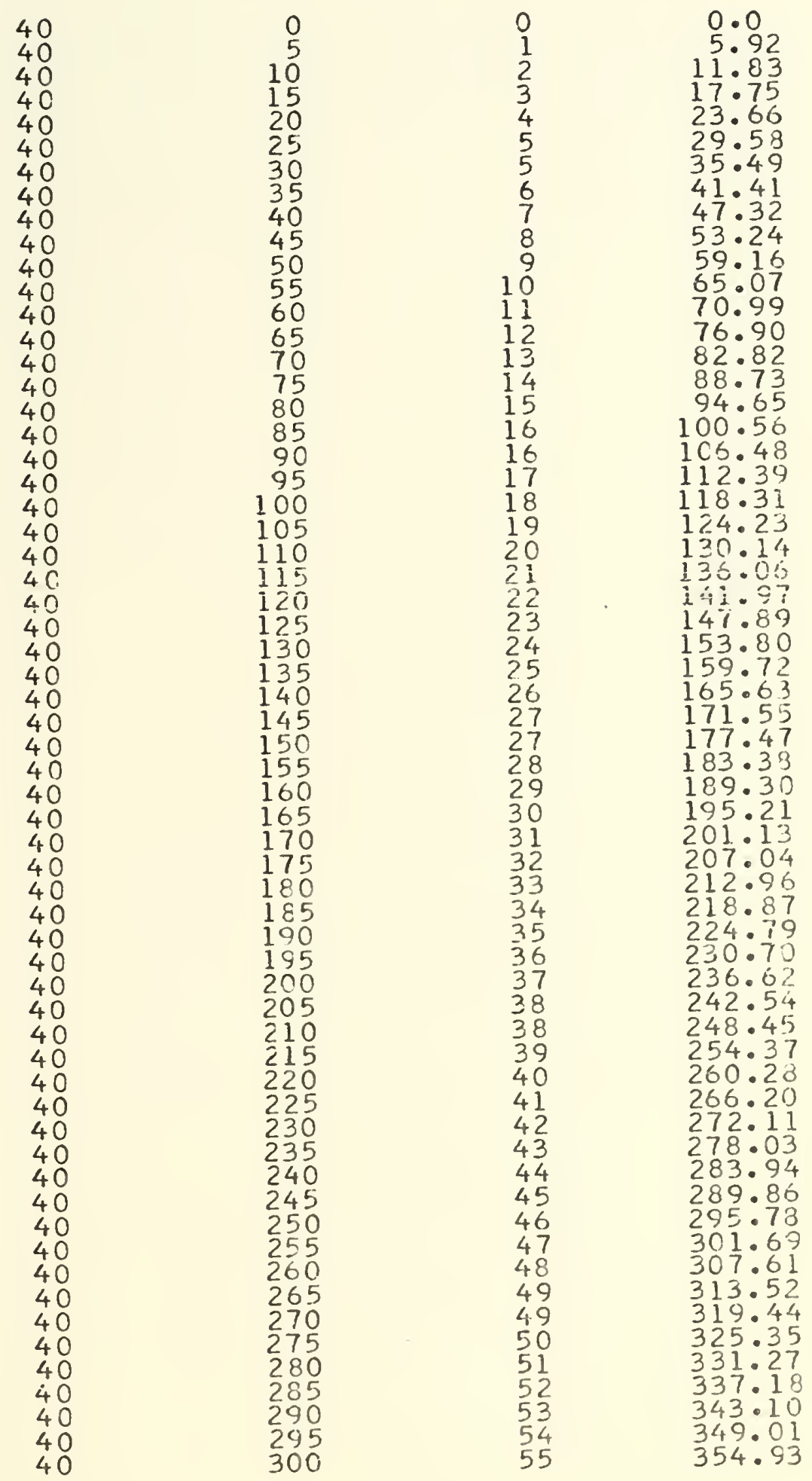

APPENDIX C

DEFTH CORRECTICNS FOR A TRUE SLCPE OF 41 DEGREES

TRUE SLOPE ECHO DEPTH INCREASE TRUE DEPTH
(DEGREES)
(FATHOMS) (FATHOMS) (FATHOMS!
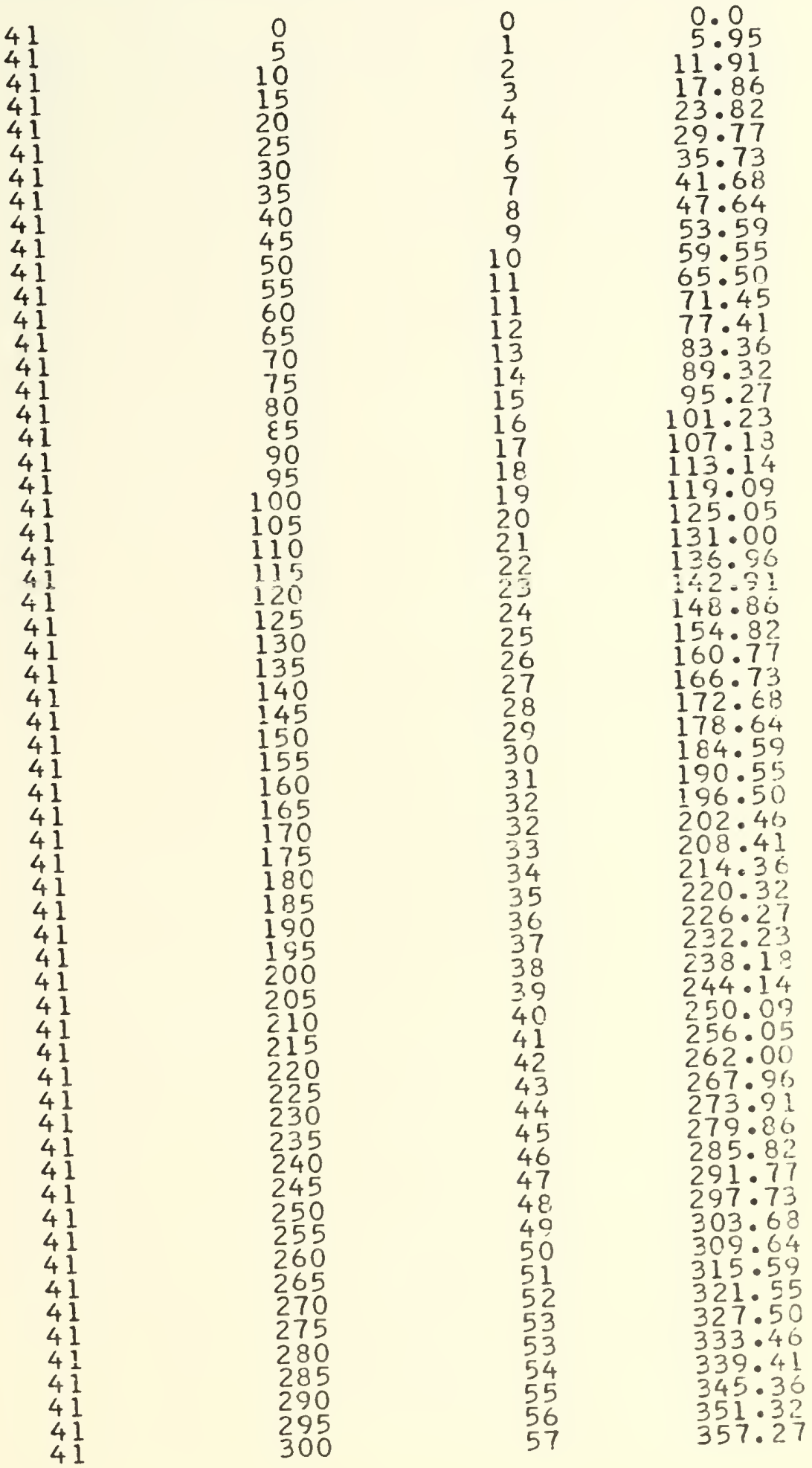

AFPENDIX C

DEPTH CORRECTICNS FOR A TRUE SLOPE OF 42 DEGREES

TRUE SLOPE
(DCHE DEPTH INCREASE TRUE DEFTH
(FATHOMS) (FATHOMS)

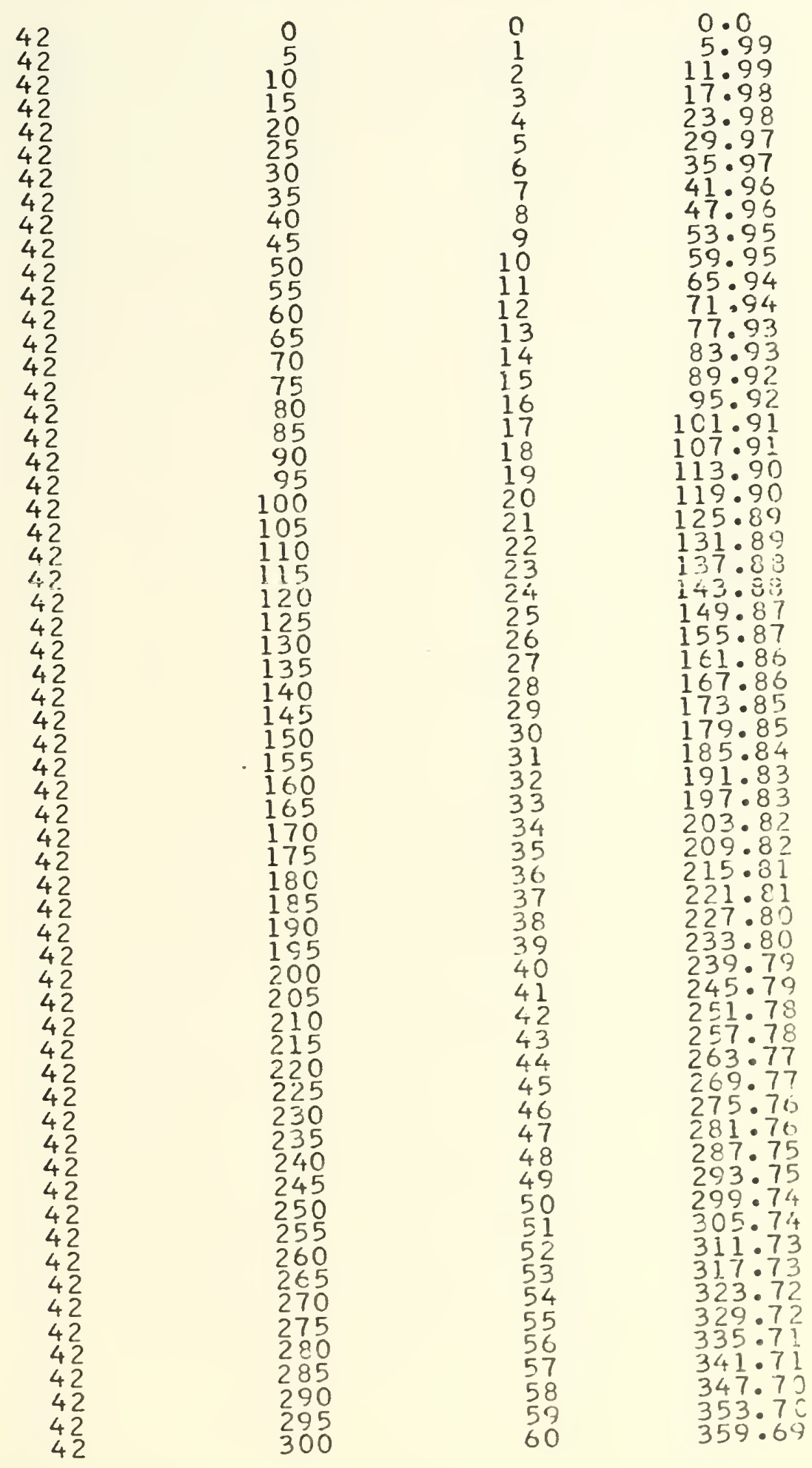



DEPTH CORFECTIONS FOR A TRUE SLCFE CF 43 DEEREES TRUE SLOPE ECHC DFPTH INCFEASE TRUE DEPTH
(DEGREES) (FATHOMS) (FATHCMS)

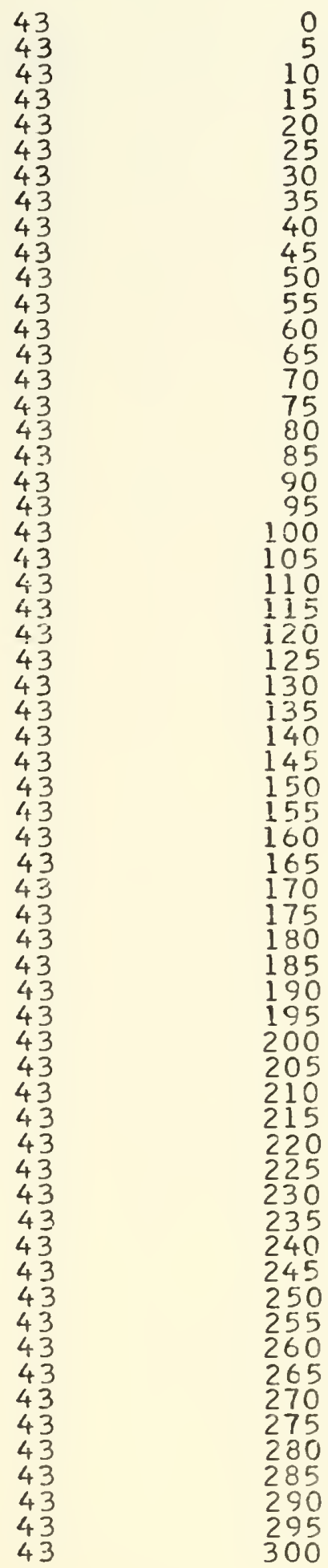

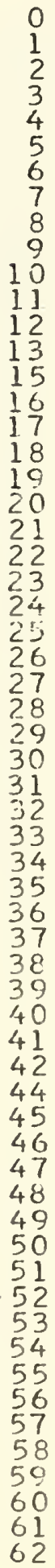

0.0
$6 \cdot 04$

12.07

18.11

24.15

30.18

$36: 22$

48.25

54.33

60.36

66.43

$72 \cdot 44$

78.47

84.51

90.55

$102 \cdot 62$

108.66

114.69

120.73

126.70

132.80

138.84

i. 44.83

$150 \cdot 91$
$156 \cdot 95$

162.99

169.02

175.06

181.09

187.13

193.16

199.20

$205 \cdot 24$

217.31

223.35

229.31

235.4 ?

$241 \cdot 413$

247.43

253.53
259.56

255.60

271.64

277.67

283.71

289.75

$301 \cdot 82$

313.89

319.93

325.97

332.00

338.04
344.07

350.11 

APFENDIX $C$

DEPTH CORRECTIONS FOR A TRUE SLCFE CF 44 DEGREES

TRUE SLOPE ECHO DEPTH INCPEASE TRUE DEPTH
(DEGREES) (FATHOMS)

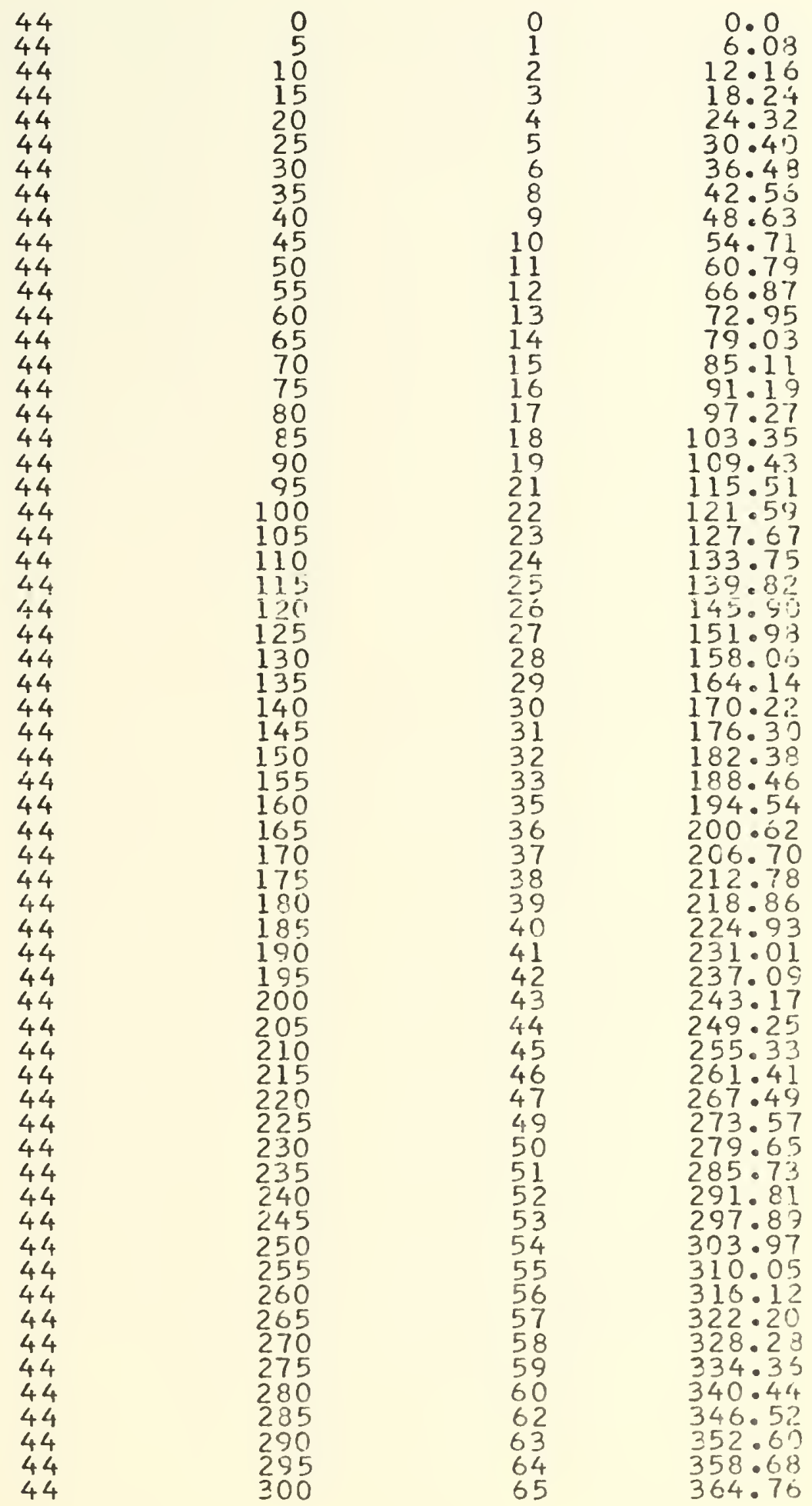



DEPTH CORRECTIONS FOF. A TRUE SLOPE OF 45 DEGREES

TFUE SLCPE ECHO DEPTH IACREASE TRUE DEPTH
(DEREES) (FATHOMS) (FATHCMS) (FATHUMS)

\begin{tabular}{|c|c|c|c|}
\hline $\begin{array}{l}45 \\
45 \\
45 \\
45 \\
45 \\
45 \\
45 \\
45 \\
45 \\
45 \\
45 \\
45 \\
45 \\
45 \\
45 \\
45 \\
45 \\
45 \\
45 \\
45 \\
45 \\
45 \\
45 \\
45 \\
45 \\
45 \\
45 \\
45 \\
45 \\
45 \\
45 \\
45 \\
45 \\
45 \\
45 \\
45 \\
45 \\
45 \\
45 \\
45 \\
45 \\
45 \\
45 \\
45 \\
45 \\
45 \\
45 \\
45 \\
45 \\
45 \\
45 \\
45 \\
45 \\
45 \\
45 \\
45 \\
45 \\
45 \\
45 \\
45 \\
45 \\
45 \\
45\end{array}$ & 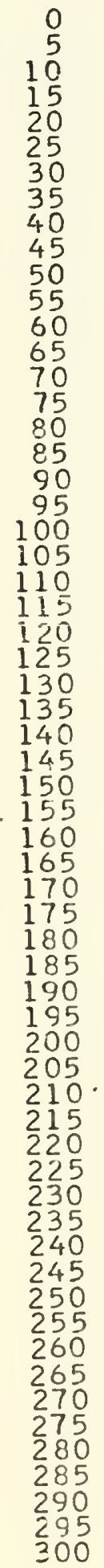 & $\begin{array}{l}0 \\
1 \\
2 \\
3 \\
4 \\
6 \\
7 \\
8 \\
9 \\
10 \\
11 \\
12 \\
13 \\
15 \\
16 \\
17 \\
18 \\
19 \\
20 \\
21 \\
22 \\
24 \\
25 \\
26 \\
27 \\
28 \\
29 \\
30 \\
31 \\
33 \\
34 \\
35 \\
36 \\
37 \\
38 \\
39 \\
40 \\
42 \\
43 \\
44 \\
45 \\
46 \\
47 \\
48 \\
49 \\
51 \\
52 \\
53 \\
54 \\
55 \\
56 \\
57 \\
58 \\
60 \\
61 \\
62 \\
63 \\
64 \\
65 \\
66 \\
67\end{array}$ & 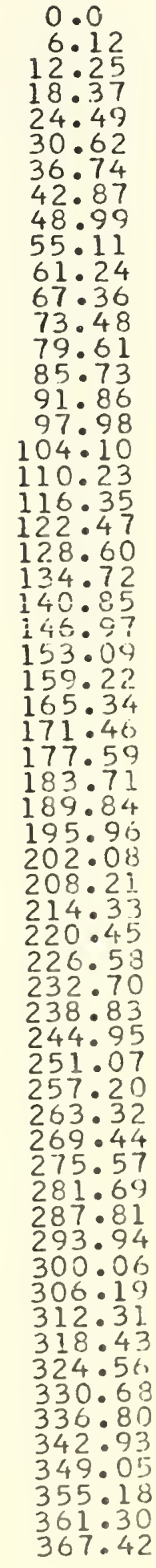 \\
\hline
\end{tabular}



DEPTH CORRECTIONS FOR A TRUE SLOPE OF 46 DEGREES

TRUE SLCPE ECHO DEPTH INCREASE TRUE DEPTH
(DEGRES) (FATHOMS)
(FATHOMS) (FATHOMS)

\begin{tabular}{|c|c|c|c|}
\hline $\begin{array}{l}46 \\
46 \\
46 \\
46 \\
46 \\
46 \\
46 \\
46 \\
46 \\
46 \\
46 \\
46 \\
46 \\
46 \\
46 \\
46 \\
46 \\
46 \\
46 \\
46 \\
46 \\
46 \\
46 \\
46 \\
46 \\
46 \\
46 \\
46 \\
46 \\
46 \\
46 \\
46 \\
46 \\
46 \\
46 \\
46 \\
46 \\
46 \\
46 \\
46 \\
46 \\
46 \\
46 \\
46 \\
46 \\
46 \\
46 \\
46 \\
46 \\
46 \\
46 \\
46 \\
46 \\
46 \\
46 \\
46 \\
46 \\
46 \\
46 \\
46\end{array}$ & $\begin{array}{l}0 \\
5 \\
10 \\
15 \\
20 \\
25 \\
30 \\
35 \\
40 \\
45 \\
50 \\
55 \\
60 \\
65 \\
70 \\
75 \\
80 \\
85 \\
90 \\
95 \\
100 \\
105 \\
110 \\
115 \\
120 \\
125 \\
130 \\
135 \\
140 \\
145 \\
150 \\
155 \\
160 \\
165 \\
170 \\
175 \\
180 \\
185 \\
190 \\
195 \\
200 \\
205 \\
210 \\
215 \\
220 \\
225 \\
230 \\
235 \\
240 \\
245 \\
250 \\
255 \\
260 \\
265 \\
270 \\
275 \\
280 \\
285 \\
290 \\
255 \\
300\end{array}$ & $\begin{array}{l}0 \\
1 \\
2 \\
4 \\
5 \\
6 \\
7 \\
8 \\
9 \\
11 \\
12 \\
13 \\
14 \\
15 \\
16 \\
18 \\
19 \\
20 \\
21 \\
22 \\
23 \\
25 \\
26 \\
27 \\
28 \\
29 \\
30 \\
32 \\
33 \\
34 \\
35 \\
36 \\
37 \\
39 \\
40 \\
41 \\
42 \\
43 \\
44 \\
46 \\
47 \\
48 \\
49 \\
50 \\
51 \\
53 \\
54 \\
55 \\
56 \\
57 \\
58 \\
61 \\
62 \\
63 \\
64 \\
53 \\
67 \\
68 \\
69 \\
70\end{array}$ & 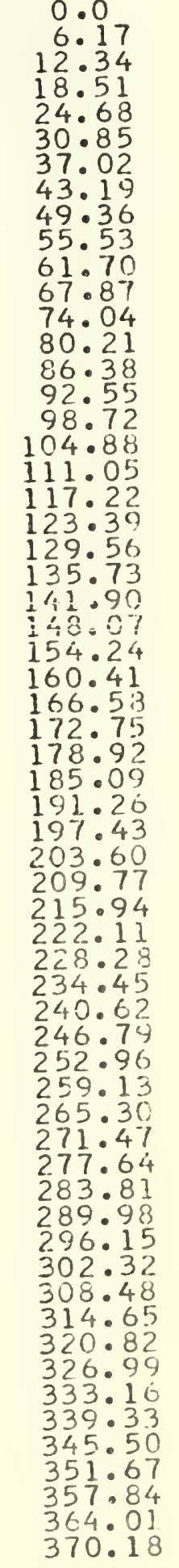 \\
\hline
\end{tabular}



APFENDIX $C$

DEPTH CCRRECTIONS FOR A TRUE SLCPE OF 47 DEGREES

TRUE SLOPE ECHCDCPTH IACPEASE TRUE DEPTH
(IDEGREEST

\begin{tabular}{|c|c|c|c|}
\hline $\begin{array}{l}47 \\
47 \\
47 \\
47 \\
47 \\
47 \\
47 \\
47 \\
47 \\
47 \\
47 \\
47 \\
47 \\
47 \\
47 \\
47 \\
47 \\
47 \\
47 \\
47 \\
47 \\
47 \\
47 \\
47 \\
47 \\
47 \\
47 \\
47 \\
47 \\
47 \\
47 \\
47 \\
47 \\
47 \\
47 \\
47 \\
47 \\
47 \\
47 \\
47 \\
47 \\
47 \\
47 \\
47 \\
47 \\
47 \\
47 \\
47 \\
47 \\
47 \\
47 \\
47 \\
47 \\
47 \\
47 \\
47 \\
47 \\
47 \\
47 \\
47\end{array}$ & $\begin{array}{l}0 \\
5 \\
10 \\
15 \\
20 \\
25 \\
30 \\
35 \\
40 \\
45 \\
50 \\
55 \\
60 \\
60 \\
65 \\
70 \\
75 \\
80 \\
85 \\
90 \\
95 \\
100 \\
105 \\
110 \\
115 \\
120 \\
125 \\
130 \\
135 \\
140 \\
145 \\
150 \\
155 \\
160 \\
165 \\
170 \\
175 \\
180 \\
185 \\
190 \\
195 \\
200 \\
205 \\
210 \\
215 \\
220 \\
225 \\
230 \\
235 \\
240 \\
245 \\
250 \\
255 \\
260 \\
265 \\
270 \\
275 \\
280 \\
285 \\
290 \\
295 \\
300\end{array}$ & $\begin{array}{l}0 \\
1 \\
2 \\
4 \\
5 \\
6 \\
7 \\
9 \\
10 \\
11 \\
12 \\
13 \\
15 \\
16 \\
17 \\
18 \\
19 \\
21 \\
22 \\
23 \\
24 \\
26 \\
27 \\
28 \\
29 \\
30 \\
32 \\
33 \\
34 \\
35 \\
37 \\
38 \\
39 \\
40 \\
41 \\
43 \\
44 \\
45 \\
46 \\
47 \\
49 \\
50 \\
51 \\
52 \\
54 \\
55 \\
56 \\
57 \\
58 \\
60 \\
61 \\
62 \\
63 \\
65 \\
66 \\
67 \\
68 \\
69 \\
71 \\
72 \\
73\end{array}$ & 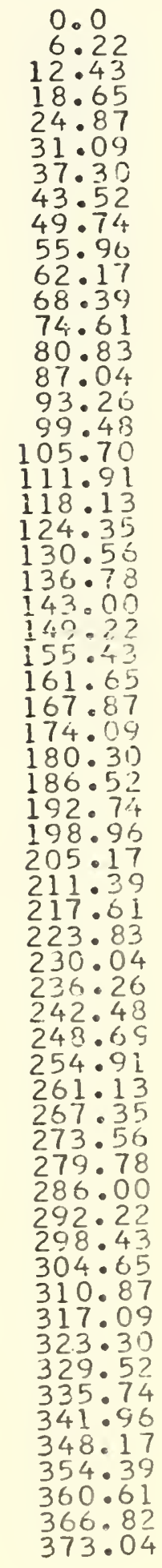 \\
\hline
\end{tabular}





\section{APPEINDIX C}

DEPTH CORRECTIONS FOR A TRUE SLOPE CF 48 DEGREES

TRUE SLOPE ECHO DEPTH INCFEASE TRUE DEPTH
(DEGRES) (FATHOMS) (FATHOMS) (FATHOMS)
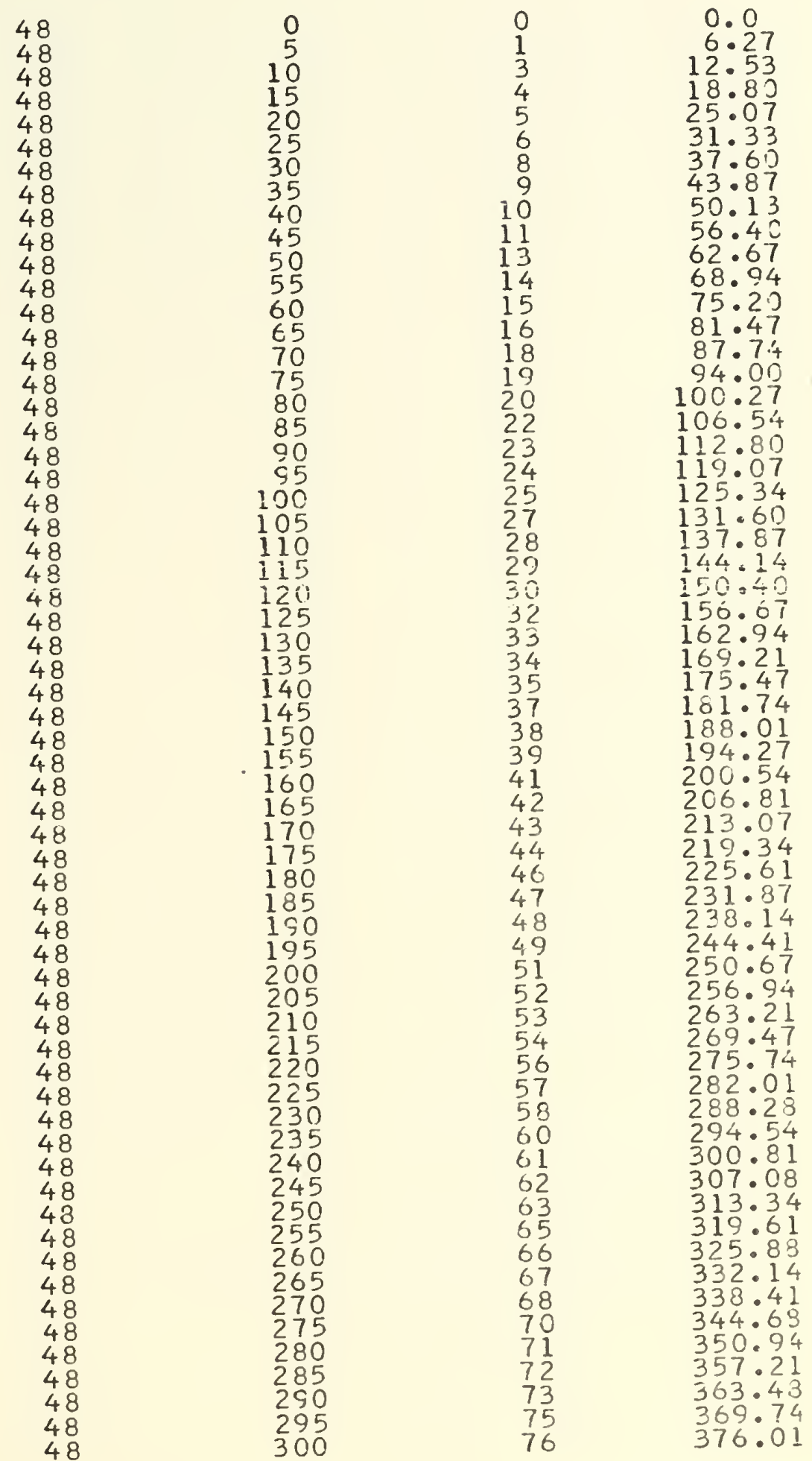

TRUE SLDPE ECHODEPTH IACREASE TRUE DEPTH
(DEREES) (FATHCMS) (FATHOMS) (FATHOYS)

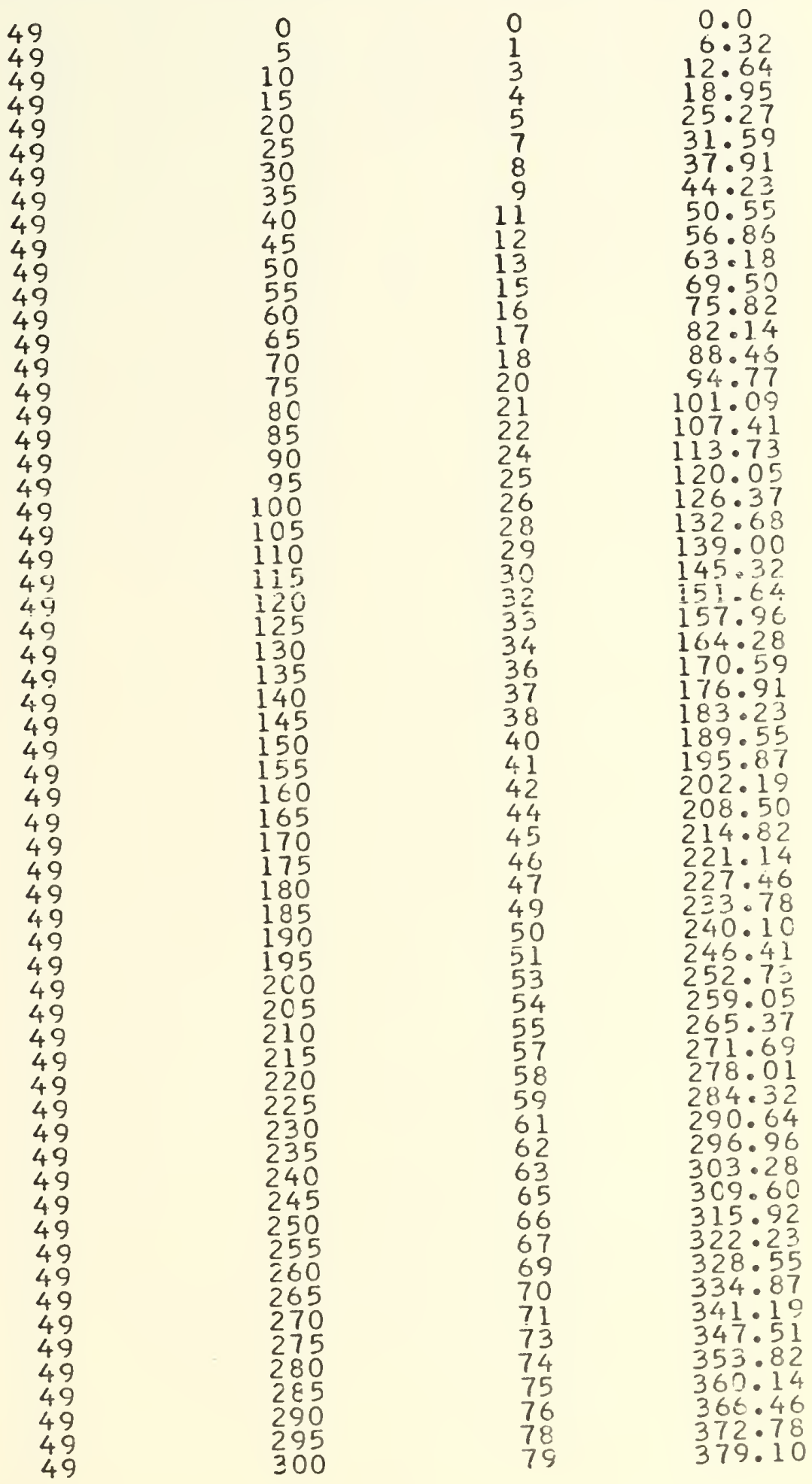



AFPENDIX C

DEPTH CORRECTICNS FOR A TRUE SLOPE OF 50 DEGREES

TRUE SLOFE ECHC DEPTH IACREASE TRUE DEPTH
(DEGRES) (FATHOMS)
(FATHOMS) (FATHONS)

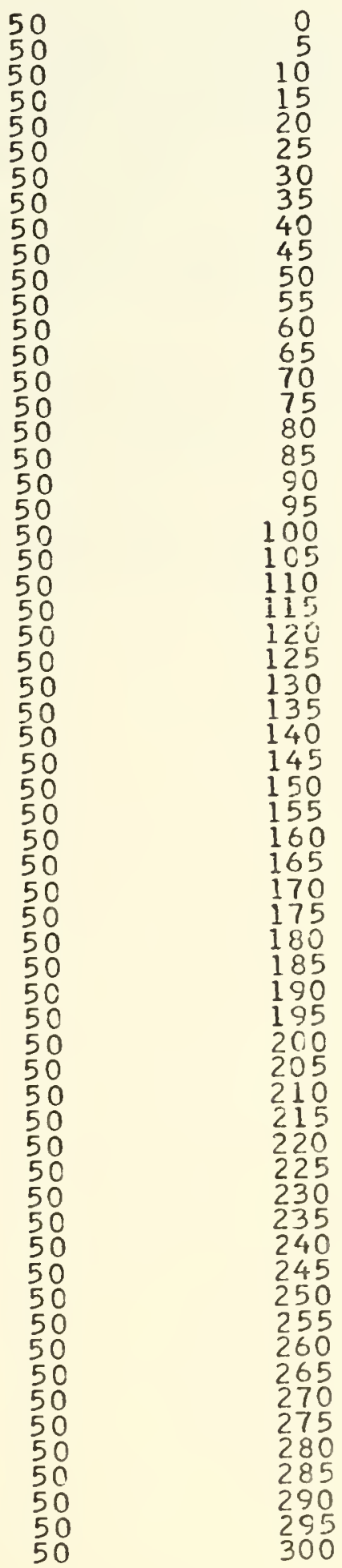

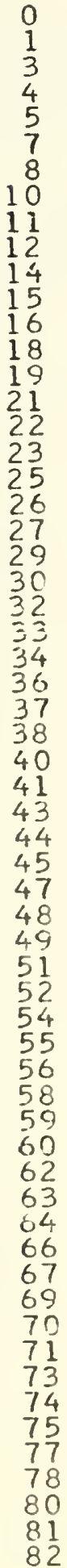

0.0

$12 \cdot 37$

$29 \cdot 12$

31.86

38.23

$44.6 \mathrm{C}$

50.97

$57 \cdot 35$

63.72
70.09

76.46

82.83

$89 \cdot 21$

$95 \cdot 58$
101.95

108.32

114.69

121.07

127.44

133.81

140.18

$146=55$

$15 \frac{5}{5} \cdot 30$

165.67

172.04

178.41

184.78

$191 \cdot 16$

197.53

203.90

210.27

216.64

223.02

$229 \cdot 39$

242.13

248.50

254.87

261.25

$267 \cdot 62$

280.36

286.73

293.11

295.48

305.85

312.22

324 . . 6

331.34

344.08

350.45

356.82

363.20
369.57

369.57
375.94

382.31 



\section{REFERENCES CITED}

1. Krause, D.C. 1962. Interpretation of Echo Sounding Profiles. Intern. Hydrog. Rev. 39 (1): 5-123.

2. Martin, B.D. 1964. Monterey Submarine Canyon, California: Genesis and Relationship to Continental Geology. PhD Dissertation, Univ. of S. Calif., Los Angeles. 249 p.

3. Shepard, F.P., and K. O. Emery. 1941. Submarine Topography off the California coast: Canyons and Tectonic Interpretation. Geol. Soc. Amer. Spec. Paper 31. $171 \mathrm{p}$.

4. U.S. Coast and Geodetic Survey. 1933. Descriptive Report Locality 5453: South of Monterey Bay, Lobos Rocks to Carmel Bay. $13 \mathrm{p}$.

5. U.S. Naval Oceanographic Office. 1962. Tables of Sound speed in sea Water. Special Publication $58.47 \mathrm{p}$. 

1. Defense Documentation Center

Cameron Station

Alexandria, Virginia 22214

2. Library, Code 0212

Naval Postgraduate School

Monterey, California 93940

3. Professor R.S. Andrews, Code 58Ad

Department of Oceanography

Naval Postgraduate School

Monterey, California 93940

4. Department of oceanography, code 58

Naval Postgraduate School

Monterey, California 93940

5. CDR W.C. Knodle, USN

Department of Oceanography, code $58 \mathrm{kn}$

NavaI Posigraduate School

Monterey, California 93940

6. LT R.A. Zardeskas, USN

Tactical Electronic Warfare Squadron 129

NAS Whidbey Island

Oak Harbor, Washington 98277

7. LT L.S. Carter, USN

Naval Postgraduate School, SMC \#1865

Monterey, California 93940

8. Mr. Thompson J. Hudson

Pt. Lobos

Carmel, California 93921

9. Mr. Frederick A. Meyer

Environmental Resources Section

Supervisor, Dept. of Parks and Recreation

State of California - Resources Agency

P.O. Box 2390

Sacramento, California 95811

10. Office of Naval Research

Code $480 D$

Arlington, Virginia 22217 

11. Point Lobos State Reserve

Carmel, California 93921

Attn: Mr. D. Rich

12. LCDR C.K. Roberts, USN

Department of Oceanography, Code $58 \mathrm{Rb}$

Naval Postgraduate School

Monterey, California 93940

13. Dr. Francis P. Shepard

Scripps Institution of Oceanography

University of California at San Diego

La Jolla, California 92038

14. LT J.P. Simpson, USN

Naval Postgraduate School, SMC \#1105

Monterey, California 93940

15. Mr. Earl Smith

Director, Monterey County Park Dept.

P.O. Box 367

Salinas, California 93901

16. Professor W. C. Thompson, Code 58Th

Department of Oceanography

Naval postgraduate School

Monterey, California 93940 



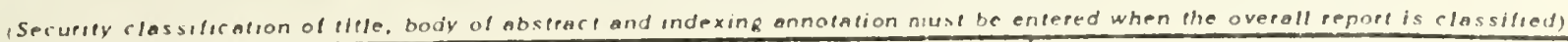
1 ORIGINATING ACTIVITY (COTporale author)

Naval Postgraduate School

Monterey, California 93940

2a. REFORT SECURITY CLASSIFICATION Unclassified

A BATHYMETRIC CHART OF CARMEL BAY, CALIFORNIA

- DESCRIPTIVE NOTES (TYPo of report and.inclusive dales)

Master's Thesis; September 1971

3. AUTHORIS) (First nome, middle initial, lasinamo)

Ralph Anthony Zardeskas; Lieutenant, United States NavY

\begin{tabular}{|c|c|c|}
\hline 6. REPORTDATE & $\begin{array}{l}\text { 7ه. TOTAL NO. OF PAGES } \\
108\end{array}$ & $\begin{array}{r}\text { 76. NO. OF REFS } \\
5\end{array}$ \\
\hline $\begin{array}{l}\text { September } 1971 \\
\text { B. CONTRACT OR GRANTTO. }\end{array}$ & 90. ORIGINATOR'S REPOA & $\frac{1}{3 E R(S)}$ \\
\hline \multicolumn{3}{|l|}{ b. PROJECT NO. } \\
\hline c. & $\begin{array}{l}\text { 2b. OTHER REPORT NO(S) } \\
\text { (his ropori) }\end{array}$ & her numbers that may bo as sifried \\
\hline d. & & \\
\hline
\end{tabular}

\begin{tabular}{l|l}
\hline 11. SUPPLEMENTARY NOTES & 12. SPONSORING MILITAAY ACTIVITY
\end{tabular}

Naval Postgraduate School

Monterey, Calizornia 93940

13. ABSTRACT

This study has as its final product a bathymetric chart of Carmel Bay, California, which is improved over any other previously existing chart. The unique problems of applying the echo-sounding corrections necessary to create accurate bathymetric charts of areas with steep bottom slopes are discussed. 

CARMEL BAY, CALIFORNIA

CARMEL SUBMARINE CANYON

HYDROGRAPHIC SURVEY

BATHYMETRIC SURVEY

ECHO-SOUNDING 




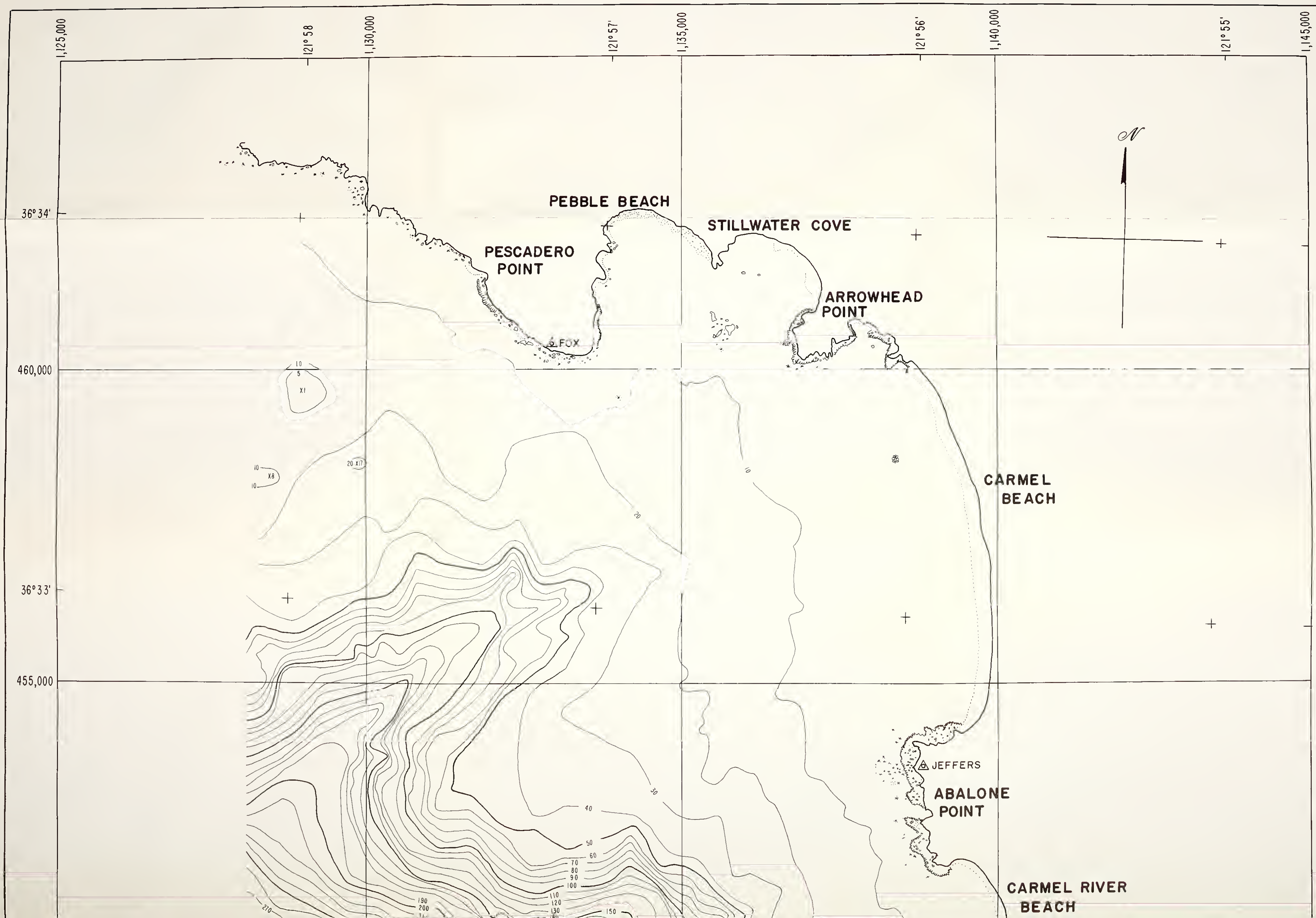




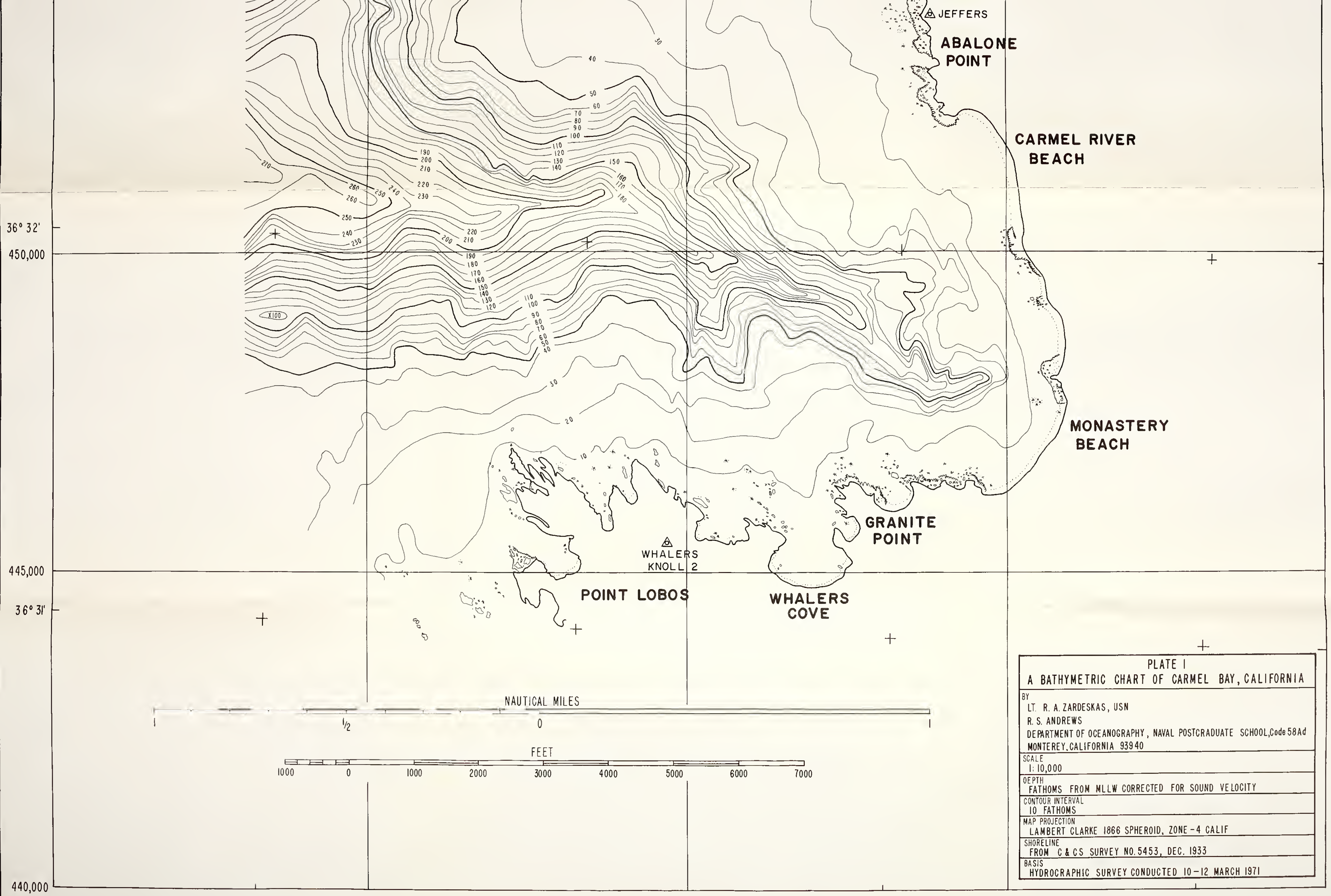







Thes is

Z243

c. 1

Zardeskas

$\therefore 50803$

A bathymetric chart of Carmel Bay, California. 
A bathymetric chart of Carmel Bay, Calif

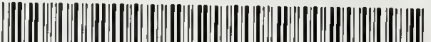

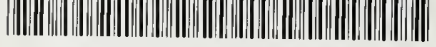
32768001904089 DUDLEY KNOX LIBRARY 